\title{
The monsoon currents in the north Indian Ocean
}

\author{
D. Shankar ${ }^{\mathrm{a}, *}$, P.N. Vinayachandran ${ }^{\mathrm{b}}$, A.S. Unnikrishnan ${ }^{\mathrm{a}}$ \\ ${ }^{a}$ Physical Oceanography Division, National Institute of Oceanography, Dona Paula, Goa 403 004, India \\ ${ }^{\mathrm{b}}$ Centre for Atmospheric and Oceanic Sciences, Indian Institute of Science, Bangalore 560 012, India
}

\begin{abstract}
The monsoon currents are the seasonally reversing, open-ocean currents that flow between the Arabian Sea and the Bay of Bengal, the two wings of the north Indian Ocean. The Summer Monsoon Current (SMC) flows eastward during the summer monsoon (May-September) and the Winter Monsoon Current (WMC) flows westward during the winter monsoon (November-February). We assemble data on ship drifts, winds and Ekman drift, and geostrophic currents derived from altimetry and hydrography to describe the observed climatological seasonal cycle of the monsoon currents. We then use an Oceanic General Circulation Model (OGCM) to simulate these currents and estimate their transports, and a 1 $\frac{1}{2}$-layer reduced-gravity model to investigate the processes that force them. The monsoon currents extend over the entire basin, from the Somali coast to the eastern Bay of Bengal. They do not, however, come into being, or decay, over this entire region at a given time. Different parts of the currents form at different times, and it is only in their mature phase that the currents exist as trans-basin flows. The westward WMC first forms south of Sri Lanka in November and is fed initially by the equatorward East India Coastal Current (EICC); the westward WMC in the southern Bay appears later. In its mature phase during December-March, the WMC flows westwards across the southern Bay; it divides into two branches in the Arabian Sea. One of these branches continues flowing westwards, whereas the other turns around the Lakshadweep high (a sea-level high off southwest India) to flow into the poleward West India Coastal Current (WICC). The WMC is primarily a geostrophic current, modulated by Ekman drift. The eastward flowing SMC first appears in the southern Bay during May. In its mature phase, which peaks with the summer monsoon in July, the SMC in the Arabian Sea is a continuation of the Somali Current and the coastal current off Oman. It flows eastward and southeastward across the Arabian Sea and around the Lakshadweep low (a sea-level low off southwest India), eastward south of Sri Lanka, and into the Bay of Bengal. Strong winds during the summer monsoon ensure that Ekman drift dominates at the surface, leading to a more complex vertical structure in the SMC than in the WMC. In the depthaveraged flow over $50 \mathrm{~m}$, the mature phase of the SMC lasts from May to September. The numerical experiments show that the dynamics of the north Indian Ocean on seasonal time scales can be explained by linear wave theory. The circulation at any point is decided by both local forcing and remote forcing, whose signals are carried by equatorial and coastal waves. Superimposed on the currents associated with these waves is the local Ekman drift. The geostrophic component of the monsoon currents is forced by several processes. In the Bay of Bengal, the monsoon currents are forced by Ekman pumping and by the winds in the equatorial Indian Ocean. In the eastern Arabian Sea, the major forcing mechanisms are the winds along the east and west coasts of India and Sri Lanka; these processes link the parts of the SMC in the Arabian Sea and the Bay during the summer monsoon, and of the WMC early during winter. Ekman pumping in the central Arabian Sea and off the Somali coast forces the monsoon currents in the central and western Arabian Sea, with Rossby waves radiated from the Indian west coast also playing a role. Therefore, the monsoon
\end{abstract}

\footnotetext{
* Corresponding author.
} 
currents consist of several parts, each of which is forced by one or more processes, which act in concert to produce the continuous currents seen flowing across the breadth of the north Indian Ocean. (C) 2002 Elsevier Science Ltd. All rights reserved.

\section{Contents}

1. Introduction $\ldots \ldots \ldots \ldots$

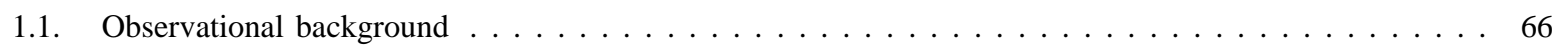

1.2. Theoretical background $\ldots \ldots \ldots \ldots \ldots$

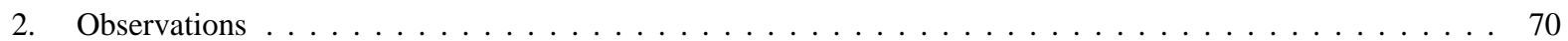

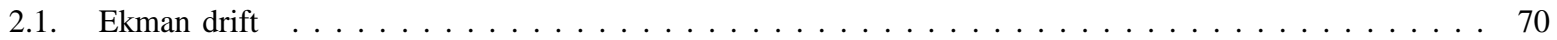

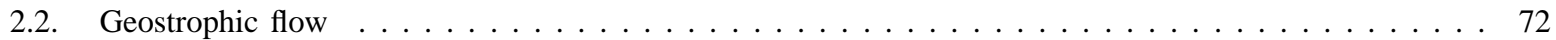

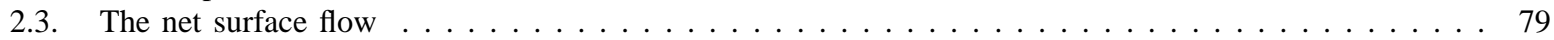

3. The monsoon currents in an $\mathrm{OGCM} \ldots \ldots \ldots$

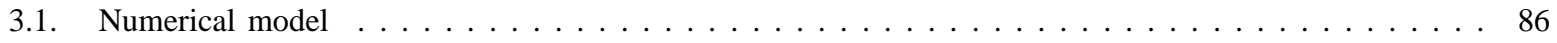

3.2. The model circulation $\ldots \ldots \ldots \ldots$

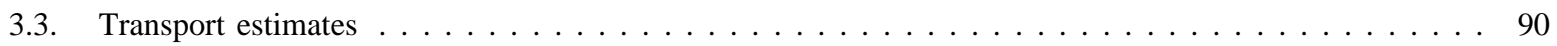

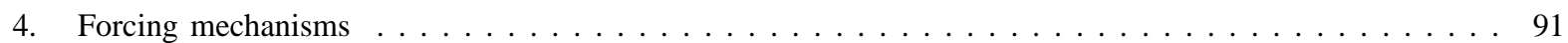

4.1. The numerical model and the control run $\ldots \ldots \ldots \ldots$



4.3. Dynamics of the north Indian Ocean $\ldots \ldots \ldots \ldots \ldots \ldots$

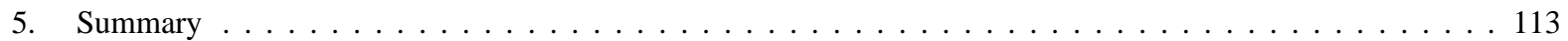

\section{Introduction}

The winds over the Indian Ocean north of $10^{\circ} \mathrm{S}$ reverse direction twice a year (Fig. 1). Over the north Indian Ocean, they generally blow from the southwest during May-September (summer monsoon) and from the northeast during November-February (winter monsoon), March-April and October being the months of transition with weak winds. The winds are much stronger during the summer monsoon than during the winter monsoon. These seasonally reversing monsoon winds over the north Indian Ocean force a seasonally reversing circulation in the upper ocean (see the schematic in Fig.2).

The best studied of the seasonally reversing currents are the Somali Current, which flows poleward (equatorward) along the coast of Somalia during the summer (winter) monsoon (see the reviews by Schott, 1983; Shetye \& Gouveia, 1998; Schott \& McCreary, 2001, and the many references therein), and the current along the equator (called the Equatorial Current in this paper), where eastward surface jets are observed during April-May and October-November (see, for example, Wyrtki, 1973a; O'Brien \& Hurlburt, 1974; Reverdin, 1987; Jensen, 1993; Han, McCreary, Anderson, \& Mariano, 1999; Schott \& McCreary, 2001, and the many references therein). In the last decade, however, coastal currents have also received attention. These include the currents along the east coast of India, called the East India Coastal Current (EICC) (Shetye et al., 1993, 1996; Shetye, Shenoi et al., 1991; Shankar, McCreary, Han, \& Shetye, 1996; McCreary, Kundu, \& Molinari, 1993; McCreary, Han, Shankar, \& Shetye,1996; Vinayachandran, Shetye, Sengupta, \& Gadgil, 1996; Shetye \& Gouveia, 1998; Schott \& McCreary, 2001), the current along the 


\section{Climatology of wind stress}
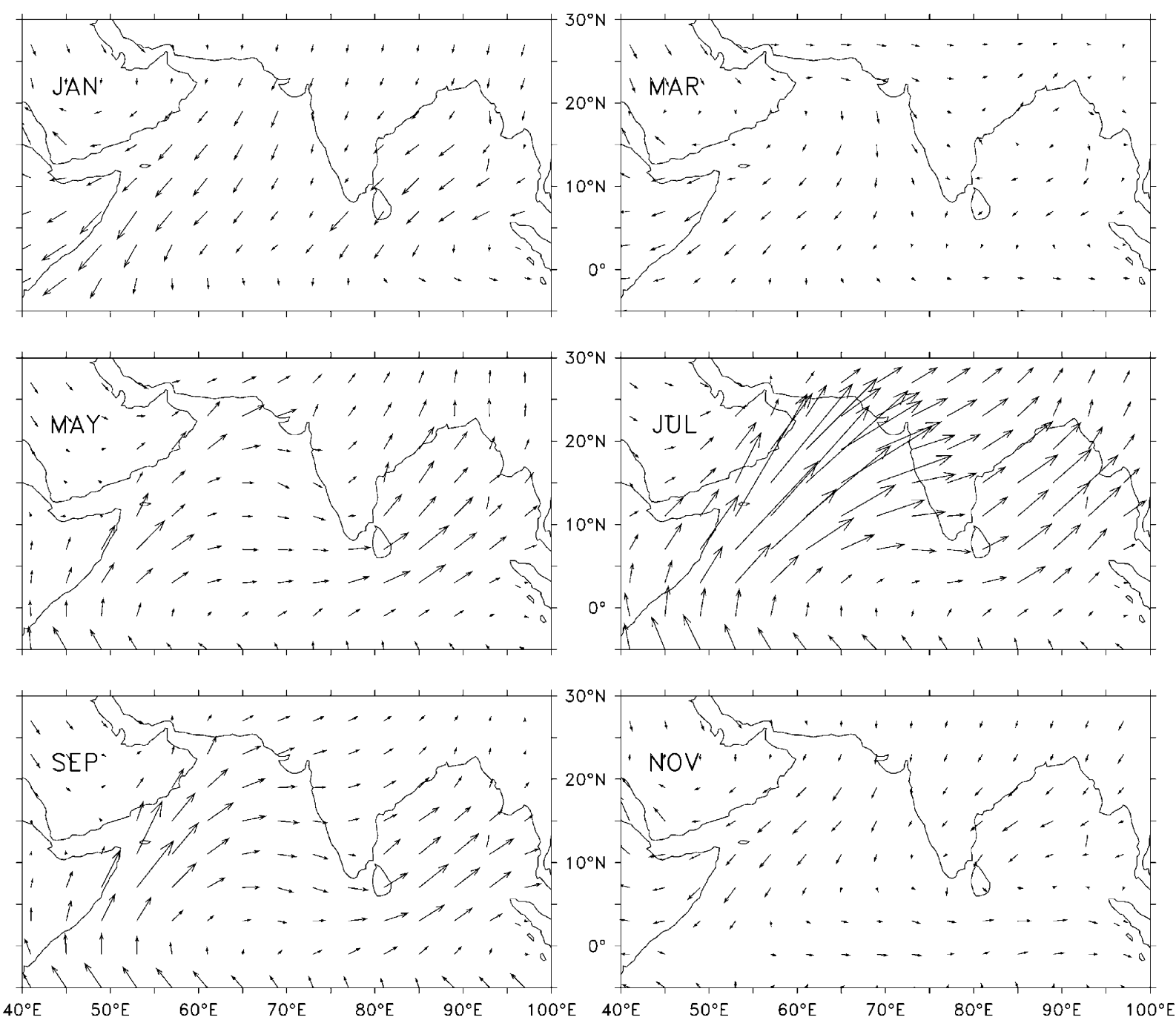

$$
\longrightarrow 2.00 \text { dyne } \mathrm{cm}^{-2}
$$

Fig. 1. Wind stress $\left(\right.$ dyne $\mathrm{cm}^{-2}$ ) from the climatology of Hellerman and Rosenstein (1983).

west coast of India, called the West India Coastal Current (WICC) (Shetye et al., 1990; Shetye, Gouveia et al., 1991; McCreary et al., 1993; Stramma, Fischer, \& Schott, 1996; Shankar \& Shetye, 1997; Shetye \& Gouveia, 1998), and the current along the Arabian-Sea coast of Oman (McCreary et al., 1993; Shetye \& Gouveia, 1998; Böhm, Morrison, Manghnani, Kim, \& Flagg, 1999; Shi, Morrison, Böhm, \& Manghnani, 2000; Schott \& McCreary, 2001). There are no observational studies on the coastal current along the eastern boundary of the Bay of Bengal. Apart from these coastal currents, the most significant large-scale currents known in the north Indian Ocean are the open-ocean, seasonally reversing monsoon currents. During the summer, the monsoon current flows eastward as a continuous current from the western Arabian Sea to the 
Bay of Bengal; during the winter, it flows westward, from the eastern boundary of the Bay to the western Arabian Sea. We call these currents the Summer Monsoon Current (SMC) and Winter Monsoon Current (WMC), respectively. It is these currents, which transfer water masses between the two highly dissimilar arms of the north Indian Ocean, the Bay of Bengal and the Arabian Sea, that form the subject of this paper.

\subsection{Observational background}

The existence of seasonally reversing currents in the Arabian Sea has been known for a long time (see Warren, 1966, for references to medieval Arab sources), but the first major description of the monsoon currents followed the International Indian Ocean Expedition (IIOE) (Duing, 1970; Wyrtki, 1971, 1973b). Based on these hydrographic data, Wyrtki (1973b) highlighted what he called "the seasonally changing monsoon gyre" as a gyre unlike those found in the other oceans. In his scheme of circulation, the monsoon gyre during the winter monsoon consists of "the westward North Equatorial Current, a southward flow off the Somali coast, and the Equatorial Counter Current, which runs east between the equator and $8^{\circ} \mathrm{S}$ across the entire width of the ocean". During the summer monsoon, his monsoon gyre consists of "the northern portions of the South Equatorial Current, which now extends almost to the equator, the strong Somali Current flowing north as a boundary current, and the monsoon current, into which the Counter Current has merged". There is no standard nomenclature for the monsoon currents (Table 1); in this paper, we shall stick to the terminology used above, i.e. SMC and WMC.

Wyrtki (1973b) noted that the circulation in the Indian Ocean is complex; the winter monsoon gyre does not close cleanly in the east, with most of the flow from the South Equatorial Counter Current (SECC) flowing into the South Equatorial Current (SEC), and a strong branch of the WMC turning north to flow along the Indian west coast, transporting low-salinity water from the Bay of Bengal into the eastern Arabian Sea. The circulation during the winter monsoon was shallow compared with that during the summer monsoon, when intense upwelling was observed in several places and the circulation penetrated deeper, affecting the movement of water masses below the thermocline, especially in the western Arabian Sea. The complexity of the circulation represented by the hydrographic data was seen in the large number of eddies (Duing, 1970; Wyrtki, 1973b), which were found to be connected intimately to the dynamics of the mon-

Table 1

Nomenclature used for currents in this paper. Many of the currents in the Indian Ocean have been referred to by different names in the literature; these are listed here. The first column lists the name and acronym used by us. The second column lists names and acronyms used earlier; this column is blank if no other name is known to have been used by other authors. The names used are based on the geographical location of the current; the monsoon currents are the exceptions. Except in the case of the monsoon currents, no allowance has been made for a change in direction with season

Name of current (acronym)

Winter Monsoon Current (WMC)

Summer Monsoon Current (SMC)

Equatorial Current

South Equatorial Counter Current (SECC)

Somali Current

West India Coastal Current (WICC)

East India Coastal Current (EICC)
Other commonly used names (acronyms)
Northeast Monsoon Current (NMC)

North Equatorial Current (NEC)

Southwest Monsoon Current (SMC)

Indian Monsoon Current (IMC)

Monsoon Current

Equatorial jet or Wyrtki jet (when flowing eastward)

South Equatorial Counter Current (SECC, SCC)

Equatorial Counter Current (ECC) 
soon gyre. The most vigorous of these eddies lay about $300 \mathrm{~km}$ offshore of the Somali coast; large parts of the Somali Current were recirculated around this eddy, known as the 'Great Whirl' (Bruce, 1968).

A different picture emerges from the ship-drift data (Defant, 1961; Cutler \& Swallow, 1984; Rao, Molinari, \& Festa, 1989) and surface-drifter data (Molinari, Olson, \& Reverdin, 1990; Shenoi, Saji, \& Almeida, 1999), which show broad eastward (westward) or south-eastward flows across the Arabian Sea during the summer (winter) monsoon. Hastenrath and Gresichar (1991) used ship drifts, hydrography and Ekman drift computed from wind-stress climatologies to study the monsoon currents in the Arabian Sea. They concluded that the monsoon currents are essentially Ekman drifts forced by the monsoon winds, the geostrophic contribution to these flows being negligible. Shenoi, Saji, and Almeida (1999) compared hydrography based on the climatologies of Levitus and Boyer (1994) and Levitus, Burgett, and Boyer (1994) to currents from surface drifters, and concluded that the role of geostrophy in representing the surface flows varies both geographically and seasonally. The agreement between the drifter data and hydrography was worst during the summer monsoon, when the drifters showed south-eastward flows all over the Arabian Sea, unlike in the hydrography.

Hydrographic data, however, were also used in later studies (Bruce, Johnson, \& Kindle, 1994; Bruce, Kindle, Kantha, Kerling, \& Bailey, 1998; Donguy \& Meyers, 1995; Murty, Sarma, Rao, \& Murty, 1992; Murty et al., 2000; Gopalakrishna, Pednekar, \& Murty, 1996; Vinayachandran, Masumoto, Mikawa, \& Yamagata, 1999), which showed strong geostrophic flows and transports associated with the monsoon currents. These estimates (Table 2) yield current strengths of $\sim 40 \mathrm{~cm} \mathrm{~s}^{-1}$ and transports of $\sim 10 \times 10^{6} \mathrm{~m}^{3}$ $\mathrm{s}^{-1}$ in the upper 400 or $1000 \mathrm{~m}$, which implies that the geostrophic flows associated with the monsoon currents are not small, even if they are weaker than the surface Ekman flows in some regions during some seasons. The geostrophic flows estimated by Hastenrath and Greischar (1991) are weak probably because of the poor resolution of the data and the averaging they did to obtain climatological currents and transports in a region. In contrast, except for the IIOE atlas (Wyrtki, 1971), the hydrographic data are usually from individual cruises. These data, which yield higher estimates for the geostrophic transports, show that the monsoon currents are not found in the same location during a given season or during different years. For example, Vinayachandran, Masumoto et al. (1999) showed that the SMC in the Bay of Bengal intensifies and shifts westwards as the summer monsoon progresses; this westward shift with time is also seen in the surface geostrophic flow inferred from TOPEX/Poseidon altimetry (Eigenheer \& Quadfasel, 2000).

In spite of these differences, all the observations-hydrography, ship drifts, and from surface driftersshow that the monsoon currents flow across the breadth of the north Indian Ocean. The branches of the SMC and WMC that flow around the Lakshadweep high and low in the south-eastern Arabian Sea (McCreary et al., 1993; Bruce et al., 1994; Shankar \& Shetye, 1997) link the circulations in the Arabian Sea and Bay of Bengal (Fig. 2). The SMC flows eastwards south of Sri Lanka and into the Bay. It is fed by a flow from the southwest near the equator and by the flow around the Lakshadweep low. East of Sri Lanka, the SMC flows northeastwards into the Bay of Bengal. An outflow from it, however, appears to flow southeastward and crosses the equator near Sumatra in the surface-drifter data (Shenoi, Saji, \& Almeida, 1999); recent hydrographic data (Unnikrishnan, Murty, Babu, Gopinathan, \& Charyulu, 2001) also show that the eastward current between $80^{\circ}$ and $88^{\circ} \mathrm{E}$ flows close to the equator and even to the south of it. The SMC transports high-salinity water (Arabian Sea High Salinity Water) into the Bay (Wyrtki, 1971; Murty et al., 1992; Gopalakrishna et al., 1996; Han \& McCreary, 2001). The WMC flows westward south of Sri Lanka, where it divides into two branches, one flowing westward into the southern Arabian Sea, the other flowing around the Lakshadweep high into the WICC. The WMC transports low-salinity water (Bay of Bengal water) into the eastern Arabian Sea, where it is entrained into the Lakshadweep high and spread along the west coast of India by the WICC (Wyrtki, 1971; Bruce et al., 1994; Han, 1999; Shenoi, Shankar, \& Shetye, 1999; Shankar \& Shetye, 1999; Han \& McCreary, 2001; Han, McCreary, \& Kohler, 2001; Howden \& Murtugudde, 2001).

The passage between Sri Lanka and the equator is, therefore, significant because the monsoon currents 
Table 2

Currents and transports $\left(1 \mathrm{~Sv}=10 \times 10^{6} \mathrm{~m}^{3} \mathrm{~s}^{-1}\right)$ associated with the monsoon currents. The direction is given in parentheses in the first column; $\mathrm{N}$ implies northward flow, $\mathrm{S}$ southward, E eastward, W westward, and NE northeastward. The acronym (SMC/WMC) listed in the last column indicates the current referred to

\begin{tabular}{|c|c|c|}
\hline $\begin{array}{l}\text { Current/transport and } \\
\text { direction }\end{array}$ & Location and period & Remarks \\
\hline $9 \mathrm{~Sv}(\mathrm{E})$ & $78^{\circ} \mathrm{E}, 3^{\circ}-5^{\circ} \mathrm{N} ;$ June 1992 & $\begin{array}{l}\text { Geostrophic transport with respect to } 400 \mathrm{db} \text {; based on XBT } \\
\text { data, with salinity from T-S relation based on climatology } \\
\text { (Levitus, 1982); Source: Murty et al. (2000). SMC }\end{array}$ \\
\hline $14 \mathrm{~Sv}(\mathrm{E})$ & $80^{\circ} \mathrm{E}, 3^{\circ}-5^{\circ} \mathrm{N}$; July 1992 & As above. SMC. \\
\hline $9.3 \mathrm{~Sv}(\mathrm{E})$ & $68^{\circ} \mathrm{E}, 4^{\circ}-7^{\circ} \mathrm{N} ;$ July 1995 & As above. SMC. \\
\hline $6 \mathrm{~Sv}(\mathrm{E})$ & $68^{\circ} \mathrm{E}, 2^{\circ}-6^{\circ} \mathrm{N} ;$ September 1993 & As above. SMC. \\
\hline $14 \mathrm{~Sv}(\mathrm{~W})$ & $72^{\circ}-79^{\circ} \mathrm{E}, \sim 6^{\circ}-8^{\circ} \mathrm{N} ;$ February 1993 & As above, but WMC. \\
\hline $7-8 \mathrm{~Sv}(\mathrm{~W})$ & $\begin{array}{l}2^{\circ}-5^{\circ} \mathrm{N} ; \text { January 1996; February } \\
1993 \text {, March } 1992\end{array}$ & $\begin{array}{l}\text { As above, but average values for the given months over three } \\
\text { different transects. WMC. }\end{array}$ \\
\hline $13 \mathrm{~Sv}(\mathrm{~W})$ & $\begin{array}{l}\sim 6^{\circ} \mathrm{N}, \text { east of Sri Lanka; January- } \\
\text { February climatology }\end{array}$ & $\begin{array}{l}\text { Geostrophic transport with respect to } 400 \mathrm{db} \text {; based on TOGA } \\
\text { XBT data for 1985-1989, with salinity from T-S relation } \\
\text { based on climatology (Levitus, 1982). Source: Donguy and } \\
\text { Meyers (1995). WMC. }\end{array}$ \\
\hline $11 \mathrm{~Sv}(\mathrm{NE})$ & $\begin{array}{l}\text { West of Lakshadweep high (see Fig. } \\
\text { 2); January-February climatology }\end{array}$ & As above. WMC. \\
\hline $19 \mathrm{~Sv}(\mathrm{~N})$ & $\begin{array}{l}10^{\circ} \mathrm{N}, \sim 66^{\circ}-70^{\circ} \mathrm{E} ; \text { winter monsoon } \\
1965 \text {. }\end{array}$ & $\begin{array}{l}\text { Geostrophic transport with respect to } 1000 \mathrm{db} \text {, evaluated from } \\
\text { IIOE data; Atlantis II, Cruise } 15 \text {. West of Lakshadweep high. } \\
\text { Source: Bruce et al. (1994). WMC. }\end{array}$ \\
\hline $15 \mathrm{~Sv}(\mathrm{~S})$ & $\begin{array}{l}10^{\circ} \mathrm{N}, \sim 67^{\circ}-72^{\circ} \mathrm{E} ; \text { summer monsoon } \\
1963\end{array}$ & As above, but for IIOE data from Atlantis II, Cruise 8. SMC. \\
\hline $35 \mathrm{~cm} \mathrm{~s}^{-1}(\mathrm{~S}), 5.2 \mathrm{~Sv}(\mathrm{~S})$ & $8^{\circ} \mathrm{N}, 72^{\circ} 10^{\prime}-75^{\circ} \mathrm{E}$; August 1993 & $\begin{array}{l}\text { Current from ADCP; geostrophic transport with respect to } \\
1000 \mathrm{db} \text { from hydrography. West of Lakshadweep low (see } \\
\text { Fig. 2). Source: Stramma et al. (1996). SMC. }\end{array}$ \\
\hline $\begin{array}{l}\sim 8 \mathrm{~Sv}(\mathrm{E}), \text { with a peak } \\
\text { transport of } 24 \mathrm{~Sv}\end{array}$ & $80.5^{\circ} \mathrm{E}$; summer monsoon 1991 & $\begin{array}{l}\text { Transport estimated from current-meter moorings and ADCP. } \\
\text { Moorings located south of Sri Lanka between } 5^{\circ} 39^{\prime} \mathrm{N} \text { and } \\
4^{\circ} 10^{\prime} \mathrm{N} \text { (transport estimated over top } 300 \mathrm{~m} \text { between } 3^{\circ} 45^{\prime} \mathrm{N} \\
\text { and } 5^{\circ} 52^{\prime} \mathrm{N} \text { ). Source: Schott et al. (1994). SMC. }\end{array}$ \\
\hline $\begin{array}{l}\sim 12 \mathrm{~Sv}, \sim 10 \mathrm{~Sv}(\mathrm{~W}), \text { with a } \\
\text { peak transport of } 25 \mathrm{~Sv}\end{array}$ & 80.5ㅌ; winter monsoon 1991, 1992 & $\begin{array}{l}\text { As above. The first value is for 1991, the second for } 1992 \text {. } \\
\text { WMC. }\end{array}$ \\
\hline $40 \mathrm{~cm} \mathrm{~s}^{-1}(\mathrm{~N})$ & $\begin{array}{l}87^{\circ}-89^{\circ} \mathrm{E}, 14^{\circ} \mathrm{N} ; \text { summer monsoon, } \\
1984\end{array}$ & $\begin{array}{l}\text { Maximum of geostrophic current between } 50 \text { and } 100 \mathrm{~m} \\
\text { depth, estimated from hydrographic data with respect to } 1000 \\
\text { db. Source: Murty et al. (1992). SMC. }\end{array}$ \\
\hline $40 \mathrm{~cm} \mathrm{~s}^{-1}(\mathrm{~N}), 17 \mathrm{~Sv}(\mathrm{~N})$ & $87^{\circ}-89^{\circ} \mathrm{E}, 11^{\circ} \mathrm{N} ;$ July 1993 & $\begin{array}{l}\text { Geostrophic current and transport with respect to } 1000 \mathrm{db} \text {, } \\
\text { estimated using hydrographic data. Source: Gopalakrishna et } \\
\text { al. (1996). SMC. }\end{array}$ \\
\hline $40 \mathrm{~cm} \mathrm{~s}^{-1}(\mathrm{~N}), 14 \mathrm{~Sv}(\mathrm{~N})$ & $87^{\circ}-89^{\circ} \mathrm{E}, 12^{\circ} \mathrm{N}$; August 1991. & As above. SMC. \\
\hline $40 \mathrm{~cm} \mathrm{~s}^{-1}(\mathrm{~N}), 12 \mathrm{~Sv}(\mathrm{~N})$ & $81^{\circ}-85^{\circ} \mathrm{E}, 6^{\circ} \mathrm{N}$; July climatology. & $\begin{array}{l}\text { Geostrophic current and transport with respect to } 400 \mathrm{db} \text {, } \\
\text { estimated from TOGA XBT data during 1985-1996. The } \\
\text { current is restricted to the top } 200 \mathrm{~m} \text { and moves westward as } \\
\text { the season progresses. Source: Vinayachandran, Masumoto et } \\
\text { al. (1999). SMC. }\end{array}$ \\
\hline
\end{tabular}

have to flow through it, making it the only location where they are geographically frozen, unlike in the open ocean, where they meander a lot. Hence, it is not surprising that the only direct current measurements of the monsoon currents have been made between Sri Lanka and the equator along $80.5^{\circ} \mathrm{E}$ (Schott, Reppin, Fischer, \& Quadfasel, 1994; Reppin, Schott, Fischer, \& Quadfasel, 1999). The current meter and ADCP (Acoustic Doppler Current Profiler) observations show that the SMC and WMC transport $\sim 10 \times 10^{6} \mathrm{~m}^{3} \mathrm{~s}^{-1}$ 


\section{Schematic of circulation in the Indian Ocean}


Fig. 2. Schematic representation of the circulation, as described in the literature, in the Indian Ocean during January (winter monsoon) and July (summer monsoon). The abbreviations are as follows: SC, Somali Current; EC, Equatorial Current; SMC, Summer Monsoon Current; WMC, Winter Monsoon Current; EICC, East India Coastal Current; WICC, West India Coastal Curent; SECC, South Equatorial Counter Current, EACC, East African Coastal Current; SEC, South Equatorial Current; LH, Lakshadweep high; LL, Lakshadweep low; and GW, Great Whirl.

in the upper $300 \mathrm{~m}$. These direct measurements also confirm hydrographic observations that the monsoon currents are shallow, with most of the variation being restricted to the upper $100 \mathrm{~m}$. The moored array showed upward phase propagation, implying downward propagation of energy. Most striking was the difference between the Equatorial Current and the monsoon currents, even though both flow together through the same bottleneck. The Equatorial Current includes a large semiannual harmonic and reverses direction four times in a year, unlike the monsoon currents, which are dominated by the annual harmonic and reverse direction only twice a year. Superimposed on these seasonal changes are large intra-seasonal oscillations (Schott et al., 1994; Reppin et al., 1999).

Though the observations differ in their presentation of the monsoon-current system in the northern Indian Ocean, they show that the open-ocean currents in the north Indian Ocean extend all the way across the 
basin, reverse direction with season, and are relatively shallow compared to the deep western boundary current off Somalia.

\subsection{Theoretical background}

Given that there are many different interpretations of the monsoon currents (contrast, for example, Hastenrath and Greischar (1991), with Wyrtki (1973b)), it is not surprising that more than one hypothesis exists to explain the observations. Early ideas attributed the monsoon currents as seen in ship drifts to direct Ekman forcing by the monsoonal winds (for example, Defant, 1961; Hastenrath \& Greischar, 1991), and as seen in hydrography to the local curl of wind stress (for example, Murty et al., 1992).

Matsuno (1966), Moore (1968), and Lighthill (1969) showed that baroclinic waves propagate fast in the tropics, and it is now appreciated that the open-ocean, equatorial, and coastal currents in the north Indian Ocean, all of which reverse seasonally, are manifestations of direct forcing by the monsoon winds (Ekman drift), and of equatorial and coastal long, baroclinic waves generated by the winds (Cane, 1980; Potemra, Luther, \& O'Brien, 1991; Yu, O'Brien, \& Yang, 1991; Perigaud \& Delecluse, 1992; McCreary et al., 1993, 1996; Jensen, 1993; Shankar et al., 1996; Vinayachandran et al., 1996; Shankar \& Shetye, 1997; Shankar, 1998, 2000; Vinayachandran \& Yamagata, 1998; Han, 1999; Han et al., 1999, 2001; Han \& McCreary, 2001). The small size of the basin and its confinement to the tropics, with its northern boundary around $25^{\circ} \mathrm{N}$, implies that these waves can traverse the basin in a few months. This is unique to the northn Indian Ocean. This framework, which has evolved in the last decade, suggests a unity of dynamics in the north Indian Ocean. Circulation at any point is decided by both local forcing and remote forcing, whose signals are carried by the equatorial and coastal waves. This is seen in numerical simulations using both layered models and multi-level general circulation models. The layered models, in particular, emphasize the quasigeostrophic dynamics that leads to the eddies and meanders so typical of hydrographic observations of the monsoon currents. In these models, the monsoon currents appear as the fronts of Rossby waves.

Thus, there appears to be more than one definition of the monsoon currents in the current literature; common to these definitions is the idea that these currents serve as the link between the circulations in the Bay of Bengal and the Arabian Sea. In this paper, we use both observations and numerical simulations to define them more precisely. In Section 2, we assemble observations to define the surface circulation associated with the monsoon currents. Numerical simulations with an OGCM follow in Section 3. In Section 4 , we use a $1 \frac{1}{2}$-layer reduced-gravity model to investigate the mechanisms that force the monsoon currents. Section 5 concludes the paper.

\section{Observations}

To define the monsoon currents and the associated circulation in the North Indian Ocean, we use climatological wind-stress data to estimate the surface Ekman drift. Hydrographic data and altimeter data from TOPEX/Poseidon are used to estimate the geostrophic contributions to the surface currents. The net surface current resulting from these two components is compared to the surface current represented by ship drifts. Defining the monsoon-current system requires more than one observational method because each method accentuates certain aspects of the flow field, thereby emphasizing a particular view of the surface currents.

\subsection{Ekman drift}

The Ekman drift is computed using the 'Ekman spiral' method. The surface Ekman drift flows at $45^{\circ}$ to the right (left) of the wind in the northern (southern) hemisphere and its magnitude, according to Pond and Pickard (1983), is given by: 


$$
V_{\mathrm{E}}=\frac{\tau}{\rho(A|f|)^{1 / 2}}
$$

where $\tau$ is the magnitude of the wind stress, $A$ the vertical eddy diffusivity, $\rho$ the average density of seawater, and $|f|$ the magnitude of the Coriolis parameter. We use $A=10^{-2} \mathrm{~m}^{2} \mathrm{~s}^{-1}$ (Hastenrath \& Greischar, 1991) and $\tau$ from the wind-stress climatology of Hellerman and Rosenstein (1983) to obtain the monthly climatology of the surface Ekman drift in the Indian Ocean north of $5^{\circ} \mathrm{S}$ (Fig. 3); we exclude the region within $2.5^{\circ}$ of the equator, where Eq. (1) does not apply.

\section{Climatology of surface Ekman drift}
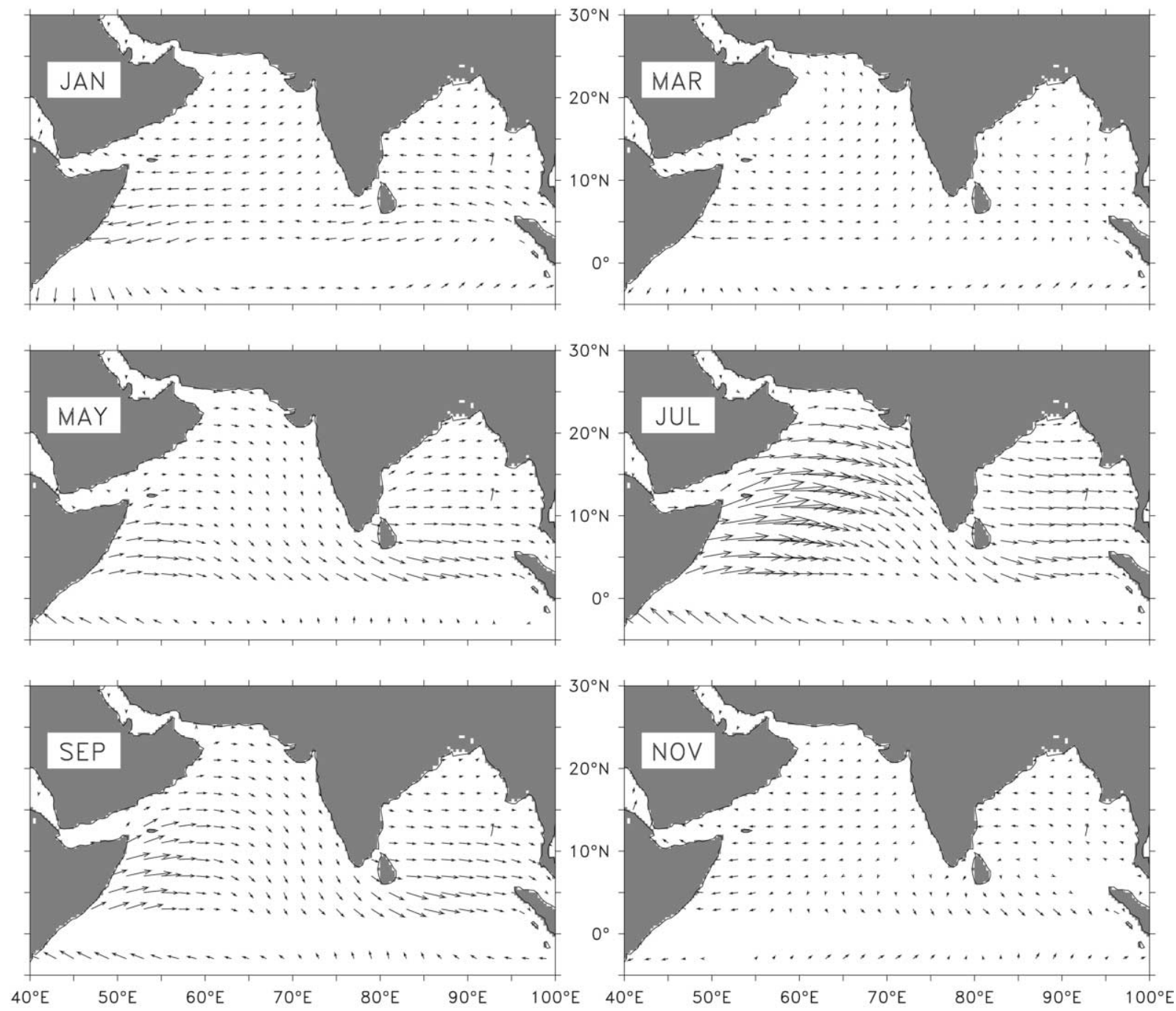

$\longrightarrow$ 100. $\mathrm{cm} \mathrm{s}^{-1}$

Fig. 3. Climatology of surface Ekman drift $\left(\mathrm{cm} \mathrm{s}^{-1}\right)$ in the north Indian Ocean. The drift is estimated from the wind-stress climatology of Hellerman and Rosenstein (1983) and is based on the 'Ekman spiral' formula. 
The winter monsoon sets in during November (Fig. 1), and the Ekman drift is westward in the Arabian Sea and the Bay of Bengal. It is weak in the eastern Arabian Sea and the eastern Bay. The winter monsoon strengthens in December; so does the Ekman drift, whose magnitude is $\sim 15 \mathrm{~cm} \mathrm{~s}^{-1}$ in the western Bay and $\sim 25 \mathrm{~cm} \mathrm{~s}^{-1}$ in the western Arabian Sea. The winter monsoon peaks in January, with northeasterly winds over most of the north Indian Ocean, and the Ekman drift is westward. The current strength approaches 20 $\mathrm{cm} \mathrm{s}^{-1}$ south of Sri Lanka and $30 \mathrm{~cm} \mathrm{~s}^{-1}$ in the southwestern Arabian Sea. The drift is weak in the eastern Arabian Sea and northern Bay. The winter monsoon weakens in February; so does the Ekman drift.

With the onset of the summer monsoon in May, the winds begin to blow from the southwest over most of the north Indian Ocean. The Ekman drift reverses to flow eastward over most of the Arabian Sea; it is southeastward in the eastern Arabian Sea, where the winds blow more from the west. In the Bay, the Ekman drift is eastward, except in the north and the west, where it is parallel to the coast. The current strength is $\sim 25 \mathrm{~cm} \mathrm{~s}^{-1}$ southeast of Sri Lanka and off the Somali coast. The Ekman drift strengthens all over the north Indian Ocean in June. It is eastward and southeastward in the Arabian Sea, with a slight anticyclonic curvature; the drift is eastward in the Bay. There direction remains the same from June to September, but the Ekman drift peaks in July, when current strength approaches $\sim 40 \mathrm{~cm} \mathrm{~s}^{-1}$ in parts of the Bay and $\sim 100 \mathrm{~cm} \mathrm{~s}^{-1}$ off the Somali coast. October is the month of transition between the summer and winter monsoons, with weak winds all over the north Indian Ocean. The Ekman drift is weaker than $5 \mathrm{~cm} \mathrm{~s}^{-1}$ over most of the basin, with currents of $\sim 20 \mathrm{~cm} \mathrm{~s}^{-1}$ seen only southeast of Sri Lanka.

During the summer monsoon, the Ekman drift is strong in the western and central Arabian Sea and south of Sri Lanka; it is relatively weak in the eastern parts of the Arabian Sea and Bay of Bengal. During the winter monsoon, the spatial variation in magnitude is much less. Most striking is the spatial uniformity of the Ekman drift in comparison with the eddy-like circulations seen in hydrography (Düing, 1970; Wyrtki, 1971; Murty et al., 1992). It strengthens and weakens almost all over the north Indian Ocean at the same time, in harmony with the seasonally reversing winds. This lack of spatial structure in the Ekman drift implies that geostrophy must make a significant contribution to the surface current in the north Indian Ocean.

\subsection{Geostrophic flow}

Climatological hydrographic data (Levitus \& Boyer, 1994; Levitus et al., 1994) are incapable of resolving, in both space and time, the geostrophic component of the rapidly changing monsoon circulation of the north Indian Ocean. Hence, we use these data only to construct the annual mean surface dynamic topography with respect to $1000 \mathrm{db}$ and the corresponding geostrophic circulation, excluding the region within $2.5^{\circ}$ of the equator (Fig. 4). The annual mean dynamic height is higher in the Bay than in the Arabian Sea (Wyrtki, 1971; Shankar \& Shetye, 2001), and the annual mean geostrophic flow is weak, the strongest current being a $\sim 10 \mathrm{~cm} \mathrm{~s}^{-1}$ flow south of Sri Lanka. These hydrographic data appear to be too coarse to capture the mean poleward flow off Somalia.

To compute the deviations of the geostrophic flow from the annual mean, we use the sea-level anomalies from TOPEX/Poseidon altimetry, which are available on a $0.25^{\circ} \times 0.25^{\circ}$ grid (Le Traon, Gaspar, Bouyssel, \& Makhmara, 1995; Le Traon \& Ogor, 1998; Le Traon, Nadal, \& Ducet, 1998). We construct a monthly climatology of sea-level anomalies using the 10-day repeat-cycle data for 1993-1997, and use this climatology to compute surface geostrophic currents in the Indian Ocean (Fig. 5), excluding the region within $2.5^{\circ}$ of the equator. (Adding the annual mean dynamic height to the sea-level anomalies accentuates the annual mean sea-level difference between the Bay and the Arabian Sea at the expense of the seasonal cycle; hence, Fig. 5 shows only the sea-level anomalies from the altimeter data and the geostrophic currents derived from these anomalies.) Unlike the Ekman drift, which shows little spatial structure, the surface geostrophic flow is dominated by eddies. The geostrophic monsoon currents do not form, or decay, across the basin all at once. Instead, patches of the currents appear or decay at different times. The monsoon 


\section{Annual-mean surface dynamic height and geostrophic flow}
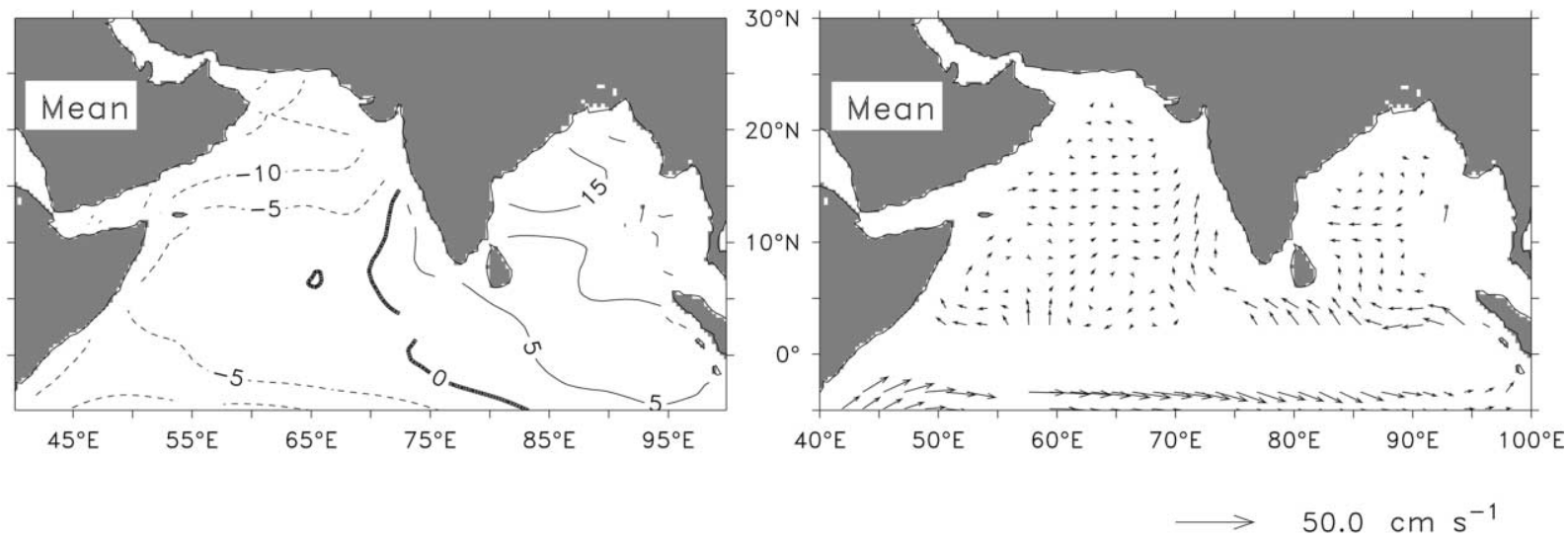

Fig. 4. Annual mean surface dynamic height (dyn $\mathrm{cm}$, left panel) and surface geostrophic flow ( $\mathrm{cm} \mathrm{s}^{-1}$, right panel) estimated with respect to a level of no motion at $1000 \mathrm{db}$ from the annual mean climatologies of Levitus and Boyer (1994) and Levitus et al. (1994). The basin-wide mean (164 dyn $\mathrm{cm}$ ) has been removed from the dynamic height field. Negative dynamic heights are indicated by dashed contours and contour interval is 5 dyn $\mathrm{cm}$.

currents can be traced as continuous trans-basin flows only in their mature phase; the mature phase of the geostrophic WMC (GWMC) peaks during January-February and that of the geostrophic SMC (GSMC) during July. At other times, incipient or relic patches are identifiable in the surface geostrophic flow.

By November, with the onset of the winter monsoon, the GSMC breaks into separate currents in the Arabian Sea and the Bay of Bengal, this split into two relic currents being caused by the continuity of the flow along the coast of the Indian subcontinent, and by the relentless westward propagation of the sealevel anomalies associated with the GSMC. In the Arabian Sea, the relic GSMC is restricted west of $72^{\circ} \mathrm{E}$, and it appears as a geostrophic flow around a low in sea level; this low has propagated westward from the Indian coast, where it appeared during the summer monsoon as the Lakshadweep low. The relic GSMC flows southwestward to the west of the low and eastward to its south. In the Bay, the relic GSMC flows northeastward as the eastern arm of a geostrophic flow around a low in sea level off the east coast of India; its western arm is the equatorward EICC. The GWMC first appears during November as a westward flow south of Sri Lanka. This incipient GWMC is fed by the equatorward EICC and, in turn, it feeds the poleward WICC.

The relic GSMC continues to shift westward, and by December, it is restricted to the west of $65^{\circ} \mathrm{E}$ in the Arabian Sea. The sea-level low abuts the Somali coast, and the southwestward GSMC to its west is now synonymous with the equatorward Somali Current. What remains of the GSMC in the Bay is barely recognizable even as a relic. In December, the GWMC is fed by the EICC and has a velocity of $\sim 40 \mathrm{~cm}$ $\mathrm{s}^{-1}$ southwest of Sri Lanka; it also appears in the southern Bay as a weak westward flow southeast of Sri Lanka. It flows west beyond $70^{\circ} \mathrm{E}$ before turning to flow around the Lakshadweep high, which has formed by this time off southwest India and Sri Lanka.

By January, the relic GSMC is restricted to a minor eastward flow west of $55^{\circ} \mathrm{E}$, and the most significant geostrophic flows in the north Indian Ocean are the GWMC, the WICC, and the recirculation around eddies in the western Arabian Sea and the western Bay. The EICC reverses to flow poleward off Sri Lanka, and the GWMC now appears as a westward flow across the southern Bay at $\sim 6^{\circ} \mathrm{N}$; it flows southwestward in the eastern Bay. The GWMC flows westward halfway across the southern Arabian Sea at $5^{\circ} \mathrm{N}$, where it turns to flow northeastwards around the Lakshadweep high and into the WICC. There are two distinct sealevel highs embedded in the region of high sea level off southwest India. A branch of the GWMC also 


\section{Climatology of sea-level anomalies and surface geostrophic flow}
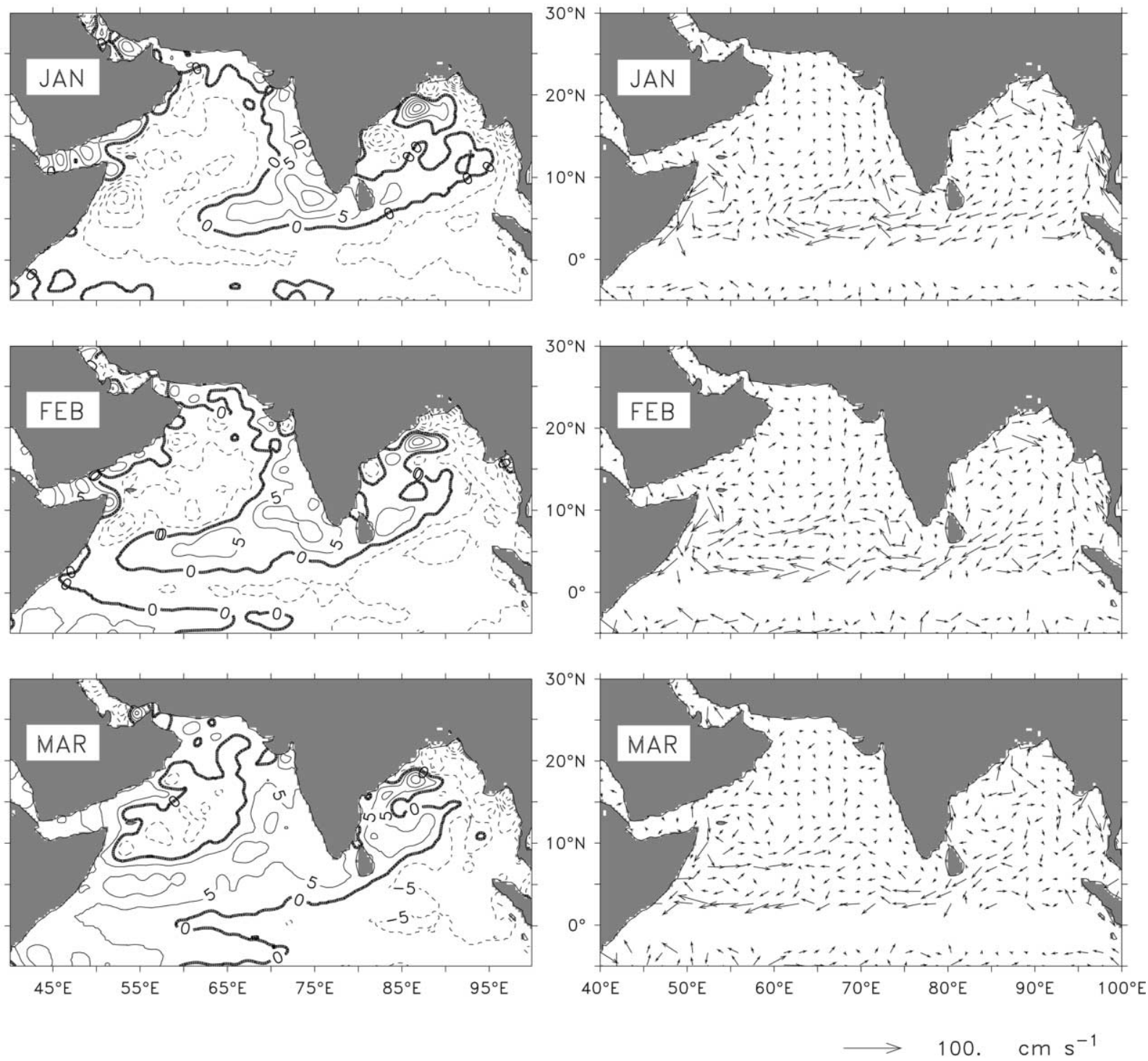

Fig. 5. Climatology of sea-level anomalies (cm, left panels) and surface geostrophic flow ( $\mathrm{cm} \mathrm{s}^{-1}$, right panels) in the north Indian Ocean. Negative anomalies are indicated by dashed contours and the contour interval is $5 \mathrm{~cm}$. The sea-level anomalies and geostrophic currents are derived from a monthly climatology constructed using the 10-day repeat-cycle TOPEX/Poseidon altimeter data for 1993-1997.

turns to flow around the eastern sea-level high and into the WICC. Thus, the GWMC flows westward to the south of the sea-level high and eastward to its north.

The relic GSMC finally disappears in February. This period, January-February, marks the mature phase of the GWMC since it appears as a continuous, trans-basin current. Its strength south of Sri Lanka is $~ 40$ $\mathrm{cm} \mathrm{s}^{-1}$. The southwestward GWMC in the eastern Bay has shifted west since January and is located at 


\section{Climatology of sea-level anomalies and surface geostrophic flow}


Fig. 5. Continued

$\sim 93^{\circ}$ E. Continuous geostrophic flow exists around a sea-level high in the southern Arabian Sea; the GWMC flows westward (eastward) to the south (north) of the high. The eastward part of the GWMC, as earlier in the season, feeds a current parallel to the Indian west coast; this poleward current was the WICC in January, but has since shifted offshore.

Westward propagation of sea-level anomalies continues during March. The GWMC no longer exists in the eastern Bay and the southwestward GWMC is located at $\sim 83^{\circ} \mathrm{E}$; this part of the GWMC is coupled to a distorted anticyclonic gyre in the western Bay. The sea-level high in the southern Arabian Sea extends across the basin. The GWMC flows around the high, and it is synonymous at the western boundary with 


\section{Climatology of sea-level anomalies and surface geostrophic flow}
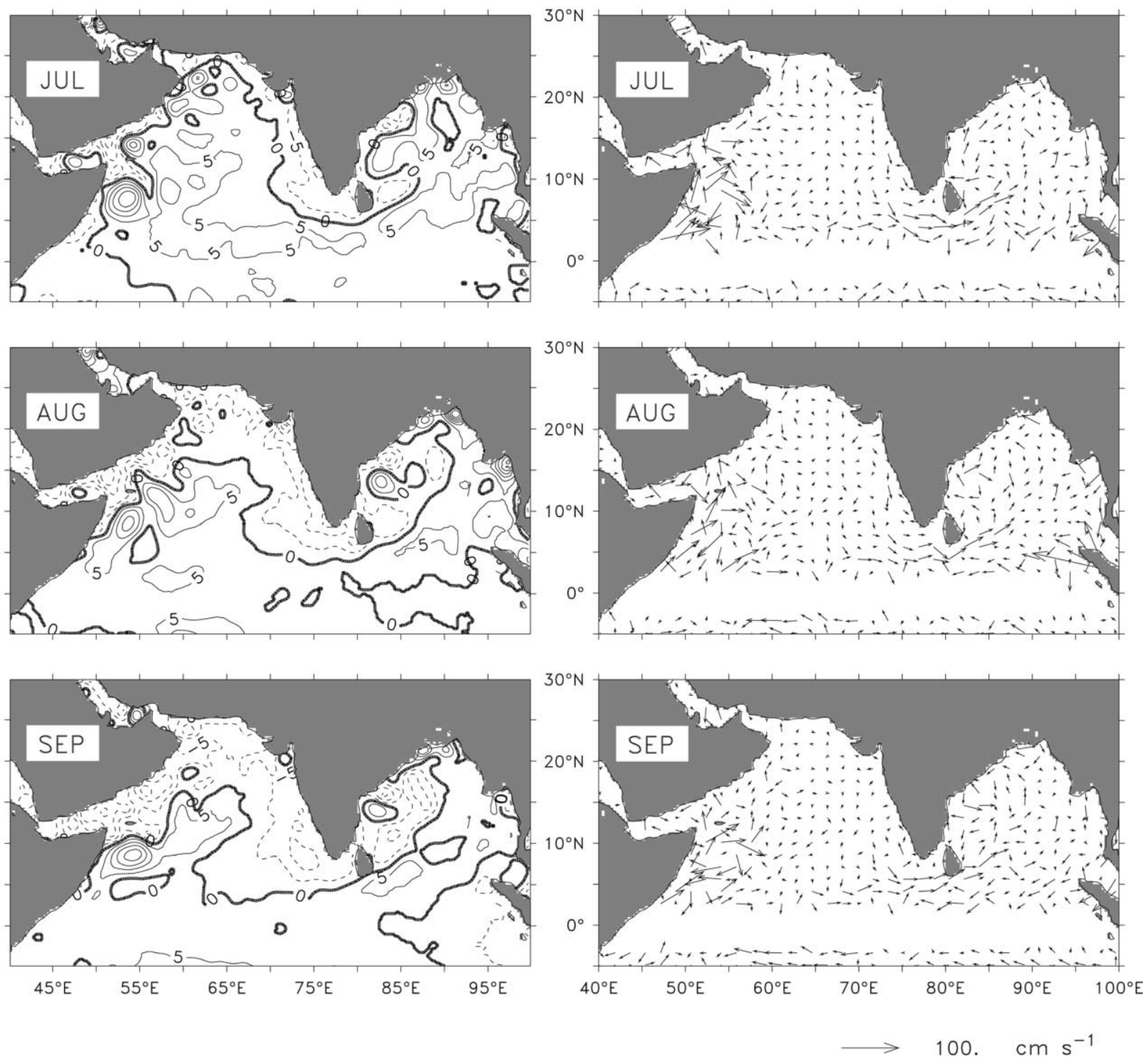

Fig. 5. Continued

the poleward Somali Current between $4^{\circ} \mathrm{N}$ and $6^{\circ} \mathrm{N}$. The Somali Current flows equatorward north of $6^{\circ} \mathrm{N}$ and feeds the eastward GWMC to the north of the high.

The geostrophic circulation during April is dominated by eddies. The GWMC in the Bay has shifted westward and it now intersects the east coast of Sri Lanka; this splits the GWMC into separate currents in the Bay and in the Arabian Sea. The relic GWMC in the Bay is the eastern arm of an anticyclonic gyre. The relic GWMC in the Arabian Sea has weakened and it meanders more, but its spatial structure is similar to that in March.

During May, the relic GWMC in the Bay flows southwestward from the central Bay to Sri Lanka. In 


\section{Climatology of sea-level anomalies and surface geostrophic flow}
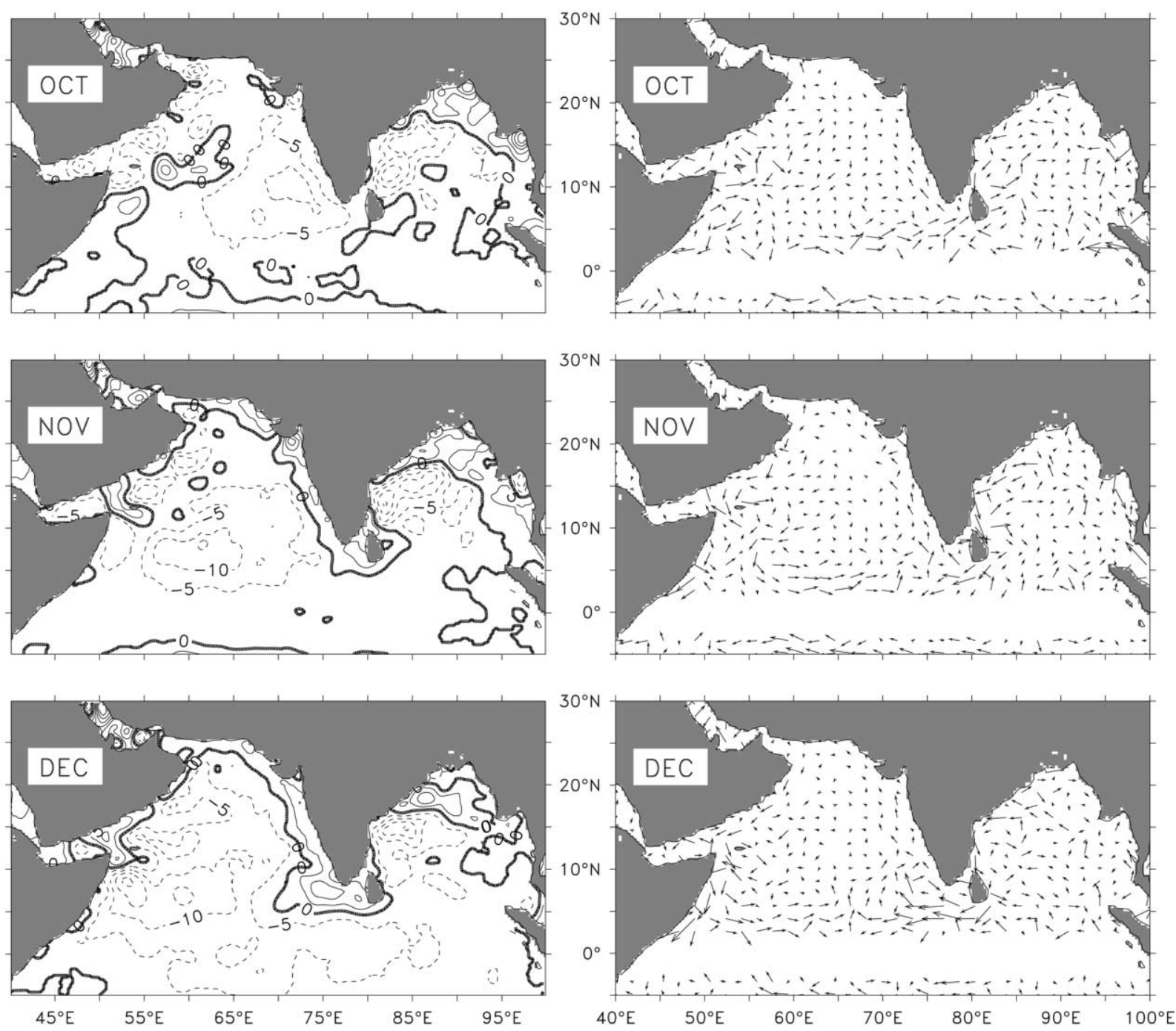

$\longrightarrow$ 100. $\mathrm{cm} \mathrm{s}^{-1}$

Fig. 5. Continued

the Arabian Sea, it appears primarily as a westward flow at $\sim 7^{\circ} \mathrm{N}$ and is now fed by the equatorward WICC. The sea-level high is now well offshore, and the eastward flow to its north is weaker and meanders more than in April. An eastward flow appears in the southern Bay between $4^{\circ}$ and $8^{\circ} \mathrm{N}$; it flows across the basin, from Sri Lanka to the eastern boundary. This is the incipient GSMC, and it appears first in the Bay even as the summer monsoon sets in.

In June, the relic GWMC is restricted in the central and western Bay to a southwestward flow from $16^{\circ} \mathrm{N} 90^{\circ} \mathrm{E}$ to the northern tip of Sri Lanka, and in the Arabian Sea to a meander to the south and north of the sea-level highs in the southwest. The GSMC flows northeastward from the southern tip of Sri Lanka 
to $14^{\circ} \mathrm{N} 90^{\circ} \mathrm{E}$; an outflow from the GSMC also recirculates around a low in sea level to the east of Sri Lanka. The GSMC in the Bay is pushed westwards by the westward shift of a sea-level high from the eastern equatorial Indian Ocean. The GSMC also appears in the Arabian Sea as a flow around the Lakshadweep low off southwest India, and it is fed by the equatorward WICC. In the southern Arabian Sea, there is eastward flow at $5^{\circ} \mathrm{N}$ between $65^{\circ} \mathrm{E}$ and $75^{\circ} \mathrm{E}$; this flow merges into the GSMC south of Sri Lanka.

The mature phase of the GSMC peaks in July when it exists as a continuous trans-basin current from the northern limits of the Somali Current to the southern tip of Sri Lanka and into the Bay of Bengal. It shifts westward in the Bay, pushed by the sea-level high to its east. One branch of the GSMC appears as a northeastward flow from the southern tip of Sri Lanka almost to the northeastern boundary of the Bay. Around $87^{\circ} \mathrm{E}$, another branch flows due north and feeds into the relic GWMC, which has shifted westward and now appears as the eastern arm of an anticyclonic circulation around a high in sea level in the western Bay. The GSMC south of Sri Lanka has a velocity of $\sim 40 \mathrm{~cm} \mathrm{~s}^{-1}$. It is fed by a flow around the Lakshadweep low, this being a branch of the GSMC that is fed by the WICC, and also by an eastward flow across the southern Arabian Sea. The eastward GSMC in the south is the continuation of the GSMC in the western and central Arabian Sea; this branch of the GSMC flows geostrophically around the sea-level high (low) in the western (eastern) Arabian Sea. It is the flow around the Lakshadweep low that provides greater inflow into the GSMC south of Sri Lanka.

Westward propagation of sea-level anomalies continues in the Bay of Bengal, and the GSMC becomes detached from its eastern boundary by August. It can be traced as a continuous current from the southern tip of Sri Lanka to the northern Bay, though there are cyclonic eddies associated with it east of Sri Lanka and in the central Bay. In the Arabian Sea, the Lakshadweep low propagates westward, taking the GSMC and WICC with it; the coastal current off the west coast of India collapses. Westward propagation of the sea-level highs in the western Arabian Sea compresses them and strengthens the geostrophic flow around them. Except for this part of the basin and south of Sri Lanka, where it has peak velocity of $\sim 50 \mathrm{~cm} \mathrm{~s}^{-1}$, the GSMC is weaker in August than in July.

As the monsoon winds weaken during September, so does the GSMC, except in the western Bay and, to a lesser extent, in the western Arabian Sea, where westward propagation compresses the sea-level lows and highs and strengthens the geostrophic flows associated with them. The Lakshadweep low is now detached from the coast and a part of the GSMC recirculates around it. The sea-level high that propagated westwards across the southern Bay is now almost at the southern tip of Sri Lanka, and the GSMC is squeezed against the coast. There is geostrophic flow around this high, and a westward current exists to its south, flowing from the Andaman Sea to south of Sri Lanka.

The sea-level high that pushed the GSMC westward through the Bay abuts the Sri Lankan coast in October, breaking the connection between the GSMC in the Bay and the Arabian Sea. In the Bay, the relic GSMC flows from the east coast of Sri Lanka into the north central Bay, and it is associated with, and is fed by, the recirculation around sea-level lows in the western Bay. The EICC reverses in October to flow equatorward as the western arm of these cyclonic geostrophic flows. The Lakshadweep low has now moved well offshore and the WICC also reverses to flow poleward off southwest India. The eddies and sea level highs in the western Arabian Sea begin disintegrating, but the relic GSMC is still traceable as a distinct southwestward current in the western Arabian Sea; this relic current turns to flow eastward in the southern Arabian Sea.

Longitude-time plots of the sea-level anomalies (Fig.6) show westward propagation at all latitudes, the speed of propagation decreasing with increasing latitude. Similar westward propagation has been noted in earlier hydrographic (Kumar \& Unnikrishnan, 1995; Unnikrishnan, Kumar, \& Navelkar, 1997; Rao, 1998) and altimetric studies (Perigaud \& Delecluse, 1992), and has been attributed to westward propagating Rossby Waves. Most striking, however, is the phase shift in the westward propagating signal at $80.5^{\circ} \mathrm{E}$, south of Sri Lanka, even though there is no land barrier there and the GSMC and GWMC form continuous currents from the Arabian Sea to the Bay of Bengal (and vice versa). 

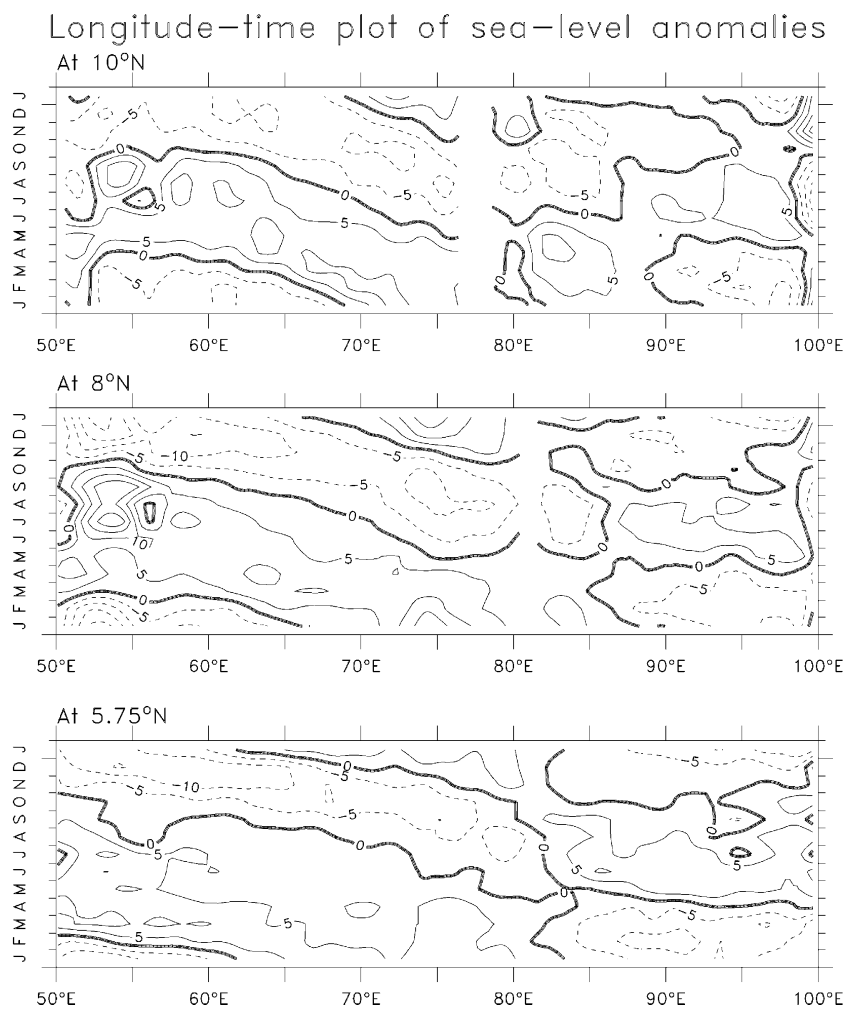

Fig. 6. Longitude-time plots of the monthly climatology of TOPEX/Poseidon sea level anomalies (cm) at $10^{\circ} \mathrm{N}\left(\right.$ top panel), $8^{\circ} \mathrm{N}$ (middle panel), and $5.75^{\circ} \mathrm{N}$ (bottom panel). Negative anomalies are indicated by dashed contours and the contour interval is $5 \mathrm{~cm}$. Westward propagation is evident in both the Arabian Sea and Bay of Bengal at all latitudes.

Latitude-time plots of the zonal component of the geostrophic current at $80.5^{\circ} \mathrm{E}$ (Fig. 7) show that the signal south of Sri Lanka is dominated by the annual harmonic north of $\sim 3^{\circ} \mathrm{N}$; this is also seen in the zonal geostrophic current derived from the climatologies of Levitus and Boyer (1994) and Levitus et. al. (1994) (Fig. 8), which also shows a strong semi-annual signal farther south in the regime of the Equatorial Current. This is in agreement with direct current measurements in this region (Schott et al., 1994; Reppin et al., 1999), and suggests that the monsoon-current system south of Sri Lanka is distinct from the Equatorial Current farther south, even though it is difficult to distinguish between these two regimes during, say, December-February, when the WMC flows westward, as does the Equatorial Current.

\subsection{The net surface flow}

The sum of the Ekman and geostrophic (annual mean from Fig. 4 plus monthly anomalies from Fig. 5) components constitutes, barring a residual, the net flow (NF) at the surface (Hastenrath \& Greischar, 1991). We compare the NF with ship drifts (SD) (Fig. 9).

During November, geostrophy dominates in the Bay of Bengal and along the coast of the Indian subcontinent. The equatorward EICC, the westward WMC south of Sri Lanka, and the poleward WICC appear as a continuous current in both NF and SD; the current, however, is stronger in the SD than in the NF. The relic SMC in the Arabian Sea appears as a southwestward flow from $\sim 12^{\circ} \mathrm{N} 65^{\circ} \mathrm{E}$ to $\sim 4^{\circ} \mathrm{N} 55^{\circ} \mathrm{E}$, where it turns to flow eastward. 




Fig. 7. Latitude-time plot of the monthly climatology of zonal geostrophic current $\left(\mathrm{cm} \mathrm{s}^{-1}\right)$, derived from TOPEX/Poseidon altimetry, at $80.5^{\circ} \mathrm{E}$ (south of Sri Lanka). Westward flow is indicated by dashed contours and the contour interval is $5 \mathrm{~cm} \mathrm{~s} \mathrm{~s}^{-1}$.

The Ekman drift strengthens in December, but it dominates geostrophy only in the northern Arabian Sea. The drift accentuates the strong westward GWMC in the southern Bay and the westward geostrophic flow to the north of the sea-level low in the southwestern Arabian Sea (Fig. 5). It attenuates the eastward GSMC to its south; as a consequence, the WMC appears farther north in the western Arabian Sea than in the eastern Arabian Sea. It branches around $65^{\circ} \mathrm{E}$, with one branch flowing around the Lakshadweep high, while the other continues to flow westward. This latter branch of the WMC is synonomous with the relic SMC to the north of the sea-level low. South of Sri Lanka, the WMC attains its maximum strength, 50 $\mathrm{cm} \mathrm{s}^{-1}$, during December. This is the result of the equatorward EICC and the Ekman drift, which also enables the WMC 'to mature' before the GWMC does; the WMC is in its mature phase during DecemberMarch, but its spatial structure undergoes changes even during this phase.

The WMC in January is similar to that in December, but it is stronger, except south of Sri Lanka. Both geostrophy and Ekman drift contribute in the Bay. In the Arabian Sea, the Ekman drift is responsible for extending the $\mathrm{WMC}$ west of $60^{\circ} \mathrm{E}$, but geostrophic flow around the Lakshadweep high dominates in the east.

During February, the Ekman drift is weak, and the NF is dominated by eddies, resulting in relatively poor agreement with the SD outside the domain of the strong WMC. Owing to the dominance of geostrophy, which continues through to April, the WMC is almost identical to the GWMC.

During March, the Ekman drift contributes only in the southwestern Arabian Sea, where it accentuates the westward WMC to the south of the Lakshadweep high and attenuates the eastward WMC to its north.

The winds are weakest in April, and the WMC is almost identical to the GWMC. It appears in three distinct parts: a southwestward relic in the western Bay, a meandering westward flow south of a sea-level high in the southern Arabian Sea, and a meandering eastward flow to the north of the high. The two relics of the WMC in the Arabian Sea are connected by a poleward Somali Current. This is in agreement with the SD, in which relics of the WMC also appear as three separate currents; the Somali Current, however, flows poleward all along the coast in the SD, but not in the NF.

The SMC appears in the Bay in both SD and NF during May, but it is broader in the latter because of the strong Ekman drift across the southern Bay. The SMC can be traced as a continuous current from the northern limit of the poleward Somali Current to the eastern Bay in both data sets; this marks the beginning of its mature phase, which starts earlier than that of the GSMC because of the Ekman drift. An equatorward, geostrophic WICC feeds into the SMC in the NF, but the WICC is weaker in the SD. Ekman drift and geostrophic flow combine to produce the SMC in the Arabian Sea, the former dominating in the west and 




Fig. 8. Depth-time plots of the meridionally averaged zonal geostrophic current $\left(\mathrm{cm} \mathrm{s}^{-1}\right)$ at $80.5^{\circ} \mathrm{E}$ derived from the climatologies of Levitus and Boyer (1994) and Levitus et al. (1994). The top (bottom) panel shows the current averaged over $0^{\circ}$ to $3^{\circ} \mathrm{N}\left(3^{\circ}\right.$ to $\left.6^{\circ} \mathrm{N}\right)$. Westward flow is indicated by dashed contours and the contour interval is $5 \mathrm{~cm} \mathrm{~s}^{-1}$.

the latter in the east. In the NF, these two components combine to form a curving flow across the Arabian Sea, but this current flows zonally across the basin at $10^{\circ} \mathrm{N}$ in the SD.

The Ekman drift overwhelms geostrophic flow when the summer monsoon winds strengthen in June. This is more so in the Arabian Sea, where the currents cross the isolines of sea level, and a little less in the Bay, where winds weaker than those in the Arabian Sea (Fig. 1) combine with the multiplicity of eddies (Fig. 5) to make the NF different from the uniform eastward Ekman drift. Although the SDs are noisier, the dominance of Ekman drift is seen in them too. In June, therefore, the SMC appears as an eastward or southeastward flow in the Arabian Sea and an eastward or northeastward flow in the Bay.

The summer-monsoon winds peak in July; so does the Ekman drift. Geostrophy makes a significant contribution to the surface currents only in the Bay and to the south of Sri Lanka. Though there is agreement between the NF and the SD, the latter also show the effects of the winds on the ships. The mature SMC flows eastward or southeastward throughout the Arabian Sea, and northeastward into the Bay. There is, however, a current that branches off from the SMC south of Sri Lanka and flows eastward-southeastward; a part of this flow, which results from the Ekman drift, also crosses the equator in the SD (Fig. 9) and surface drifter data (Shenoi, Saji, \& Almeida, 1999). 


\section{Climatology of net surface flow and ship drifts}
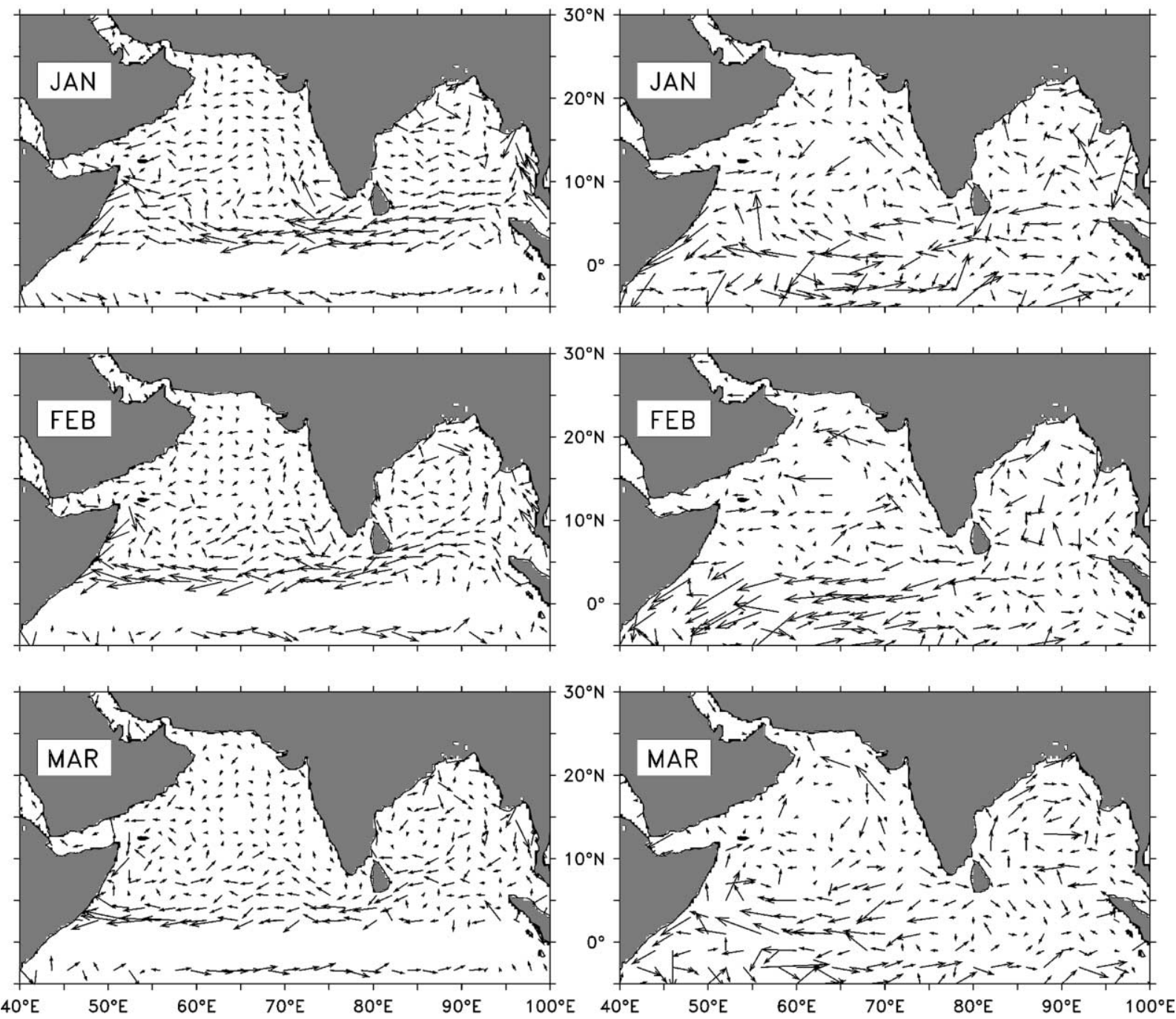

$\longrightarrow$ 100. $\mathrm{cm} \mathrm{s}^{-1}$

Fig. 9. The net flow (NF) at the surface ( $\mathrm{cm} \mathrm{s}^{-1}$, left panels), computed as the sum of Ekman drift (Fig. 3) and geostrophic flow (Figs. 4 and 5), and ship drift (SD) ( $\mathrm{cm} \mathrm{s}^{-1}$, right panels). The source for the ship drifts are the Ocean Current Drifter Data CDROMs NODC-53 and NODC-54 (NODC, Department of Commerce, NOAA).

Apart from a weakening of the SMC owing to slightly weaker winds, the NF and the SD during August are as in July.

The summer-monsoon winds continue to weaken through September, making geostrophy more relevant to the surface flow field. In the Arabian Sea, the Ekman drift dominates, except in the southeast, where geostrophic flow around the Lakshadweep low is important, and in the vicinity of the Great Whirl off Somalia, where there is strong geostrophic flow around a sea-level high. In the Bay, the Ekman drift dominates in the south, forcing a broad eastward SMC, but geostrophy is strong enough to make a part 


\section{Climatology of net surface flow and ship drifts}
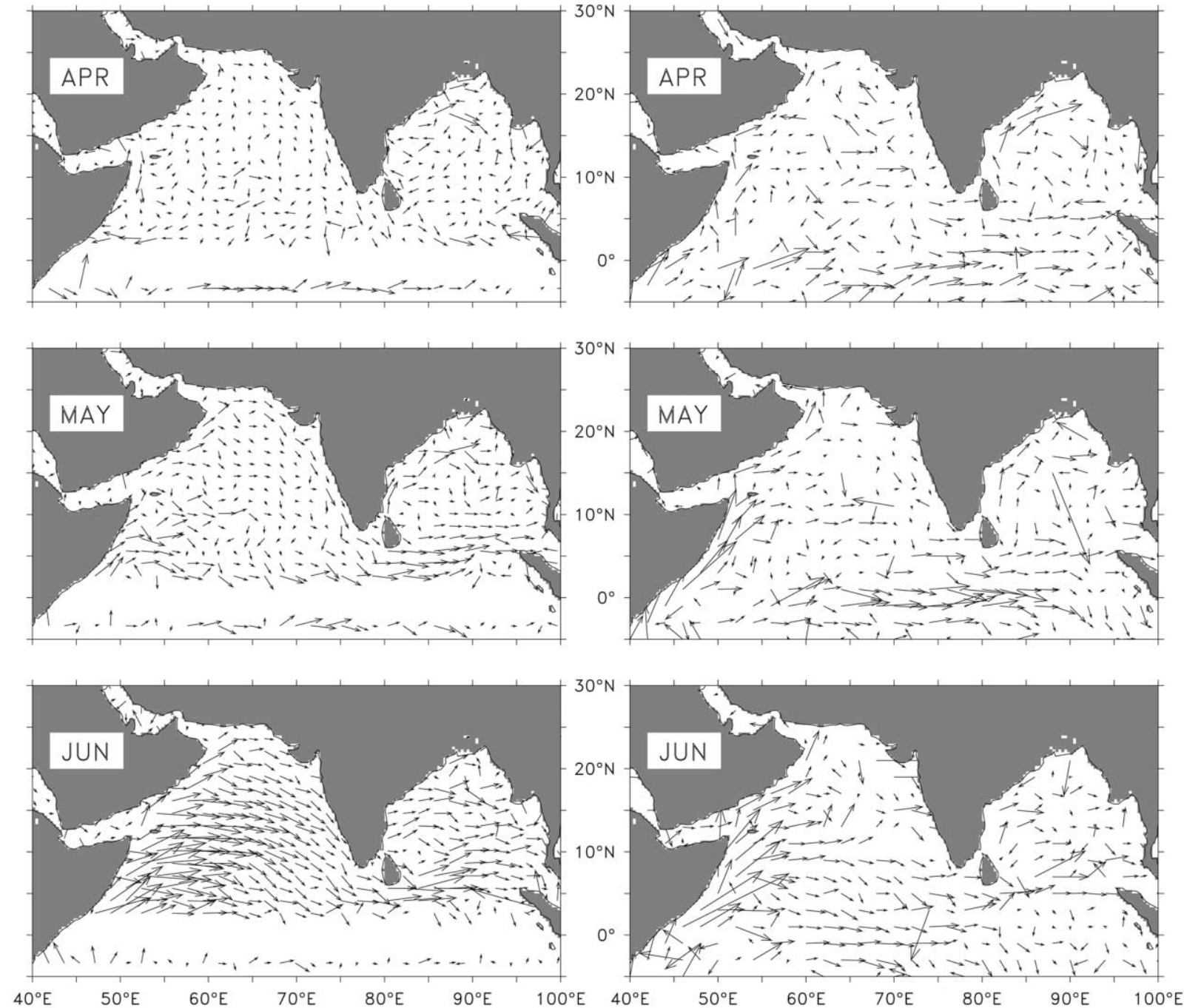

$\longrightarrow$ 100. $\mathrm{cm} \mathrm{s}^{-1}$

Fig. 9. Continued

of the flow turn northeastward into the central Bay. In the rest of the Bay, geostrophic flow around eddies dominates.

October is a month of transition, so the Ekman drift is negligible, except in the southern Bay and to the southwest of Sri Lanka. Nevertheless, it combines with geostrophy to sustain the SMC as a continuous current from the Arabian Sea to the Bay; the mature phase of the SMC, therefore, extends beyond the summer monsoon, unlike that of the GSMC. The SMC is split in the Bay, a separate relic existing as a geostrophic northeastward flow from eastern Sri Lanka to the central Bay. These features are also evident in the SD, except that the relic SMC is farther east. 


\section{Climatology of net surface flow and ship drifts}
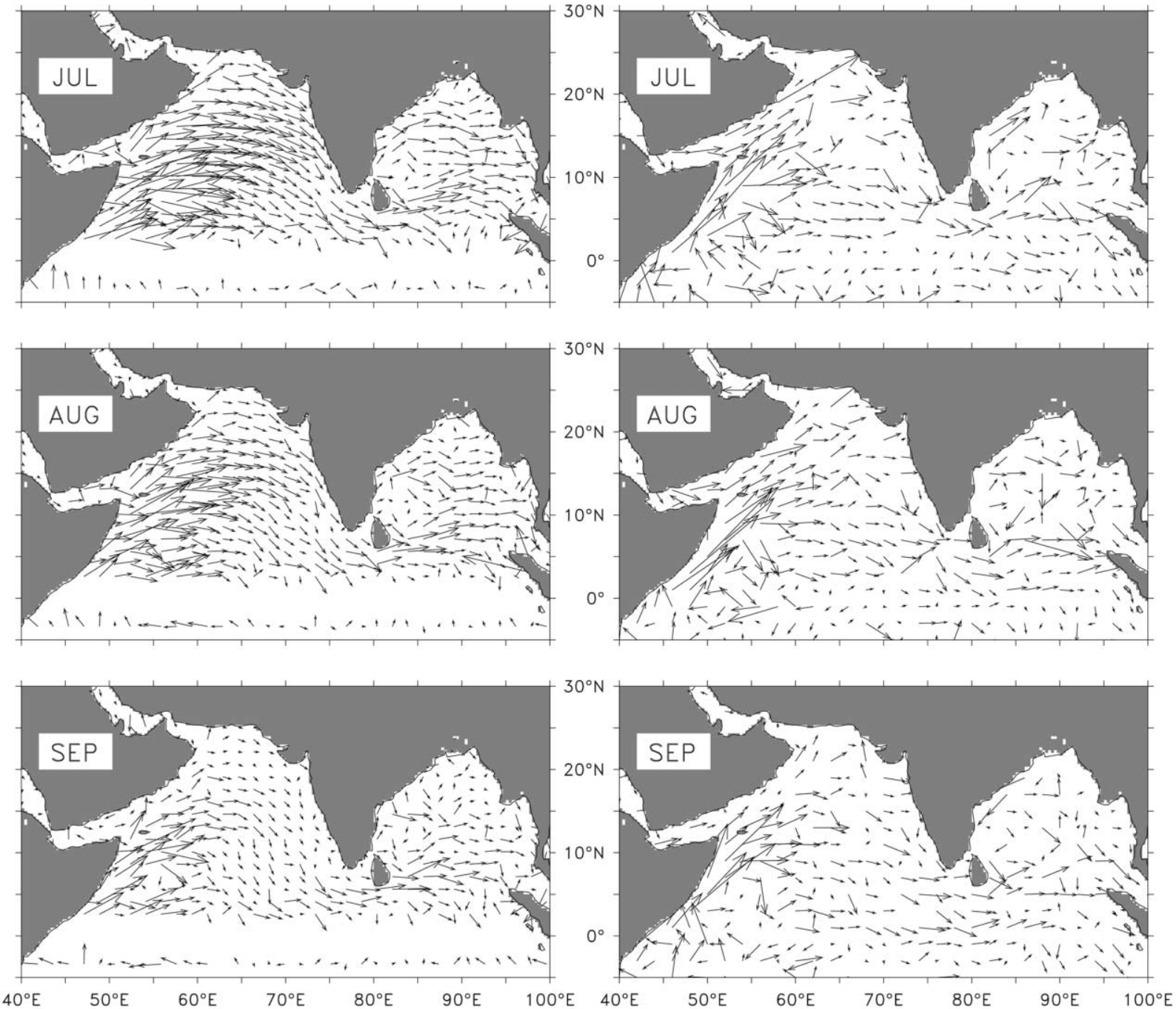

Fig. 9. Continued

Although there are differences between the NF and the SD, the major discrepancy being the greater strength of the SD, the two exhibit similar features in the domain of the monsoon currents. The Ekman drift dominates the surface circulation in the north Indian Ocean during the summer monsoon, with geostrophy being significant only south of Sri Lanka, around the eddies off Somalia, and in the Bay of Bengal. Both geostrophy and Ekman drift are important during the winter monsoon. During the transitions between the monsoons, in March-April and October, geostrophy dominates the circulation. 


\section{Climatology of net surface flow and ship drifts}


$\longrightarrow$ 100. $\mathrm{cm} \mathrm{s}^{-1}$

Fig. 9. Continued

\section{The monsoon currents in an OGCM}

The observations show that both Ekman drift and geostrophy contribute to the surface circulation in the north Indian Ocean. The former rapidly decays with depth, but the latter is expected to be significant even in the subsurface layers. We use a multi-level Oceanic General Circulation Model (OGCM) to ascertain the vertical structure of the monsoon currents and to estimate their transports. 


\subsection{Numerical model}

The OGCM used is based on the Modular Ocean Model (Pacanowski, 1996). The model domain covers the tropical Indian Ocean $\left(30^{\circ} \mathrm{S}-30^{\circ} \mathrm{N}, 30^{\circ}-115^{\circ} \mathrm{E}\right)$. The model has realistic coastline and topography based on the ETOPO5 data set. The horizontal resolution is $0.33^{\circ} \times 0.33^{\circ}$ and there are 25 levels in the vertical, of which eight are in the top $100 \mathrm{~m}$. Horizontal eddy viscosity and diffusivity are $2 \times 10^{7} \mathrm{~cm}^{2} \mathrm{~s}^{-1}$ and $10^{7}$ $\mathrm{cm}^{2} \mathrm{~s}^{-1}$, respectively, and vertical mixing is parameterized using the scheme of Pacanowski and Philander (1981). The model is spun up for five years from a state of rest and climatological temperature (Levitus \& Boyer, 1994) and salinity (Levitus et al., 1994) using the wind-stress climatology of Hellerman and Rosenstein (1983).

The model reproduces the monsoon circulation in the Indian Ocean reasonably well. Vinayachandran, Masumoto et al. (1999) compared the SMC along $6^{\circ} \mathrm{N}$ in a similar model with TOPEX/Poseidon altimetry and geostrophic currents. They found that the model SMC near Sri Lanka compares well with that derived from TOPEX/Poseidon altimetry, but the core of the SMC east of Sri Lanka was weaker in the model than that derived from XBT data. Vinayachandran, Saji, and Yamagata (1999) used the model to investigate the unusual conditions in the equatorial Indian Ocean in 1994 and noted that the model Equatorial Current is consistent with the direct current measurements of Reppin et al. (1999).

\subsection{The model circulation}

The flow in the first thre model levels is dominated by Ekman flow, and geostrophy dominates below that. At each level, however, both contribute to the model flow field. Hence, we present the model circulation at depths of 5 and $35 \mathrm{~m}$, comparing them with the Ekman drift and geostrophic flow. We then present the depth-averaged flow in the topmost $50 \mathrm{~m}$, which is more representative of the shallow monsoon currents than the surface flow alone.

As the model flow is a composite of both Ekman and geostrophic flows, there are several additional features in it at $5 \mathrm{~m}$ (Fig. 10) compared to the estimated Ekman drift (Fig. 3). For example, the model flow at $5 \mathrm{~m}$ contains strong coastal currents, including the Somali Current, the coastal current off Oman, the EICC, and the WICC. The EICC flows equatorwards during November and feeds the westward WMC south of Sri Lanka, this flow standing out from the eastward Equatorial Current (i.e. the fall Wyrtki jet). In the western Arabian Sea, there is a westward drift at $\sim 9^{\circ} \mathrm{N}$; this is either the relic SMC or the incipient WMC. The mature, trans-basin WMC exists at the surface during December-March. Most of the flow is westward at $\sim 5^{\circ} \mathrm{N}$, but a branch of the WMC turns to flow around the Lakshadweep high in the southwestern Arabian Sea; this branch of the WMC propagates westwards. Apart from the WMC, the outstanding feature during the winter monsoon is the anticyclonic gyre in the Bay. Thus, during the winter monsoon, when the winds are relatively weak, geostrophy dominates even at the surface, the Ekman drift modulating the geostrophic currents.

The Ekman drift dominates the model surface flow during the summer monsoon. Nevertheless, the coastal currents, the intrusion of the SMC into the Bay, and the flow around the eddies off Somalia, which are the result of geostrophy, are evident even at $5 \mathrm{~m}$. At the surface, the mature phase of the SMC extends from May to October, as in the NF and the SD data. The model SMC south of Sri Lanka is fed by the southeastward drift across the Arabian Sea; unlike in the NF, the contribution from the due west flow is much less. As in the NF, a current branches off from the SMC south of Sri Lanka to flow eastwardsoutheastward and across the equator.

The model currents at $35 \mathrm{~m}$ (Fig. 11) compare well with the geostrophic flow (Fig. 5). The genesis and decay of the (G)WMC and (G)SMC follow the pattern established from satellite altimetry. There does not, however, seem to be a clear link between the recirculation in the eddies off Somalia and the SMC south of Sri Lanka; the latter is fed more by the branch of the SMC that flows around the Lakshadweep low, 


\section{OGCM currents at $5 \mathrm{~m}$}
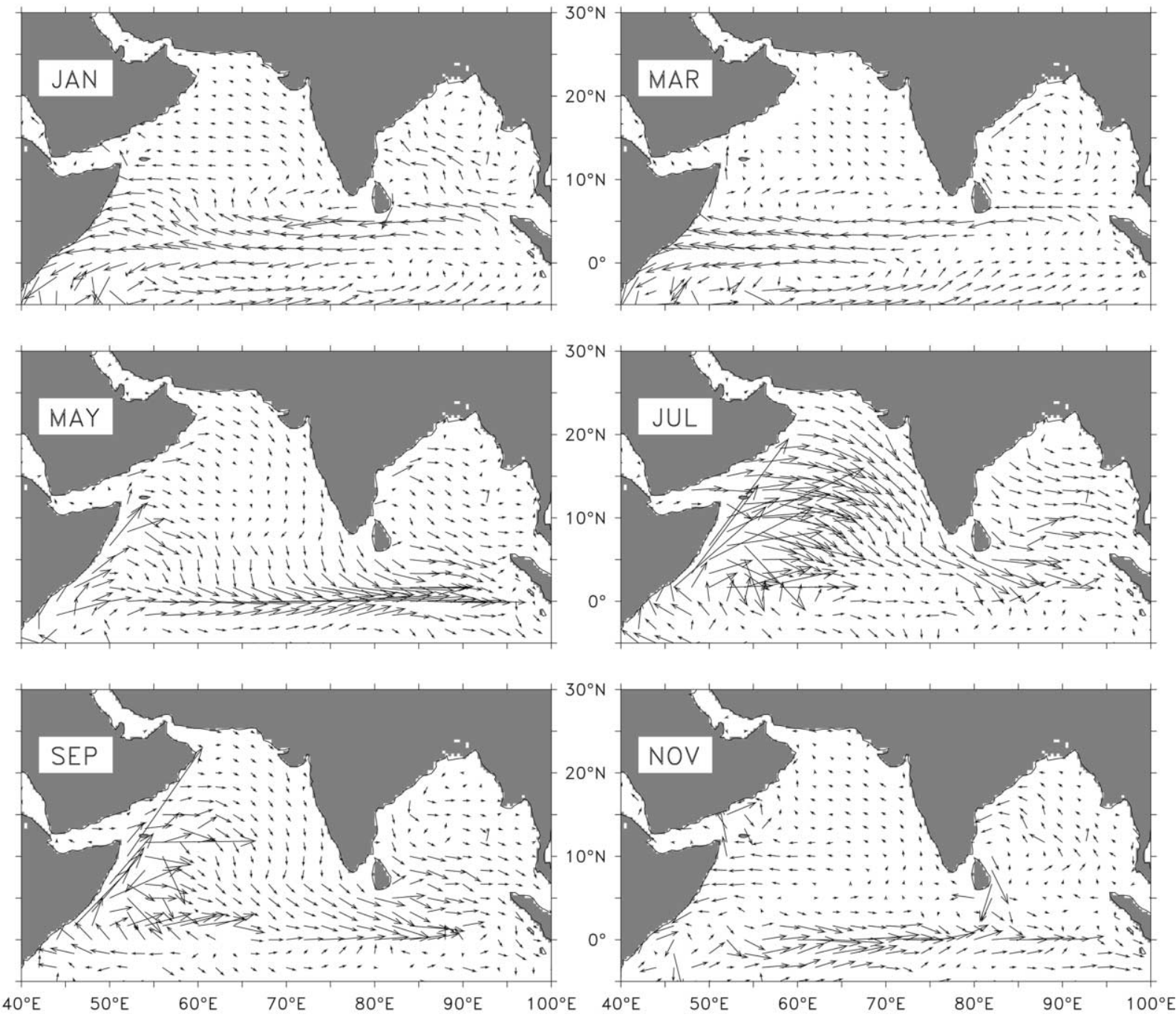

Fig. 10. OGCM currents $\left(\mathrm{cm} \mathrm{s}^{-1}\right)$ at $5 \mathrm{~m}$. The model flow at this depth is dominated by Ekman drift.

and this flow is, in turn, fed by the WICC and the flow across the central Arabian Sea. The recirculation in the eddies off Somalia instead feeds mostly into the eastward current in the western equatorial Indian Ocean. This eastward current feeds the SMC south of Sri Lanka in the SD (Fig. 9) and in the simulations of McCreary et al. (1993); however, in the OGCM simulations and in the surface-drifter data (Shenoi, Saji, \& Almeida, 1999), it crosses the equator.

In the depth-averaged flow (DAF) in the top $50 \mathrm{~m}$ (Fig. 12), the mature WMC is as in the NF and appears primarily as a geostrophic flow modulated by the Ekman drift; the mature phase of the depthaveraged WMC also extends from December to March. A part of the DAF around the eddies off Somalia 


\section{OGCM currents at $35 \mathrm{~m}$}


$\longrightarrow$ 100. $\mathrm{cm} \mathrm{s}^{-1}$

Fig. 11. OGCM currents $\left(\mathrm{cm} \mathrm{s}^{-1}\right)$ at $35 \mathrm{~m}$. The model flow at this depth is dominated by geostrophy.

feeds the eastward Equatorial Current in the western Indian Ocean, but, unlike in the $35 \mathrm{~m}$ flow field, most of it merges with the Ekman drift to form a broad, basin-wide, southeastward flow across the Arabian Sea; this current forms the broad western arm of the flow around the Lakshadweep low off southwest India, and feeds into the SMC south of Sri Lanka. In the Bay, the northeastward SMC is primarily geostrophic. The mature phase of the depth-averaged SMC extends from May to September, ending a month before that at the surface; this is because the Ekman drift is weaker in the DAF.

Westward propagation associated with Rossby waves forms an essential component of the monsoon circulation in the northern Indian Ocean (Fig. 13); this is best seen in the flow at $35 \mathrm{~m}$. In the Bay, however, 


\section{OGCM currents averaged over top $50 \mathrm{~m}$}


Fig. 12. OGCM currents $\left(\mathrm{cm} \mathrm{s}^{-1}\right)$ averaged over the top $50 \mathrm{~m}$.

westward propagation is seen at all depths throughout the entire year, indicating geostrophy is dominant there. During the summer monsoon, the dominance of the Ekman drift eliminates the Rossby wave signal at $5 \mathrm{~m}$, but westward propagation is seen at $35 \mathrm{~m}$; this signal is, however, weak, possibly because the strong eastward Ekman drift slows down the Rossby waves (Vinayachandran \& Yamagata, 1998).

The monsoon currents are shallow, unlike the deep currents observed off Somalia during the summer monsoon (Schott \& McCreary, 2001). The shallowness of the monsoon currents in the OGCM, especially in the SMC, is seen in the depth-time plot of the zonal current at $80.5^{\circ} \mathrm{E}$ (Fig. 14). The SMC was shown by Vinayachandran and Yamagata (1998) to be trapped close to the surface because of the downwelling 

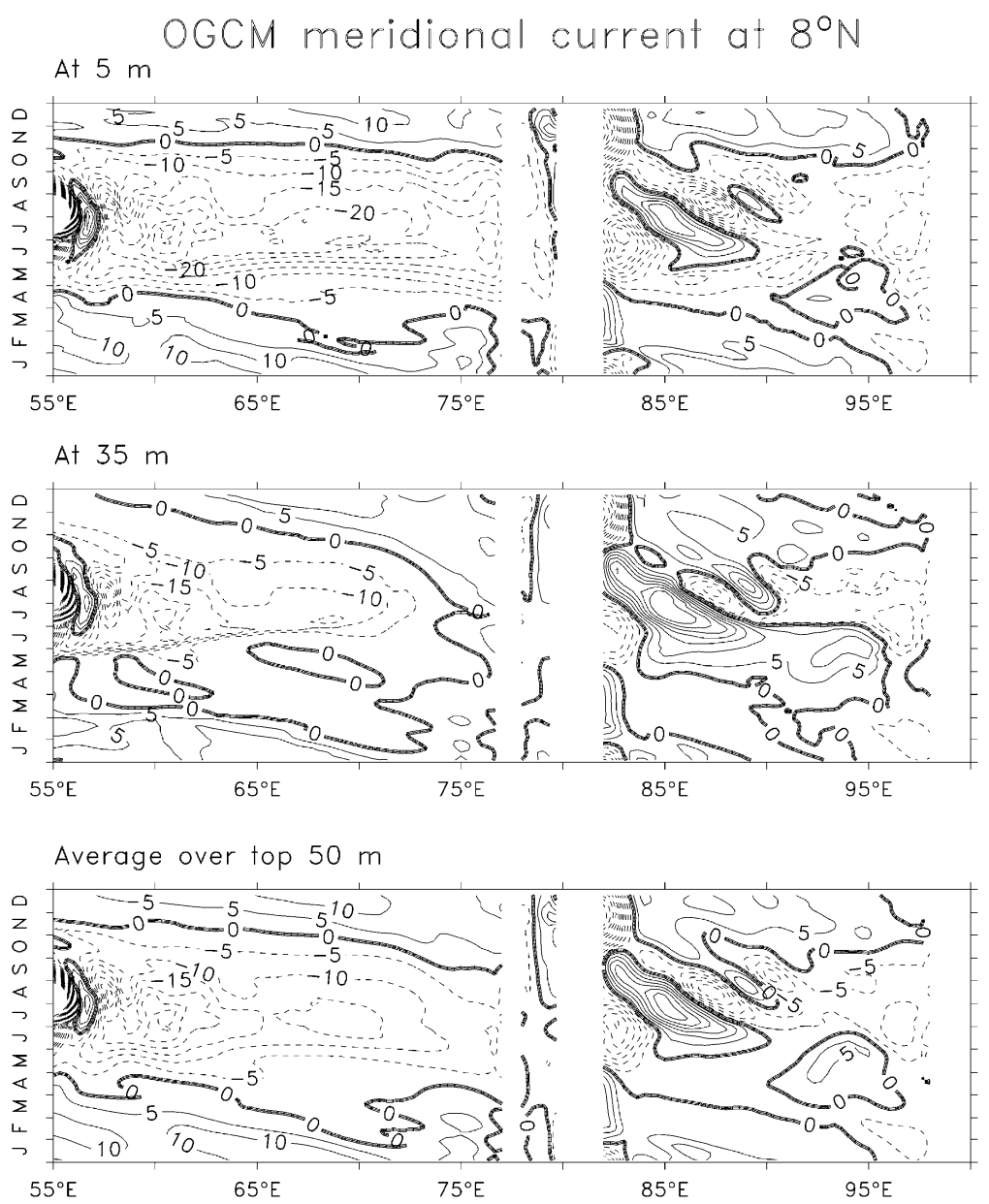

Fig. 13. Longitude-time plots of the OGCM meridional current $\left(\mathrm{cm} \mathrm{s}^{-1}\right)$ at $8^{\circ} \mathrm{N}$. Southward flows are indicated by dashed lines and the contour interval is $5 \mathrm{~cm} \mathrm{~s}^{-1}$.

Rossby wave that propagates westwards from the eastern boundary of the equatorial Indian Ocean. This downwelling Rossby wave is associated with southwestward geostrophic flow. As it propagates westward, the westward geostrophic flow dominates the eastward Ekman component, causing the latter to shoal. This signature of westward flow is seen in the westward flow below the eastward SMC during the summer monsoon; upward (downward) propagation of phase (energy) is evident (Fig. 14), as in the observations (Schott et al., 1994; Reppin et al., 1994), indicating the existence of free propagating waves.

\subsection{Transport estimates}

Since subsurface observations of these seasonal, open-ocean currents are limited (see Table 2), numerical models that simulate the observed surface circulation well are an important source of information on the transports associated with them. Given the significant contribution of Ekman flow to the depth-averaged flow in the top $50 \mathrm{~m}$, comparisons between the model transports and estimates based on hydrography are not meaningful. Hence, we choose to compare the model transports with those estimated from direct current 

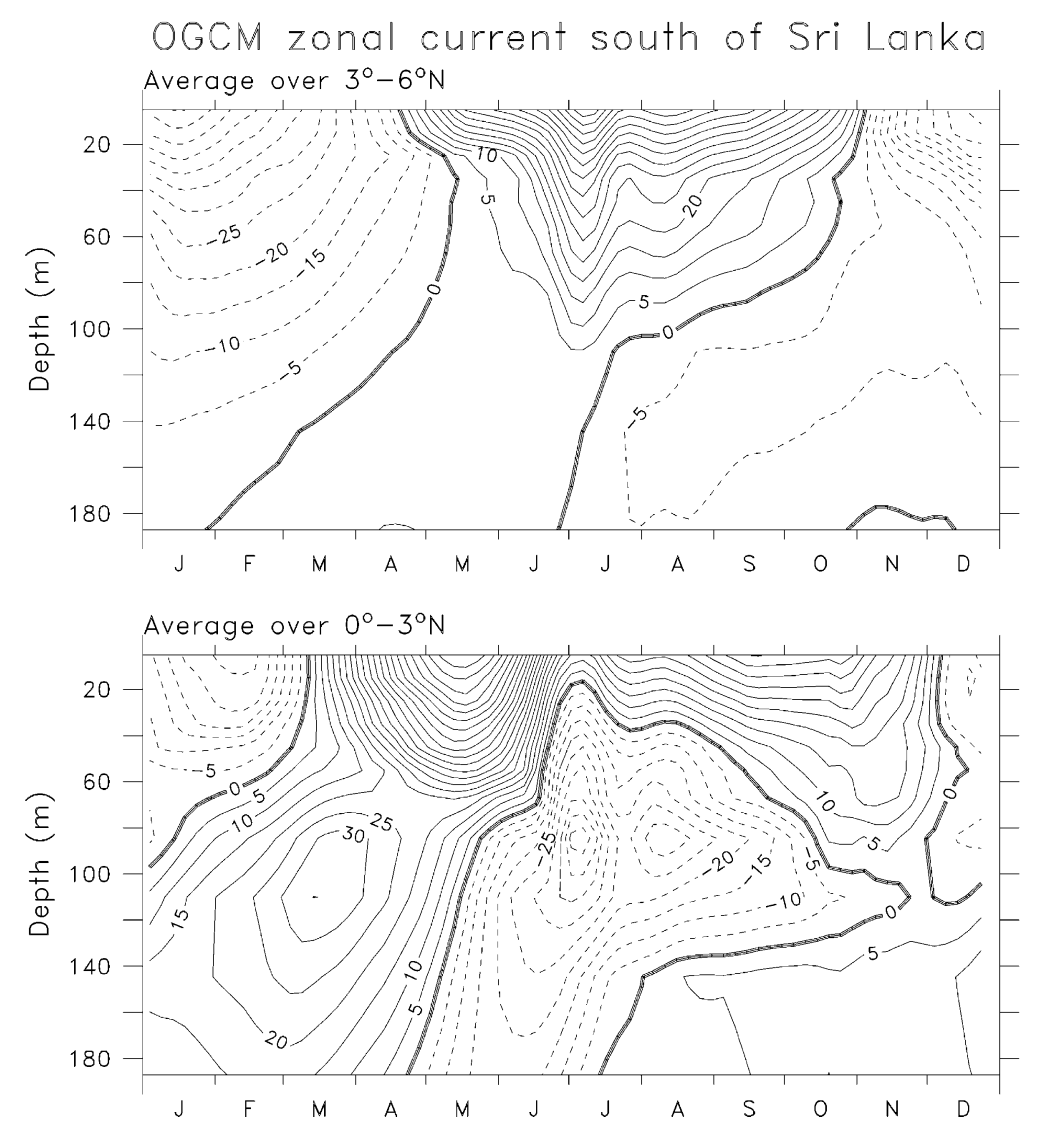

Fig. 14. Depth-time plots of the OGCM zonal current $\left(\mathrm{cm} \mathrm{s}^{-1}\right)$ at $80.5^{\circ} \mathrm{E}$ (south of Sri Lanka). The top (bottom) panel shows the current averaged over $3^{\circ}-6^{\circ} \mathrm{N}\left(0^{\circ}-3^{\circ} \mathrm{N}\right)$. Westward flows are indicated by dashed contours and the contour interval is $5 \mathrm{~cm} \mathrm{~s}^{-1}$.

measurements south of Sri Lanka (Schott et al., 1994). Given that the observations are from a particular year, while the model represents a climatology, the comparison is good (Table 3).

Latitude-time plots of the depth-integrated zonal current (Fig. 15) show that the WMC is relatively narrow and strong across the basin. In contrast, the SMC stands out only south of Sri Lanka and in the Bay, where its eastward flow is seen to shift poleward with time, marking the westward propagation of the northeastward SMC across the Bay. In the Arabian Sea at $65^{\circ} \mathrm{E}$, the depth-integrated SMC is weak, but broad, the eastward flow extending from $\sim 12^{\circ}-20^{\circ} \mathrm{N}$ during the summer monsoon; the weak westward flow between $4^{\circ}$ and $6^{\circ} \mathrm{N}$ and the weak eastward flow between $0^{\circ}$ and $4^{\circ} \mathrm{N}$ both show the complicated spatial structure of the geostrophic flow associated with the SMC (Fig. 11). The model transports associated with the SMC and WMC are listed in Table 4.

\section{Forcing mechanisms}

\subsection{The numerical model and the control run}

Though the OGCM simulations compare well with the observations, the OGCM is too complex to yield insight into the dynamics underlying the monsoon-current system. To isolate the processes responsible for 
Table 3

Observed and model zonal transports (in $\mathrm{Sv} ; 1 \mathrm{~Sv}=10^{6} \mathrm{~m}^{3} \mathrm{~s}^{-1}$ ) in the top $300 \mathrm{~m}$ between $3^{\circ} 45^{\prime} \mathrm{N}$ and $5^{\circ} 52^{\prime} \mathrm{N}$ at $80.5^{\circ} \mathrm{E}$ (south of Sri Lanka). Positive (negative) values indicate eastward (westward) flow, and the values listed are averages over the period indicated. All observations, except that marked $(*)$ were for 1991; the marked observation was for 1992 . The observed transports are derived from the direct current measurements of Schott et al. (1994). The model was forced by climatological wind stress (Hellerman \& Rosenstein, 1983). The last two values are average model transports for the winter and summer monsoons, respectively

\begin{tabular}{lcc}
\hline Period & Observed & Model \\
\hline 10 Jan-15 Feb & -12.8 & -10 \\
10 Jan-15 Feb* & -10.4 & -10 \\
1 June-5 July & 8.4 & 9.1 \\
10 July-15 Aug & 4.1 & 6.2 \\
1 June-15 Aug & 7.8 & 7.9 \\
1 Nov-30 Mar & - & -7.1 \\
1 May-20 Sept & - & 5.4 \\
\hline
\end{tabular}

forcing the monsoon currents, we need a model that has only the minimum physics required for simulating the wind-forced circulation in the upper ocean. For this, we use a dynamical $1 \frac{1}{2}$-layer reduced-gravity model, in which the densities of the model layers do not vary in space or time. The active upper layer is much shallower than the infinitely deep, motionless, lower layer. The equations for the upper layer are (Shankar, 1998):

$$
\begin{aligned}
& (H \boldsymbol{v})_{t}+\nabla \cdot(\boldsymbol{v} H \boldsymbol{v})+f \mathbf{k} \times(H \boldsymbol{v})+g \bar{\Gamma} H \nabla H=\tau / \rho_{1}+v \nabla^{2}(H \boldsymbol{v})-\chi \mathbf{i} \cdot(H \boldsymbol{v}) \\
& H_{t}+\nabla \cdot(H \boldsymbol{v})=\kappa \nabla^{2} H \\
& \eta=\bar{\Gamma}(H-\bar{H})
\end{aligned}
$$

where $H=\bar{H}+h$ is the instantaneous layer thickness, $\bar{H}$ the initial layer thickness, $h$ the deviation of the layer thickness from the initial value, $\boldsymbol{v}=(u, v)$ the velocity, $f=\beta y$ the Coriolis parameter, $\tau=\left(\tau^{x}, \tau^{y}\right)$ the wind stress, $g$ the acceleration due to gravity, and $\bar{\Gamma}=\Delta \rho / \bar{\rho}$ the reduced-gravity parameter; $\Delta \rho=\rho_{2}-$ $\rho_{1}$, and $\bar{\rho}$ is an average density that is representative of the ocean; $v$ and $\kappa$ are the Rayleigh mixing coefficients for momentum and thickness, the latter being included to damp the small-scale noise in the $H$ field, and $\chi$ is a Rayleigh friction coefficient; $\eta$ is the deviation of model dynamic height, computed with respect to the motionless deep ocean, from the initial state. In the discussion that follows, we refer to $\eta$ as the model sea level rather than as dynamic height. The model parameters are listed in Table 5.

Eqs. (2) are integrated numerically on an Arakawa C-grid using the leapfrog scheme; diffusive terms are evaluated at the backward time level and all other terms at the central time level. To inhibit timesplitting instability, the fields are averaged between successive time levels every 41 time steps. The model domain is as in McCreary et al. (1993). The upper-layer thickness is not allowed to shallow beyond 10 $\mathrm{m}$, or deepen beyond $190 \mathrm{~m}$. The no-slip condition is applied at continental boundaries and the zerogradient condition is applied at the open southern boundary at $29^{\circ} \mathrm{S}$. A linear damper (Rayleigh friction) is applied on the zonal velocity field near the southern boundary; it is required to inhibit the development of large-scale instability along the boundary caused by the application of the zero-gradient condition on $u$. The damper is present only near the boundary, with $\chi=1$ day $^{-1}$ within $150 \mathrm{~km}$ of the boundary, and decreasing linearly to zero in the interval from 150 to $300 \mathrm{~km}$. There is no corresponding damper on $v$ and $H$, so that fluid can pass freely through the boundary.

The forcing is derived from the wind-stress climatology of Hellerman and Rosenstein (1983) (Fig. 1), their wind stress being interpolated linearly to the model grid and then smoothed (McCreary et al., 1993; Shankar \& Shetye, 1997). The model is spun up from a state of rest, the winds being ramped up from 
At $65^{\circ} \mathrm{E}$

OGCM zonal transport in top $100 \mathrm{~m}$

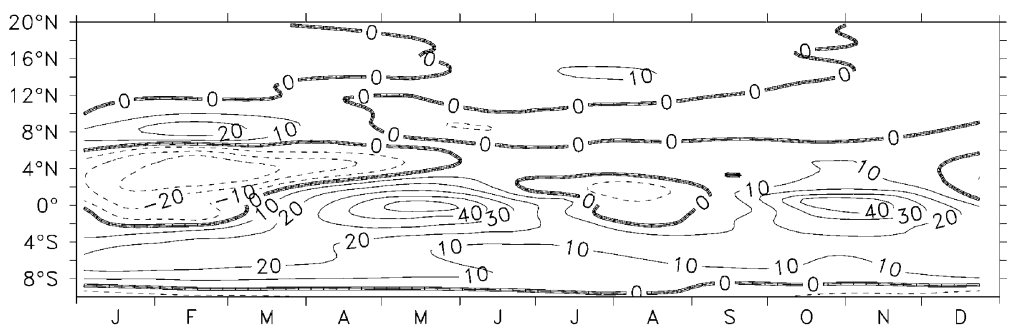

At $80.5^{\circ} \mathrm{E}$

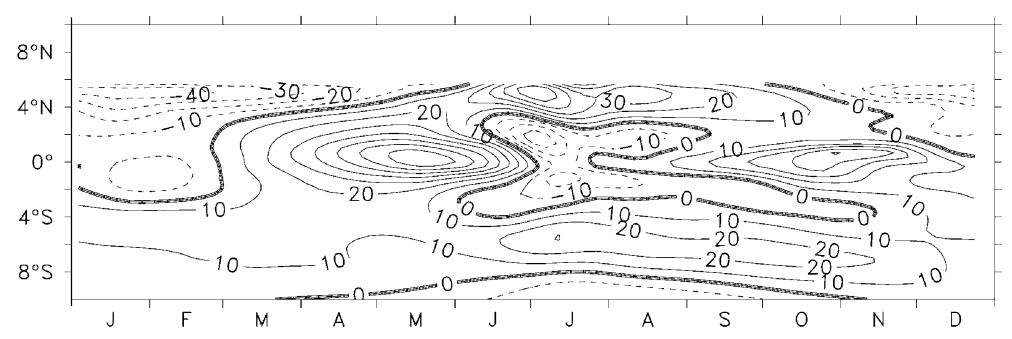

At $85^{\circ} \mathrm{E}$

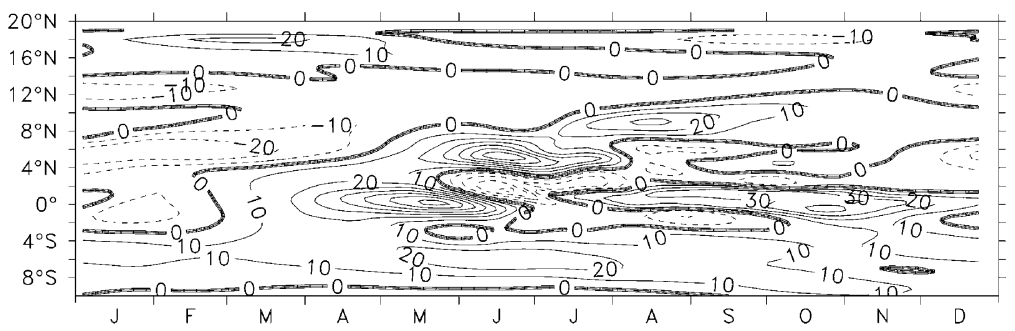

Fig. 15. Latitude-time plots of the depth-integrated zonal current $\left(\mathrm{m}^{2} \mathrm{~s}^{-1}\right)$ in the OGCM. The current is integrated over the top 100 $\mathrm{m}$. Westward flows are indicated by dashed contours and the contour interval is $10 \mathrm{~m}^{2} \mathrm{~s}^{-1}$. In the Arabian Sea $\left(65^{\circ} \mathrm{E}\right)$, the core of the westward (eastward) part of the WMC is at $4^{\circ} \mathrm{N}\left(8^{\circ} \mathrm{N}\right)$; in the Bay $\left(85^{\circ} \mathrm{E}\right)$ and south of Sri Lanka $\left(80.5^{\circ} \mathrm{E}\right)$, the core of the westward $\mathrm{WMC}$ is at $\sim 5^{\circ} \mathrm{N}$. In contrast, the SMC has a more complicated spatial structure owing to the curvature of the geostrophic flow.

Table 4

OGCM zonal transport (in Sv; $1 \mathrm{~Sv}=10^{6} \mathrm{~m}^{3} \mathrm{~s}^{-1}$ ) in the top $100 \mathrm{~m}$ in the domain of the monsoon currents. Negative values indicate westward flows and the transports are averages over the periods mentioned

\begin{tabular}{lllr}
\hline Current & Location & Period & Transport \\
\hline WMC & $2.5^{\circ}-6^{\circ} \mathrm{N} ; 65^{\circ} \mathrm{E}$ & February & -13.1 \\
WMC & $0^{\circ}-6^{\circ} \mathrm{N} ; 65^{\circ} \mathrm{E}$ & February & -19.0 \\
WMC & $3^{\circ}-7^{\circ} \mathrm{N} ; 80.5^{\circ} \mathrm{E}$ & January & -10.1 \\
WMC & $3^{\circ}-7^{\circ} \mathrm{N} ; 85^{\circ} \mathrm{E}$ & January & -8.1 \\
SMC & $12^{\circ}-20^{\circ} \mathrm{N} ; 65^{\circ} \mathrm{E}$ & July & 6.8 \\
SMC & $3^{\circ}-6^{\circ} \mathrm{N} ; 80.5^{\circ} \mathrm{E}$ & June-July & 8.1 \\
SMC & $4^{\circ}-8^{\circ} \mathrm{N} ; 85^{\circ} \mathrm{E}$ & June & 15.3 \\
SMC & $7^{\circ}-11^{\circ} \mathrm{N} ; 85^{\circ} \mathrm{E}$ & August & 7.4 \\
\hline
\end{tabular}


Table 5

Parameters for the reduced-gravity model

\begin{tabular}{|c|c|c|}
\hline Parameter (units) & Symbol & Value \\
\hline Laplacian mixing coefficient for momentum $\left(\mathrm{cm}^{2} \mathrm{~s}^{-1}\right)$ & $v$ & $5 \times 10^{7}$ \\
\hline Laplacian mixing coefficient for thickness $\left(\mathrm{cm}^{2} \mathrm{~s}^{-1}\right)$ & $\kappa$ & $1 \times 10^{7}$ \\
\hline Thermal expansion coefficient $\left({ }^{\circ} \mathrm{C}^{-1}\right)$ & $\alpha_{\mathrm{T}}$ & -0.00025 \\
\hline Haline contraction coefficient $\left(\mathrm{PSU}^{-1}\right)$ & $\alpha_{\mathrm{s}}$ & 0.00125 \\
\hline Reduced gravity parameter & $\bar{\Gamma}$ & 0.0035 \\
\hline Initial upper layer thickness (m) & $\bar{H}$ & 100 \\
\hline Minimum upper layer thickness (m) & $H_{\min }$ & 10 \\
\hline Maximum upper layer thickness (m) & $H_{\max }$ & 190 \\
\hline Linear Kelvin wave speed for $\bar{H}=100 \mathrm{~m}\left(\mathrm{~cm} \mathrm{~s}^{-1}\right)$ & $c$ & 185 \\
\hline Rossby wave speed at $10^{\circ} \mathrm{N}\left(\mathrm{cm} \mathrm{s}^{-1}\right)$ & $c_{\mathrm{R}}$ & 12.2 \\
\hline Grid size $(\mathrm{km})$ & $\Delta x, \Delta y$ & 55 \\
\hline Time step (minutes) & $\Delta t$ & 72 \\
\hline
\end{tabular}

zero to the appropriate level over five days to damp inertial oscillations. Results discussed below are from the tenth year of the simulation, by when the solution approaches stationarity.

The solution (Fig. 16) emphasizes the geostrophic contribution to the flow. The contribution of the Ekman drift is weak, except in the western Arabian Sea, because the currents are averaged over the model upper layer. Westward propagation of sea-level anomalies is evident in the solution, especially in the eastern Bay of Bengal and the southeastern Arabian Sea (Fig. 17). This solution compares well with the DAF of the OGCM (Fig. 12), except that the recirculation in the eddies off Somalia does not cross the equator, the eastward flow in the western equatorial Indian Ocean instead feeding the SMC south of Sri Lanka, as in the simulations of McCreary et al. (1993). The observations are also unclear in this regard, there being differences between the flow revealed by the ship drifts (Fig. 9) and surface drifters (Shenoi, Saji, \& Almeida, 1999). Though there is less detail in the solution compared to the geostrophic flow estimated from TOPEX/Poseidon altimetry (Fig. 5), the model does capture the essential features of the monsoon currents on the seasonal time scale.

To examine to what extent these are attributable to nonlinear effects, we linearize the model equations to obtain (Shankar, 1998)

$$
\begin{aligned}
& \boldsymbol{v}_{t}+f \mathbf{k} \times \boldsymbol{v}+g \bar{\Gamma} \nabla h=\frac{\tau}{\rho_{1} \bar{H}}+v \nabla^{2} \boldsymbol{v}-\chi \mathbf{i} \cdot v \\
& h_{t}+\overline{\mathrm{H}} \nabla \cdot \boldsymbol{v}=\kappa \nabla^{2} h \\
& \eta=\bar{\Gamma} h
\end{aligned}
$$

The solution to these linear equations (Fig. 18) reproduces all the features seen in the nonlinear simulation; the one major exception is the Great Whirl off Somalia, which owes its existence to non-linear dynamics (Shankar \& Shetye, 1997) and appears in the linear solution as part of a large anticyclonic gyre in the western Arabian Sea. Notwithstanding this discrepancy, the linear solution shows the strong poleward Somali Current, its recirculation in the gyres offshore, and the continuity of this current across the Arabian Sea to the southern tip of Sri Lanka.

\subsection{Process solutions}

Since a linear system is capable of describing the seasonal, open-ocean monsoon currents, we can split the solution into components forced by different processes, the sum of these parts then being equal to the 


\section{Nonlinear simulation with reduced-gravity model}
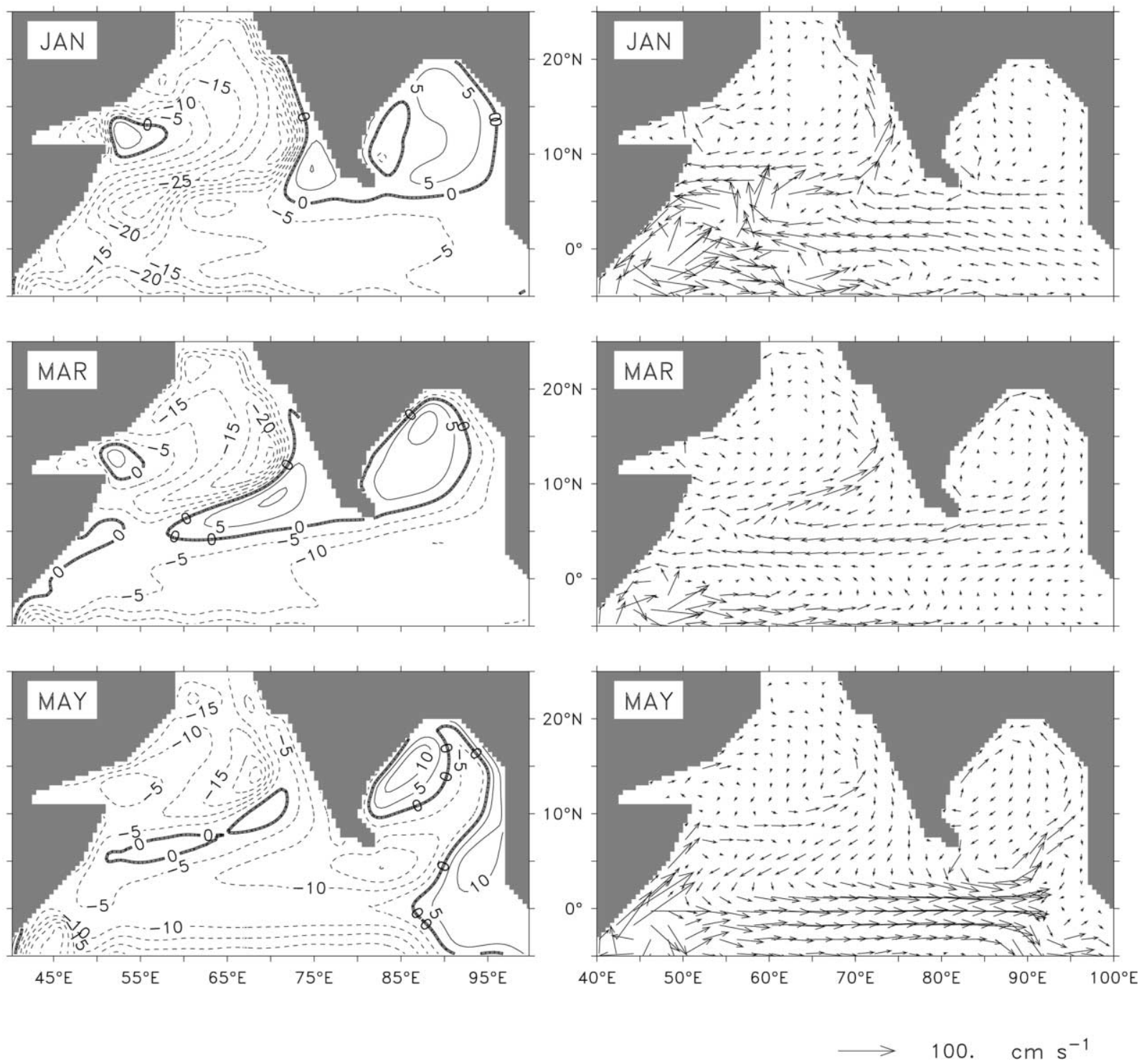

Fig. 16. Sea-level deviation from the initial surface (cm, left panels) and upper-layer velocity ( $\mathrm{cm} \mathrm{s}^{-1}$, right panels) for the nonlinear simulation. Negative sea level is indicated by dashed contours and the contour interval is $5 \mathrm{~cm}$.

whole, the linear solution, which we call the control run. To isolate the effect of individual processes on the monsoon currents, we apply two sets of boundary conditions along continental boundaries (McCreary et al., 1996; Shankar, 1998). One set is the usual no-slip condition.

$$
u=v=0
$$

The other set, 


\section{Nonlinear simulation with reduced-gravity model}


Fig. 16. Continued

$$
\tilde{u}=\mathbf{n} \cdot \boldsymbol{v}=-\mathbf{n} \cdot \mathbf{k} \times \frac{\tau}{f}, \tilde{v}=\mathbf{k} \times \mathbf{n} \cdot v
$$

is applied to the boundaries of the Bay of Bengal and the Arabian Sea in some of the process solutions. In Eq. (4b) $\mathbf{k}$ is a unit vector directed out of the $\beta$-plane and $\mathbf{n}$ is a unit vector normal to the boundary; $\mathbf{n}$ points out of the Bay of Bengal (inshore) along its eastern and northeastern margins, into the Bay (offshore) along its northern and western margins, out of the sea (inshore) along the southern boundaries of India and Sri Lanka and along their west coast, and into the sea (offshore) along the northern and 
Sea-level anomalies: Reduced-gravity model At $10^{\circ} \mathrm{N}$


Fig. 17. Longitudinal-time plots of sea-level anomalies $(\mathrm{cm})$ from the reduced-gravity model (nonlinear simulation) at $10^{\circ} \mathrm{N}$ (top panel), $8^{\circ} \mathrm{N}$ (middle panel), and $5.75^{\circ} \mathrm{N}$ (bottom panel). The annual mean sea level has been removed to obtain the anomalies. Negative sea level is indicated by dashed contours and the contour interval is $5 \mathrm{~cm}$. 


\section{Linear simulation (control run)}


100. $\mathrm{cm} \mathrm{s}^{-1}$

Fig. 18. Sea-level deviation from the initial surface (cm, left panels) and upper-layer velocity $\left(\mathrm{cm} \mathrm{s}^{-1}\right.$, right panels) for the linear simulation. Negative sea level is indicated by dashed contours and the contour interval is $5 \mathrm{~cm}$.

western boundaries of the Arabian Sea; $\boldsymbol{v}=(\tilde{u}, \tilde{v})$, where $\tilde{u}$ and $\tilde{v}$ are the velocity components normal to and along the boundary; and $\tau=\left(\tau^{x}, \tau^{y}\right)$ is the wind stress. Conditions (4b) allow Ekman flows to pass through the boundaries, filtering circulations driven by coastal Ekman pumping out of the solutions; this implies that coastal Kelvin waves are not generated along the coasts where this condition is applied. Condition (4a) is applied at continental boundaries for the control run. The modifications made to obtain the process solutions are described below. The acronyms used for the processes are listed in Table 6 . 


\section{Linear simulation (control run)}
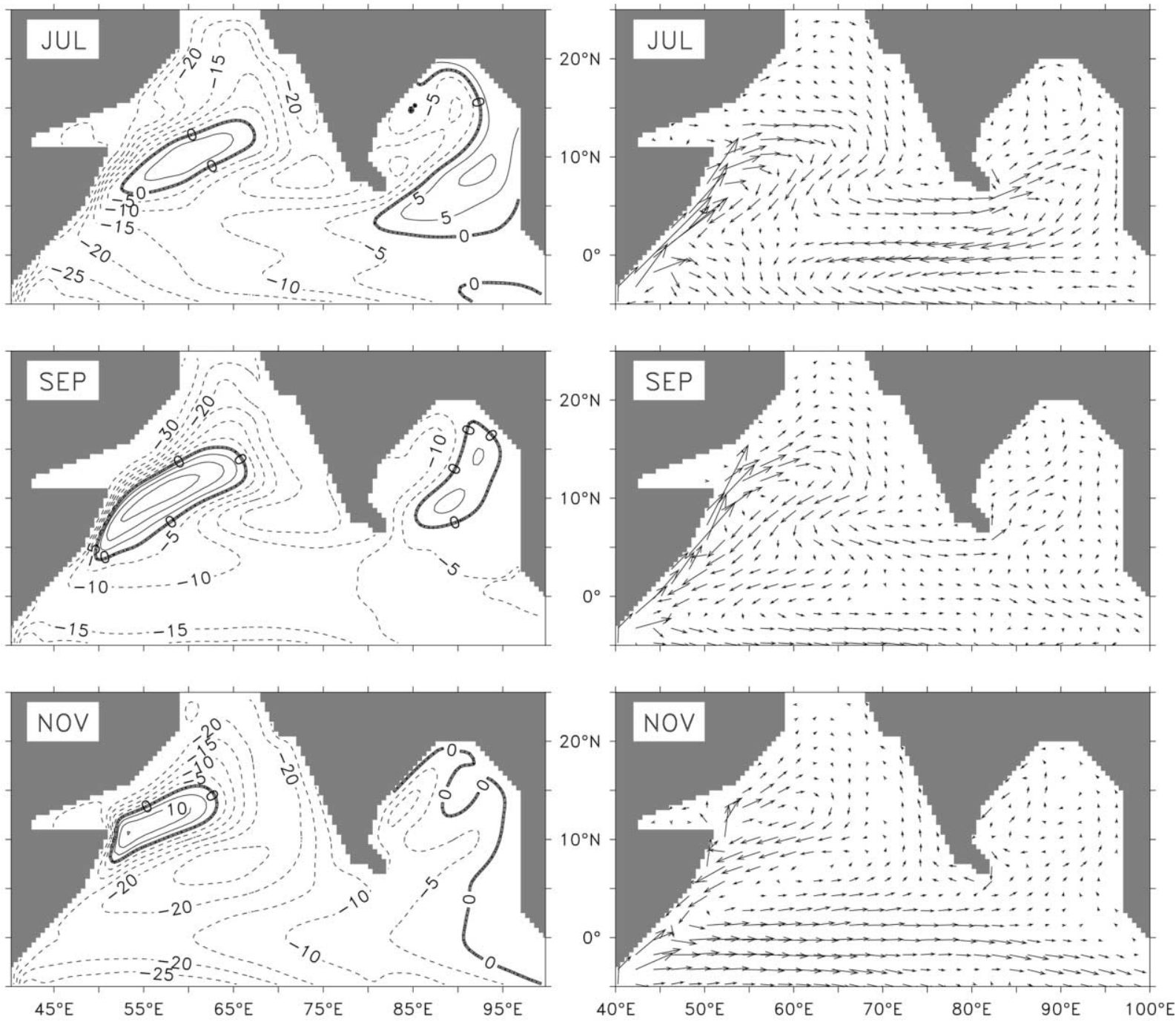

$\longrightarrow$ 100. $\mathrm{cm} \mathrm{s}^{-1}$

Fig. 18. Continued

To isolate the effect of the winds that blow along the eastern and northern boundaries of the Bay of Bengal (process EB here, process RA in McCreary et al., 1996 and Shankar, 1998), we apply conditions (4b) along these coasts from $2.5^{\circ} \mathrm{N}$ at the eastern boundary to $20^{\circ} \mathrm{N} 87^{\circ} \mathrm{E}$, thereby eliminating the effect of alongshore winds there. The difference between the control run and this run gives the process solution forced by EB (not shown). These winds force Kelvin waves, which propagate anticlockwise along the perimeter of the Bay, radiating Rossby waves from the eastern boundary in the process. Though the winds in the eastern Bay are not significantly weaker than those in the western Bay (Fig. 1), the Kelvin waves 
Table 6

Acronyms used for the process solutions

\begin{tabular}{ll}
\hline Acronym & Process \\
\hline EB & $\begin{array}{l}\text { Effect of winds along the eastern and northern boundaries of the Bay of Bengal (coasts of Thailand, Myanmar, } \\
\text { and Bangladesh). }\end{array}$ \\
WB & $\begin{array}{l}\text { Effect of winds along the western boundary of the Bay of Bengal (east coasts of India and Sri Lanka). } \\
\text { EAfect of winds along the eastern boundary of the Arabian Sea (west coasts of Sri Lanka and India). }\end{array}$ \\
WA & $\begin{array}{l}\text { Effect of winds along the northern and western boundaries of the Arabian Sea (except the coast of Somalia). } \\
\text { SA }\end{array}$ \\
EW & $\begin{array}{l}\text { Effect of winds along the coast of Somalia. } \\
\text { of processes, EB, WB, EA, WA, and SA). }\end{array}$ \\
OP & $\begin{array}{l}\text { Other processes-effect of filtering out the alongshore winds (process AW) in the north Indian Ocean. This } \\
\text { solution includes Ekman pumping in the interior of the basin and the effect of winds in the equatorial Indian }\end{array}$ \\
\hline
\end{tabular}

forced by these winds are weak; it is the alignment of the coast, almost normal to the wind vector, that results in a weak alongshore component, and hence, in a weak response.

To isolate the effect of the strong winds that blow along the western boundary of the Bay of Bengal, or the east coast of India and Sri Lanka (process WB herein, and process LA in McCreary et al., 1996 and Shankar, 1998), we apply conditions (4b) along these coasts (from $20^{\circ} \mathrm{N} 87^{\circ} \mathrm{E}$ to $6.5^{\circ} \mathrm{N} 82^{\circ} \mathrm{E}$ ), thereby eliminating the effect of the alongshore winds there. The difference between the control run and this run gives the process solution forced by WB (Fig. 19). The winds along the western boundary of the Bay are southwesterly during the summer monsoon and northeasterly during the winter monsoon. The southwestnortheast alignment of the coast makes the wind vector parallel to the coast and these winds generate strong coastal Kelvin waves; the EICC closely follows the wind field. Since the coastal Kelvin waves propagate with the coast on their right in the Northern Hemisphere, process WB affects only the EICC and has no effect on the circulation elsewhere in the Bay. It does, however, have a strong effect on the circulation in the southeastern Arabian Sea (McCreary et al., 1993; Shankar \& Shetye, 1997; Shankar, 1998). By itself, it can force the Lakshadheep high and low, the WICC, and parts of the GWMC and GSMC associated with them. The Lakshadweep high forced by process WB, however, is much stronger than that forced in the control run.

To isolate the effect of the winds that blow along the eastern boundary of the Arabian Sea, or the south and west coasts of Sri Lanka and India (process EA here, process WLA in Shankar, 1998), we apply conditions (4b) along this coast (from $6.5^{\circ} \mathrm{N} 82^{\circ} \mathrm{E}$ to $25^{\circ} \mathrm{N} 67.5^{\circ} \mathrm{E}$ ), thereby eliminating the effect of the alongshore winds there. The difference between the control run and this run gives the process solution forced by EA (Fig. 20). Along this coast, the winds blow equatorward throughout the year, the winds along the west coast of Sri Lanka being the exception; here, in the Gulf of Mannar, the winds are similar to those along the Indian east coast (Shankar, 1998; Luis \& Kawamura, 2000). The alongshore winds generate coastal Kelvin waves that propagate poleward along the eastern boundary of the Arabian Sea, radiating westward propagating Rossby waves into the interior in the process. During the summer monsoon, the southwesterlies over the Arabian Sea turn around in the central Arabian Sea to blow from the northwest along the Indian west coast. These winds favour coastal upwelling and are stronger than the equatorward winds during the winter monsoon. The alignment of the coast also ensures that the winds during the winter monsoon generate but a weak coastal Kelvin wave. Therefore, though the winds along the eastern boundary of the Arabian Sea do not contribute significantly to the Lakshadweep high, they contribute to the Lakshadweep low and force strong upwelling in the eastern and northern Arabian Sea during the summer mon- 


\section{Process WB}
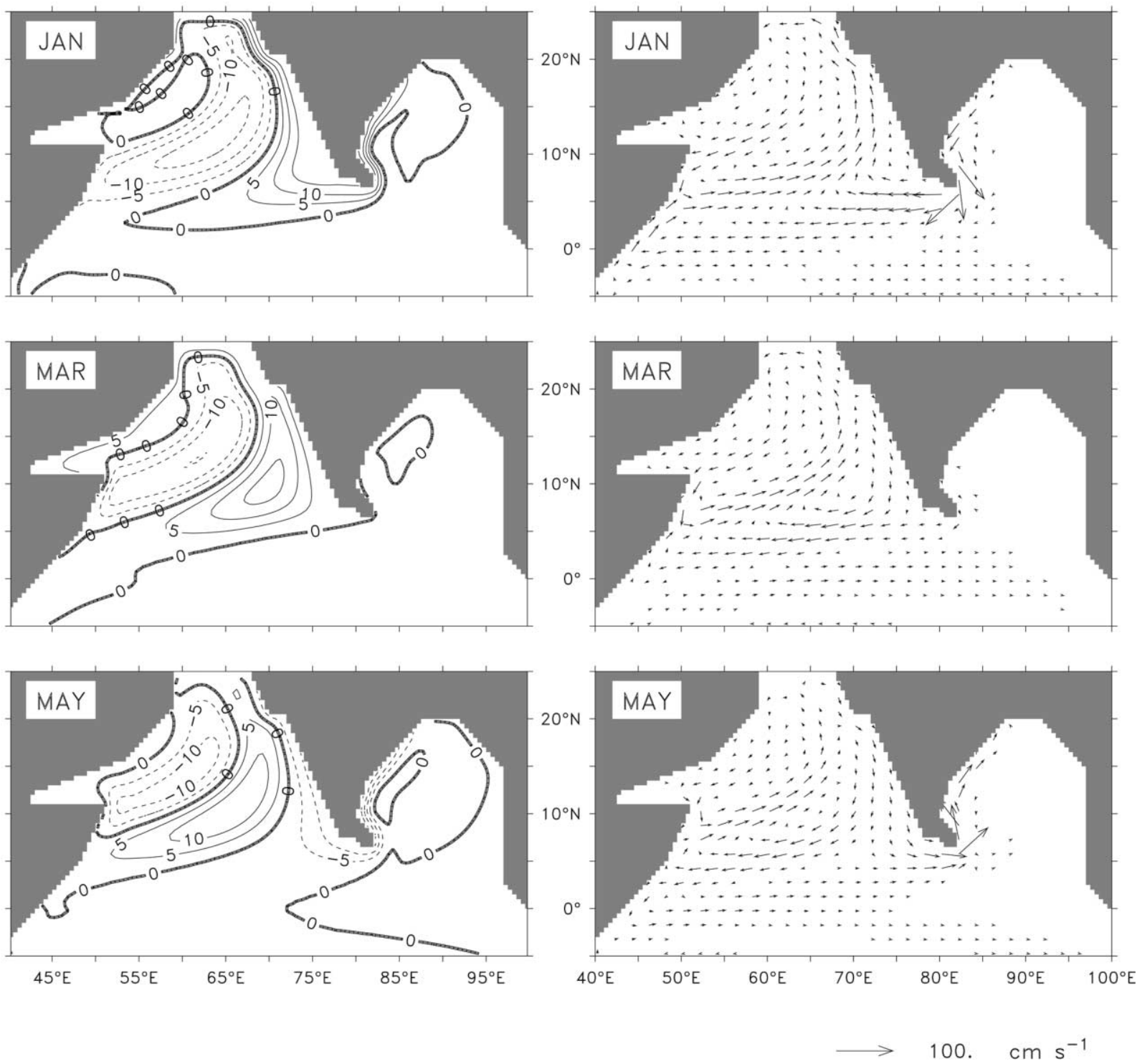

Fig. 19. Effect of winds along the western boundary of the Bay of Bengal (process WB). Sea-level deviation (cm, left panels) and upper-layer velocity ( $\mathrm{cm} \mathrm{s}^{-1}$, right panels) are shown. Negative sea level is indicated by dashed contours and the contour interval is $5 \mathrm{~cm}$.

soon. Hence, process EA contributes to the curving flow of the GSMC in the eastern and central Arabian Sea.

The effect of the winds along the northern and western boundaries of the Arabian Sea is evaluated in two parts. First, we consider the effect of winds along the boundary from the northeastern corner of the model Arabian Sea $\left(25^{\circ} \mathrm{N} 67.5^{\circ} \mathrm{E}\right)$ to the northern tip of Somalia (process WA), applying conditions (4b) only over this part of the continental boundary; the difference between the control run and this run gives 
Process WB
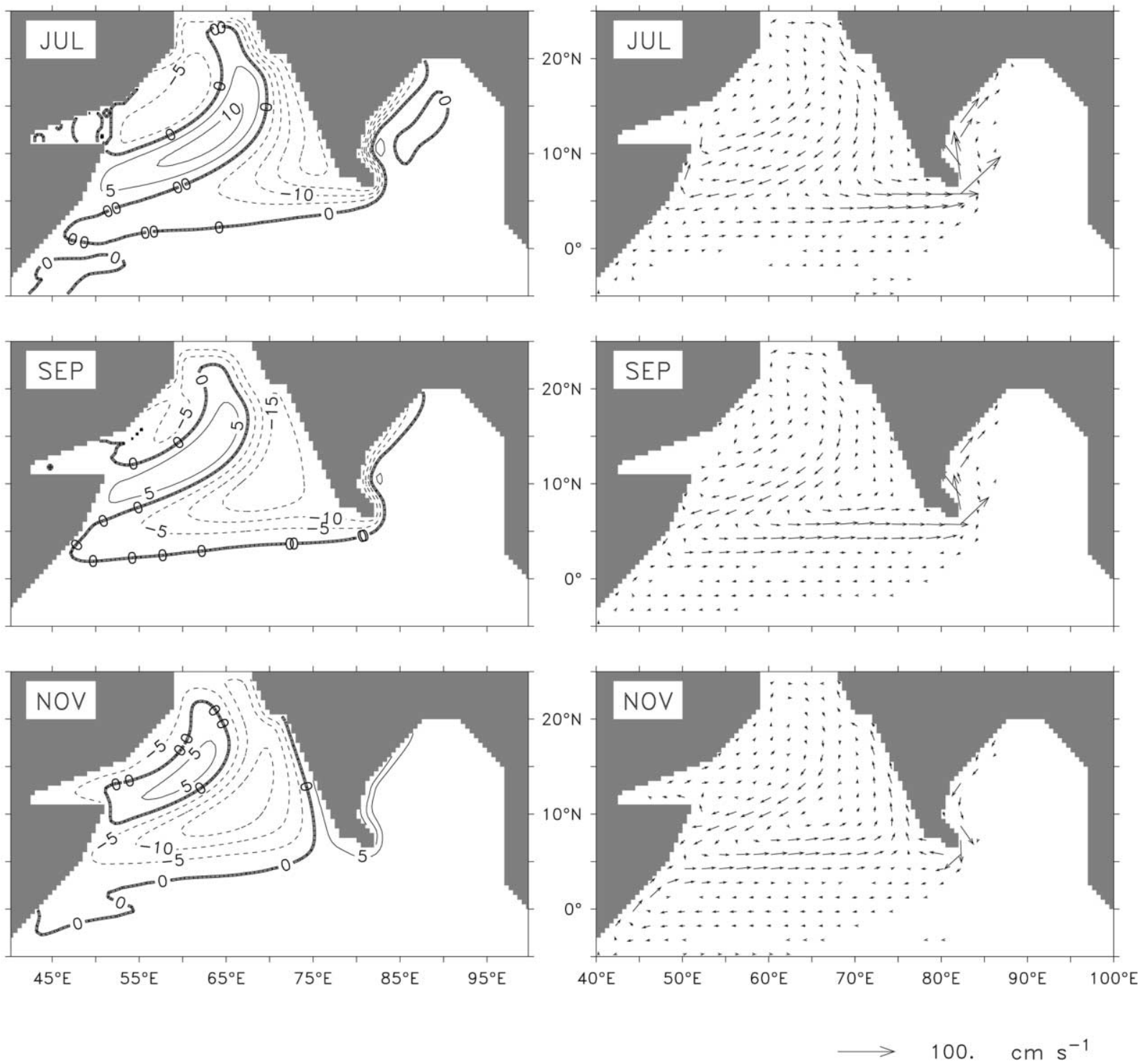

Fig. 19. Continued

the effect of process WA. Second, we consider the effect of the winds along the coast of Somalia, from the northern tip of Somalia to $2.5^{\circ} \mathrm{N}$ (process SA), applying conditions (4b) only over this part of the continental boundary; the difference between the control run and this run gives the effect of process SA.

Process WA has only a local effect (Fig. 21). The winds force the local coastal current, with some of the energy propagating equatorwards along the coast via coastal Kelvin waves to the Somali coast.

Process SA is the major forcing mechanism for the strong Somali Current, but its effect is also felt in the equatorial Indian Ocean via Kelvin wave propagation, and in the Bay of Bengal (Fig. 22). The winds 


\section{Process EA}


Fig. 20. Effect of winds along the eastern boundary of the Arabian Sea (process EA). Sea-level deviation (cm, left panels) and upper-layer velocity ( $\mathrm{cm} \mathrm{s}^{-1}$, right panels) are shown. Negative sea level is indicated by dashed contours and the contour interval is $5 \mathrm{~cm}$.

off Somalia force strong local upwelling during the summer monsoon, and this signal is carried into the equatorial Indian Ocean, forcing a westward, upwelling-favourable Equatorial Current. This, together with the effect of the Rossby wave reflected from the coast of Sumatra in May, ensures a westward Equatorial Current during June-September in the eastern equatorial Indian Ocean and weakens the eastward current in the western equatorial Indian Ocean. This separates the eastward GSMC south of Sri Lanka from the westward flow at the equator. 


\section{Process EA}
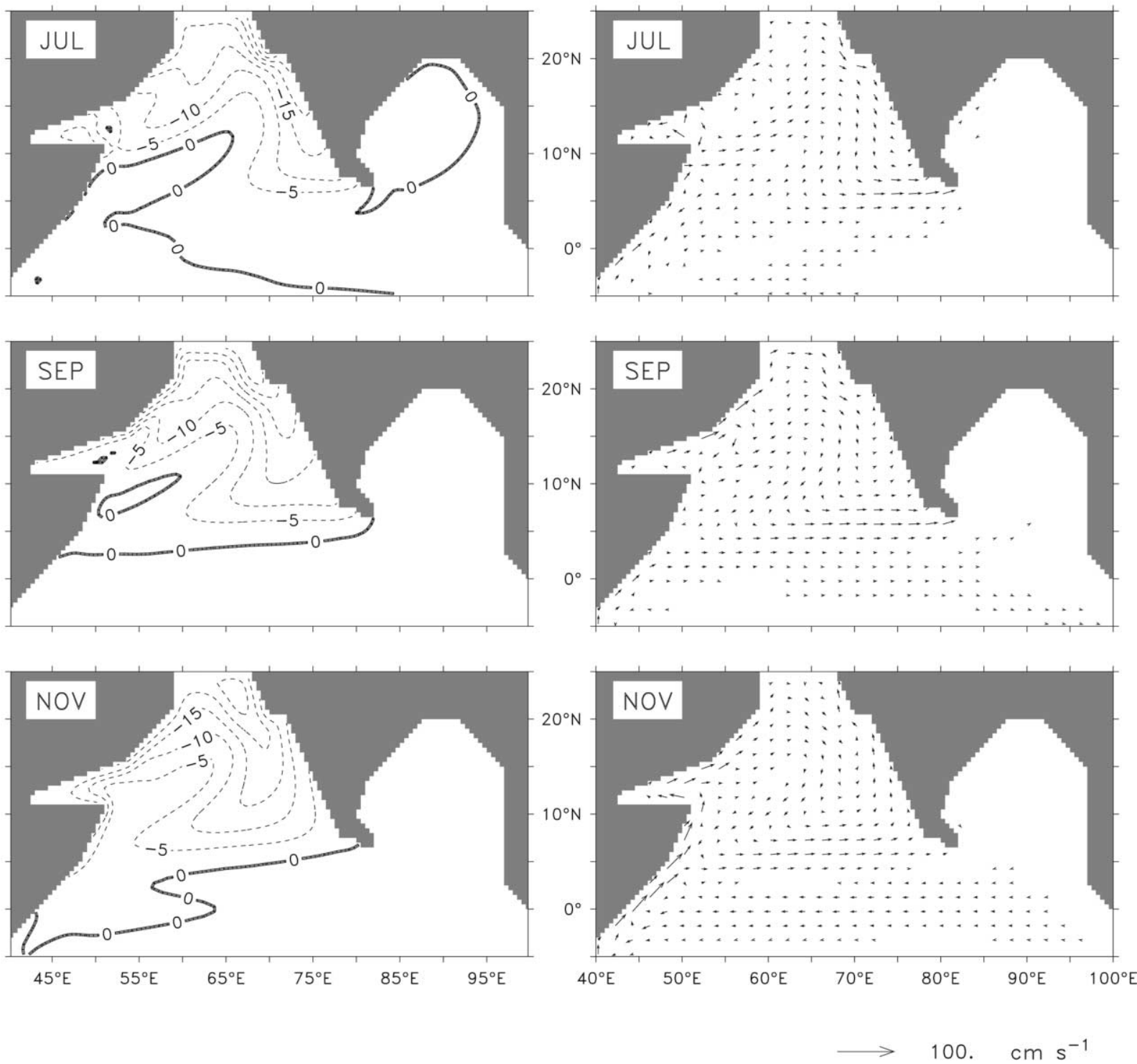

Fig. 20. Continued

Applying condition (4b) along all the continental boundaries of the north Indian Ocean (from $2.5^{\circ} \mathrm{N}$ in the eastern Bay to $2.5^{\circ} \mathrm{N}$ in the western Arabian Sea) eliminates the effect of these coastal winds, filtering out the effect of the coastal Kelvin waves generated by them; this leaves the effect of winds in the equatorial Indian Ocean and of Ekman pumping in the interior of the basin (process OP). The difference between the control run and this run gives the effect of the alongshore winds in the north Indian Ocean (process AW); therefore, process AW is the sum of processes EB, WB, EA, WA, and SA.

Process AW contributes significantly to the circulation (Fig. 23) through the excitation of coastal Kelvin 
Process WA
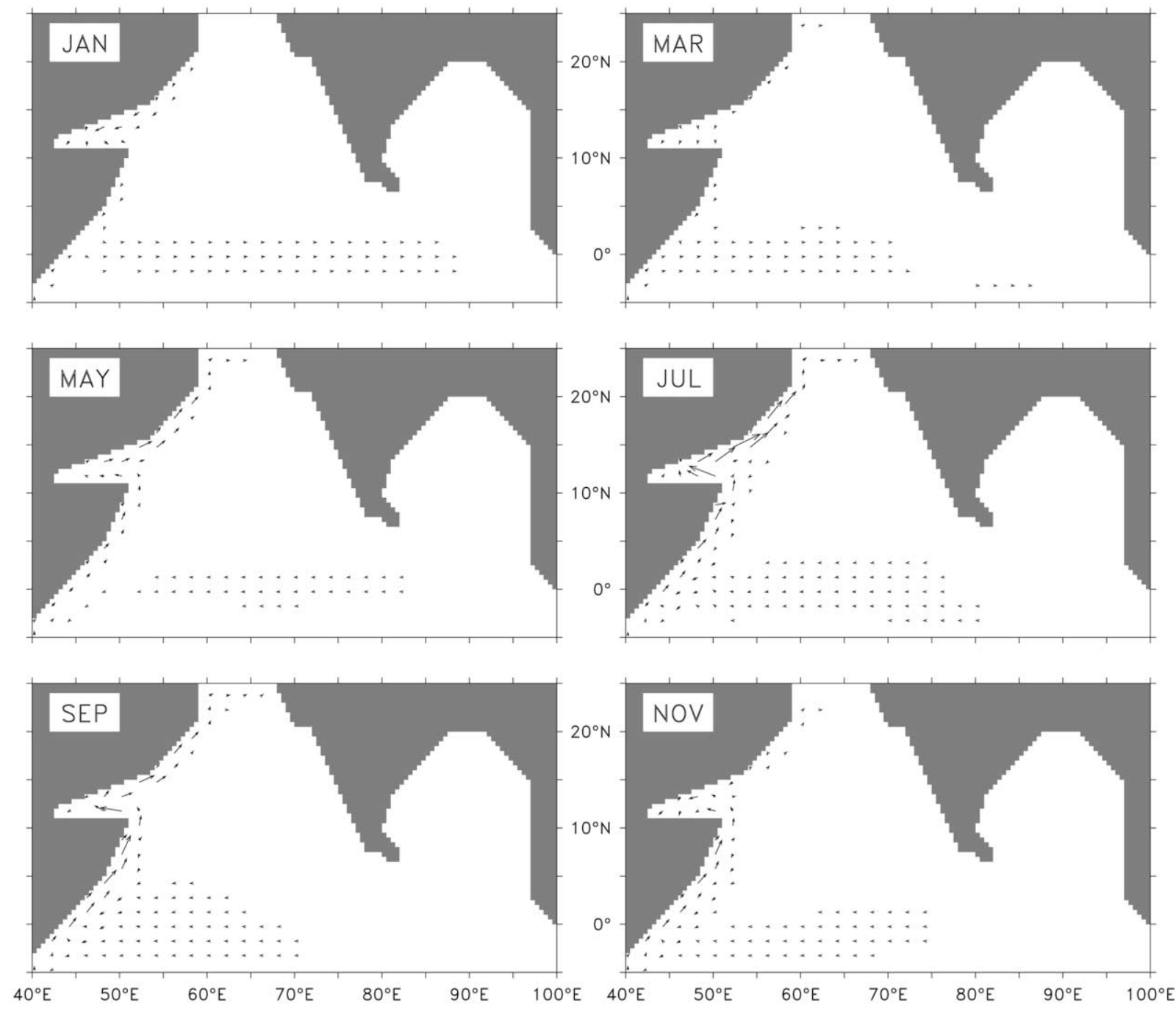

$$
\longrightarrow \text { 100. } \mathrm{cm} \mathrm{s}^{-1}
$$

Fig. 21. Effect of winds along the northern and western boundaries of the Arabian Sea, except the Somali coast (process WA). Upper-layer velocity $\left(\mathrm{cm} \mathrm{s}^{-1}\right)$ is shown.

waves and the westward propagating Rossby waves that these Kelvin waves radiate when propagating poleward along an eastern ocean boundary. Most important for the monsoon currents are the winds along the coasts of India and Sri Lanka (processes WB and EA) because it is the forcing by these winds that forces the GSMC and GWMC south of Sri Lanka and in the eastern Arabian Sea, linking the circulation between the two basins. The GWMC and GSMC, however, do not form in the Bay of Bengal in the absence of other processes. The GSMC forced by process AW also flows too far north in the Arabian Sea during the summer monsoon before turning to flow into the WICC, which, in turn, feeds the GSMC around 


\section{Process SA}


$\longrightarrow$ 100. $\mathrm{cm} \mathrm{s}^{-1}$

Fig. 22. Effect of winds along the Somali coast (process SA). Upper-layer velocities $\left(\mathrm{cm} \mathrm{s}^{-1}\right)$ are shown.

the Lakshadweep low. In the absence of forcing by interior Ekman pumping, the sea-level high in the western Arabian Sea is weak and stretched out, and the GSMC that flows to its south and east does not turn to flow eastward across the southern Arabian Sea.

Process OP, in contrast, is important for the monsoon currents in the Bay of Bengal, where the currents forced by the alongshore winds (process AW) oppose the SMC and WMC, and in the western and central Arabian Sea (Bauer, Hitchcock, \& Olson, 1991), where it forces the sea-level highs and the recirculation around them during the summer monsoon (Fig. 24). It is also the only process solution that contains the Ekman drift. The WMC and SMC in the Bay are the result of Ekman pumping in the southern Bay, 


\section{Process AW}
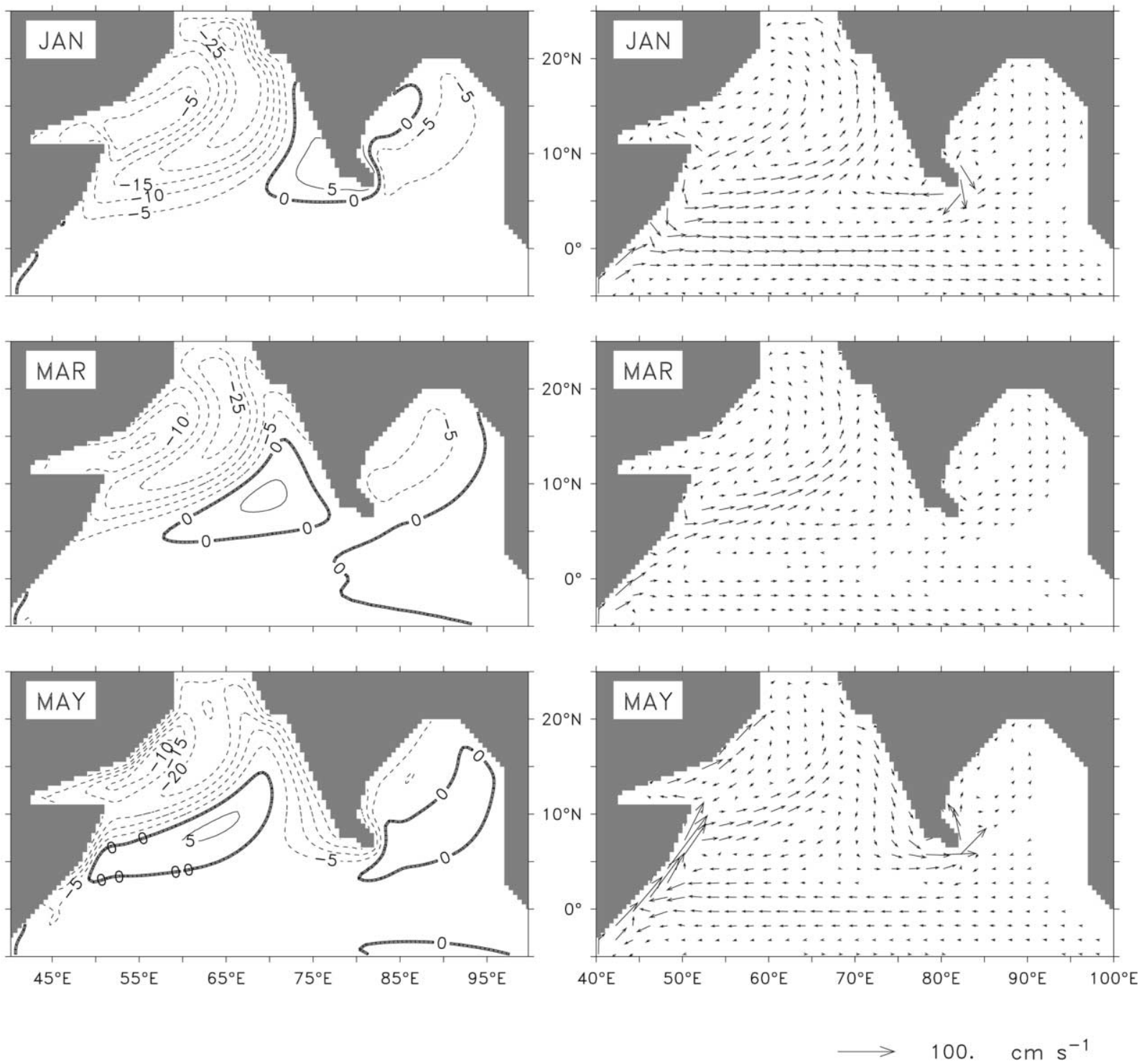

Fig. 23. Effect of alongshore winds in the north Indian Ocean (process AW). Sea-level deviation (cm, left panels) and upper-layer velocity ( $\mathrm{cm} \mathrm{s}^{-1}$, right panels) are shown. Negative sea level is indicated by dashed contours and the contour interval is $5 \mathrm{~cm}$.

especially in the southwest, and of the westward propagating Rossby wave that radiated from the eastern boundary owing to the reflection of the equatorial Kelvin wave off Sumatra (Vinayachandran \& Yamagata, 1998; Vinayachandran, Masumoto et al., 1999; McCreary et al., 1993). Not only are these currents forced by Rossby waves, but their elimination in the eastern Bay and their propagation to the west is also the result of Rossby waves, but of waves of the opposite sign (Vinayachandran \& Yamagata, 1998; Vinayachandran, Masumoto et al., 1999; McCreary et al., 1993). During the summer monsoon, the SMC forced by process 


\section{Process AW}


$\longrightarrow$ 100. $\mathrm{cm} \mathrm{s}^{-1}$

Fig. 23. Continued

OP flows westward in the southeastern Arabian Sea, breaking the connection between the SMC in the two basins. This is the result of the strong cyclonic Ekman pumping in the vicinity of Sri Lanka (Fig. 25). The continuity of the mature SMC south of Sri Lanka is the result of processes WB and EA. This abrupt switch in the mechanisms forcing the SMC south of Sri Lanka (from OP alone to OP, WB, and EA) results in the phase shift there in the sea-level anomalies both in observations (Fig. 6) and the model simulations (Fig. 17).

Process OP includes the effect of interior Ekman pumping and that of the winds in the equatorial Indian 
Process OP
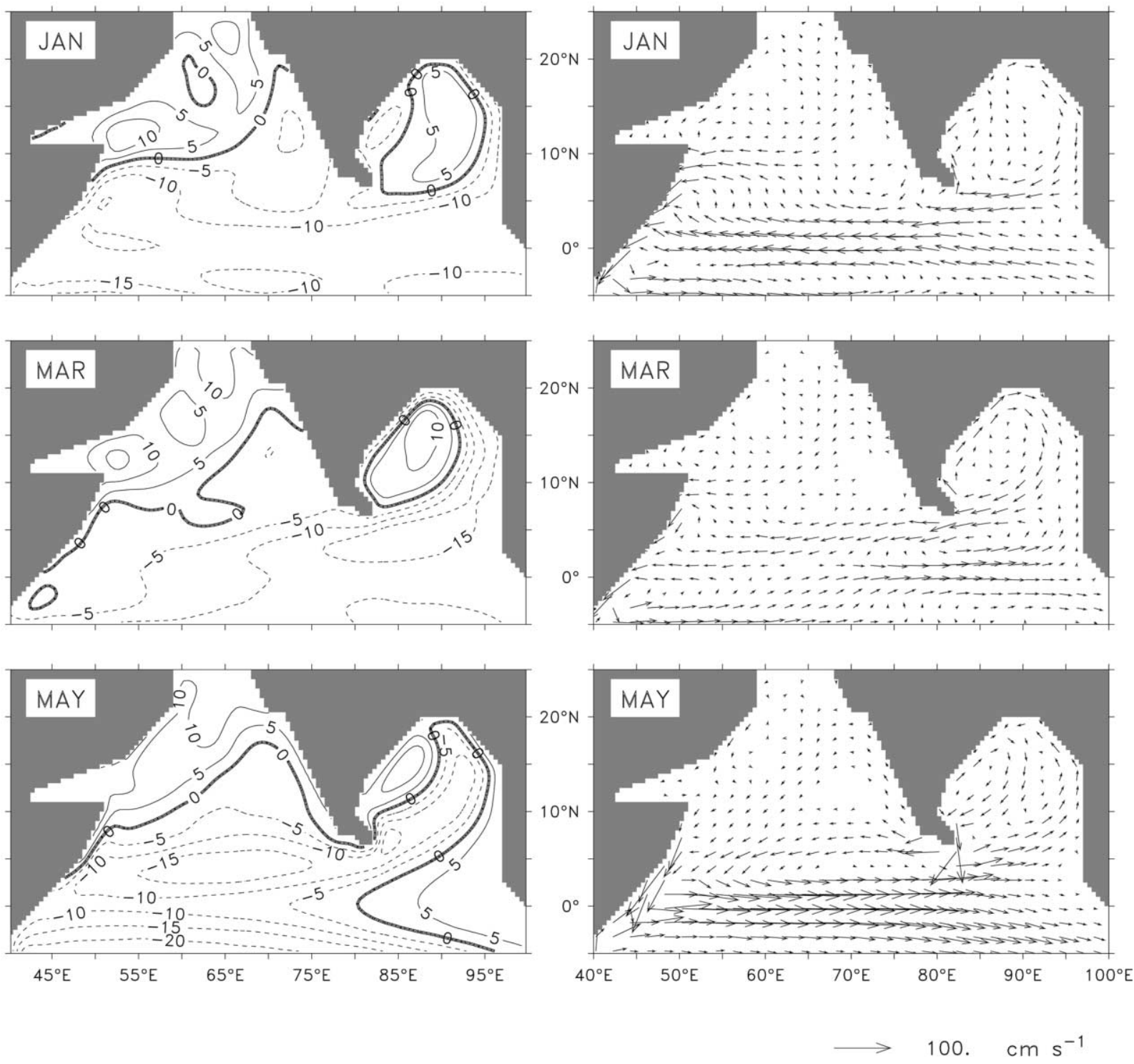

Fig. 24. Effect of filtering out forcing by alongshore winds in the north Indian Ocean (process OP). Sea-level deviation (cm, left panels) and upper-layer velocity ( $\mathrm{cm} \mathrm{s}^{-1}$, right panels) are shown. Negative sea level is indicated by dashed contours and the contour interval is $5 \mathrm{~cm}$. Process OP includes forcing by interior Ekman pumping and the winds in the equatorial Indian Ocean. It is the only process solution that includes the model Ekman drift.

Ocean. It is difficult to separate these two processes. Applying a damper (McCreary et al., 1996) distorts the reflected Rossby wave; forcing the model with only the equatorial winds (McCreary et al., 1993) distorts the forcing towards the northern and southern edges of the equatorial waveguide because the winds have to be ramped to zero away from it, introducing an additional forcing from the resulting wind-stress curl. Hence, we make no attempt in this paper to break process OP into its constituent processes. 
Process OP
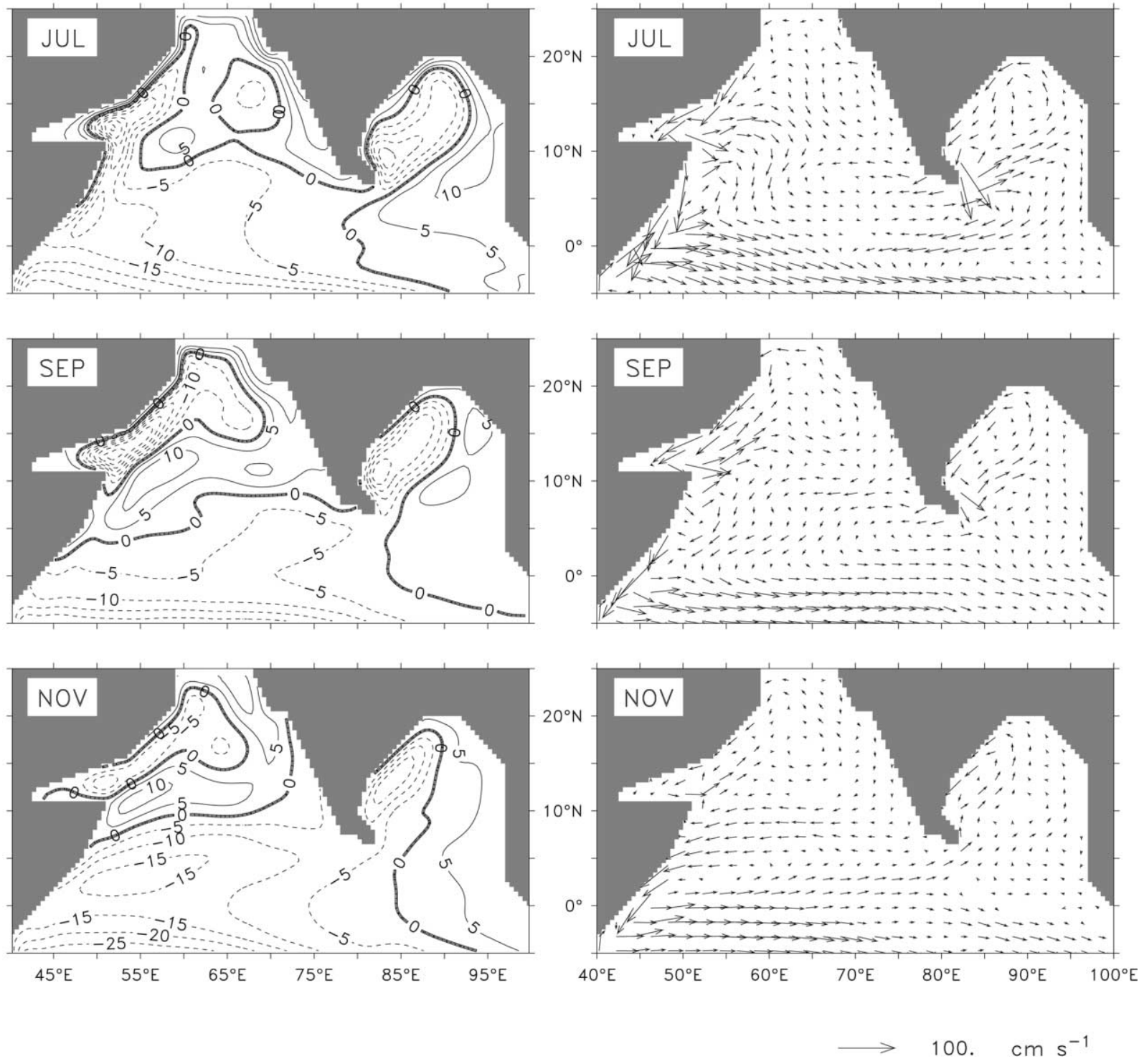

Fig. 24. Continued

The equatorial winds, however, have been shown to be an important forcing mechanism for the EICC and the WICC (Yu et al., 1991; McCreary et al., 1993, 1996), and the GWMC and GSMC in the Bay of Bengal (McCreary et al., 1993; Vinayachandran, Masumoto et al., 1999). The forcing from the equatorial Indian Ocean consists of two parts. First, there is the effect of direct forcing, or the generation of equatorial Kelvin and Rossby waves. Second, there is the effect of the reflection of these waves at the eastern and western boundaries. Both processes are crucial to the circulation in the north Indian Ocean, the reflection 


\section{Climatology of Ekman pumping}
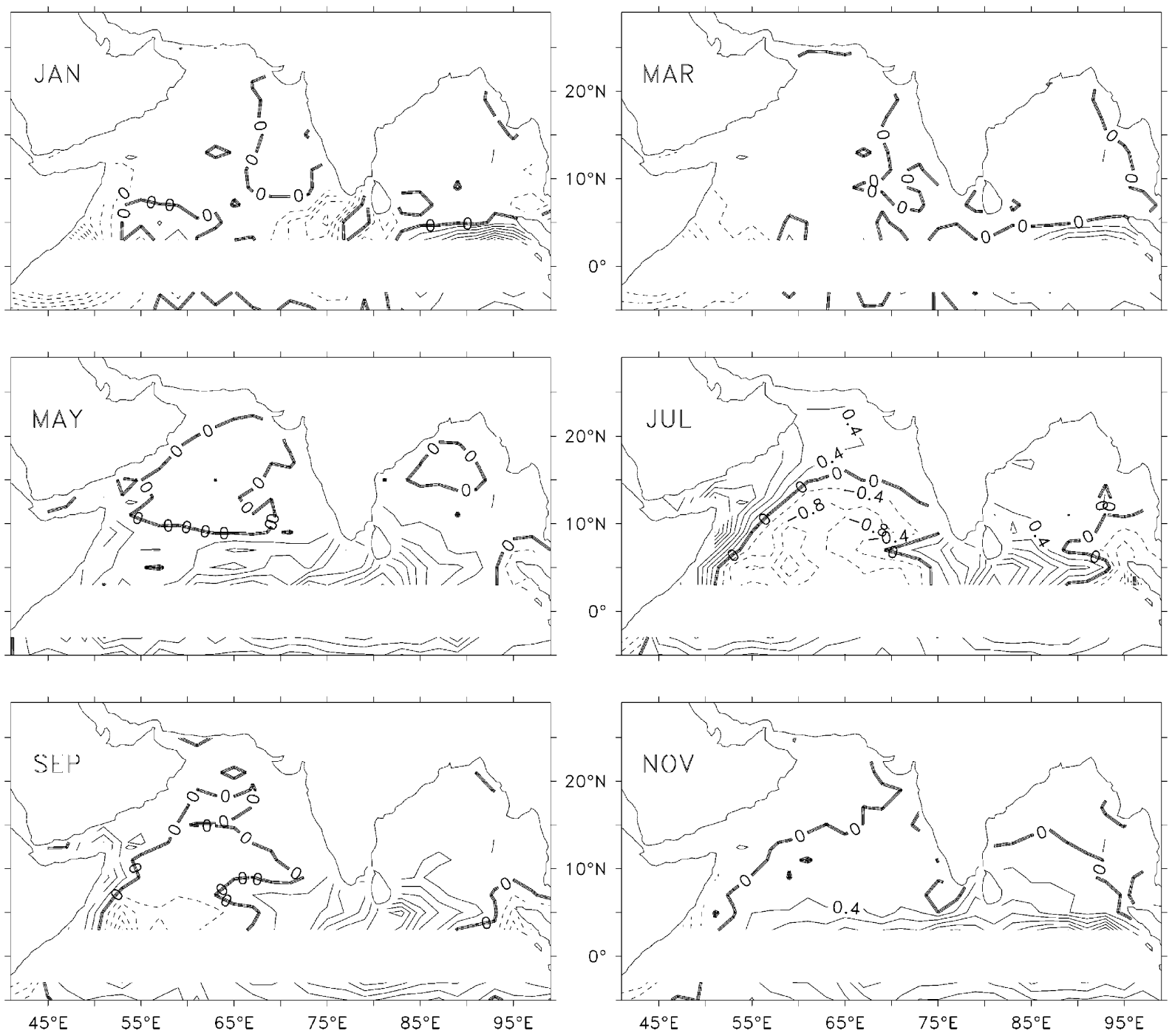

Fig. 25. Ekman pumping ( $\mathrm{m}_{\text {day }}^{-1}$ ) derived from the wind-stress climatology of Hellerman and Rosenstein (1983). Negative (downward) Ekman velocity is indicated by dashed contours and the contour interval is 0.4 units.

and resulting resonance being responsible for the large semiannual harmonic at the equator (Figs. 8 and 14) (Jensen, 1993).

\subsection{Dynamics of the north Indian Ocean}

The numerical experiments described above show that the GSMC and GWMC are complex currents, forced by several processes. The effects of the processes vary in time and space, each process being important at some time and in some part of the north Indian Ocean. The continuity of the GSMC and 
GWMC across the north Indian Ocean is the result of the way these processes interact, connecting the various strands of these currents into a continuous trans-basin current. In spite of this complexity, however, the dynamics of the monsoon currents is explicable by a simple linear theoretical framework, which can be summarized by the 'leaky waveguide' (Shetye, 1998; Shankar, 1998) depicted in the schematic in Fig. 26. The framework depicted here invokes the equatorial Kelvin wave (which propagates eastwards along the equator at a speed of $\sim 2 \mathrm{~m} \mathrm{~s}^{-1}$ and is trapped within $\sim 2.5^{\circ}$ of the equator), the equatorial Rossby wave (which propagates westward with a speed that decreases with increasing latitude, its speed at the equator being $\sim 0.5 \mathrm{~m} \mathrm{~s}^{-1}$ ), and the coastal Kelvin wave (which propagates with the coast on its right in the Northern Hemisphere with a speed of $\sim 2 \mathrm{~m} \mathrm{~s}^{-1}$, and has an offshore $e$-folding length scale of $\sim 100 \mathrm{~km}$ ). These three waves merge the equatorial Indian Ocean, the Bay of Bengal, and the Arabian Sea into a single dynamical entity, the north Indian Ocean, which must be modelled as a whole even to simulate the circulation in its parts.

The process solutions show that the Kelvin waves forced by the winds along the east and west coasts of India and Sri Lanka (processes WB and EA) are crucial for maintaining the continuity of the monsoon currents south of Sri Lanka. The coastal Kelvin waves forced by the winds along the east coast (process WB) bend around Sri Lanka to propagate polewards along the west coast. This is possible because the sum of the $e$-folding scales of the coastal Kelvin waves south of Sri Lanka $\left(\sim 2.25^{\circ}\right)$ and the equatorial Kelvin waves $\left(\sim 2.5^{\circ}\right)$ is less than the distance between the southern tip of Sri Lanka and the equator $\left(\sim 6^{\circ}\right)$, forcing a separation between the equatorial and coastal waveguides. This allows the Kelvin waves from the Bay of Bengal to pass unhindered into the Arabian Sea, making the eastern boundary of the Arabian Sea a continuation of a western boundary, that of the Bay. Westward propagating Rossby waves, however, are not restricted to the equatorial waveguide at semiannual and annual periods. Hence, they can interact

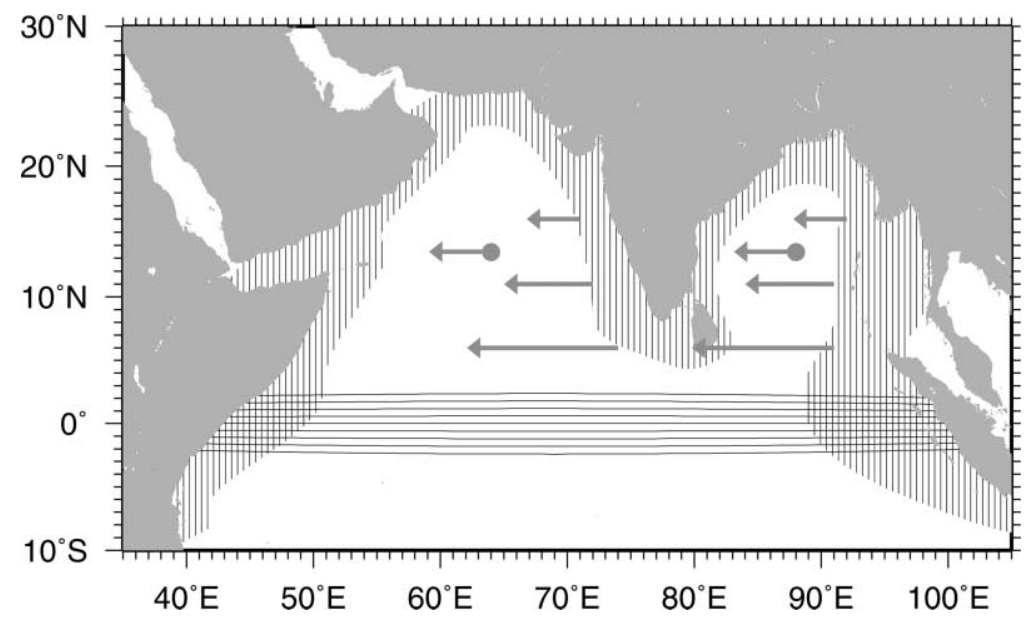

Fig. 26. Schematic illustrating the dynamics of the north Indian Ocean. The linear theoretical framework depicted here invokes the equatorial Kelvin wave, the equatorial Rossby wave, and the coastal Kelvin wave. These three waves combine the equatorial Indian Ocean, the Bay of Bengal and the Arabian Sea into a single dynamical entity. The horizontal hatching indicates the equatorial waveguide, which extends about $2.5^{\circ}$ on either side of the equator; the vertical hatching indicates the coastal waveguide. The coastal Kelvin wave is trapped at the coast poleward of a critical latitude; equatorward of this latitude, westward radiation of energy is possible, and the coastal Kelvin wave is inseparable from the westward propagating Rossby wave. The critical latitudes for Rossby waves at annual (semiannual) period is $\sim 42^{\circ}\left(\sim 21^{\circ}\right)$; hence, annual and semiannual Kelvin waves are inseparable from westward propagating Rossby waves in the north Indian Ocean, and energy leaks at these periods from the eastern boundary into the open ocean (shown by arrows pointing out of the coastal waveguide). Shetye (1998) and Shankar (1998) called this the 'leaky waveguide' of the north Indian Ocean. Energy is also generated by Ekman pumping (shown by the closed circles) in the interior of the basin; this signal also propagates westward as a Rossby wave. 
with the coastal Kelvin waves forced by process WB, and influence the monsoon currents south of Sri Lanka.

The two waveguides overlap at the western and eastern boundaries of the equatorial Indian Ocean. Energy from the coastal waveguide leaks into the equatorial waveguide at the western boundary via coastal Kelvin waves, and energy from the equatorial waveguide leaks into the coastal waveguide at the eastern boundary via the reflection of equatorial Kelvin waves. This reflection at the eastern boundary results in a part of the energy propagating poleward along the eastern boundary of the basin as coastal Kelvin waves (Moore, 1968; Yu et al., 1991). These coastal Kelvin waves are inseparable from the westward propagating Rossby waves almost all over the north Indian Ocean at the semiannual and annual periods (Fig. 26). Energy also leaks out of the coastal waveguide from the eastern boundaries into the interior of the basin via radiation of westward propagating Rossby waves. Westward propagating Rossby waves are also generated in the interior by Ekman pumping.

Thus, complex circulation patterns can be generated even by the simple linear framework described above, which seems to be remarkably good at describing the wind-forced, seasonal circulation in the north Indian Ocean.

\section{Summary}

We have described the climatological seasonal cycle of surface circulation associated with the openocean monsoon currents in the north Indian Ocean. Both Ekman drift, estimated from climatological wind stress, and surface geostrophic currents, derived from hydrography and TOPEX/Poseidon altimetry, contribute to the net surface current. The monsoon currents extend over the entire basin, but they do not come into being, or decay, over this region at a given time. Different parts of the currents form and decay at different times, and it is only in their mature phases that the monsoon currents exist as continuous, transbasin currents. Both Ekman drift and geostrophy make significant contributions to the monsoon currents and to the transports associated with them.

Observations and numerical simulations using an OGCM show that the WMC, in its mature phase during December-March, is primarily a geostrophic current, with Ekman drift modulating it. It flows westward from the eastern Bay of Bengal to Sri Lanka and beyond. In the Arabian Sea, the WMC branches; one branch flows westward, the other turns around the Lakshadweep high in the southern Arabian Sea to flow eastward into the poleward WICC. The Ekman drift, in contrast to the geostrophic flow, is unidirectional (westward); hence, at the surface, it accentuates the westward flow of the WMC to the south of the Lakshadweep high, and attenuates the eastward flow of the WMC to its north. The curving flow of the WMC around the high is, therefore, only clear below $\sim 20 \mathrm{~m}$. This definition of the WMC differs from that in earlier studies, which considered only the westward flow to be the WMC; we do not differentiate between the two parts of this continuous current because they form the front of the westward propagating Rossby wave radiated from the Indian west coast, and are, therefore, dynamically indistinguishable.

In its mature phase, the SMC flows eastward, from the western Arabian Sea to the eastern Bay of Bengal. The strong winds during the summer monsoon ensure that Ekman drift dominates at the surface, with geostrophy dominating below $\sim 20 \mathrm{~m}$. This leads to a more complex vertical structure than is associated with the WMC. Hence, the mature phase extends from May to October at the surface, but ends a month earlier in the depth-averaged flow over the top $50 \mathrm{~m}$. At the surface, the mature SMC in the Arabian Sea flows eastward and southeastward over most of the basin, feeding into the eastward SMC south of Sri Lanka; this current flows eastward and northeastward into the Bay. The geostrophic SMC, which dominates below $\sim 20 \mathrm{~m}$, is a part of the Somali Current. A part of the recirculation around the eddies off Somalia merges with the flow to the west of the Lakshadweep low off southwest India to form a curving current that flows into the eastward SMC south of Sri Lanka; this flows northeastwards into the Bay. In our 
definition, the mature SMC in the Arabian Sea is the broad, basin-wide, east-southeastward flow whose signature is seen in both surface flow and depth-averaged flow. The core of this current lies in the central Arabian Sea, where the geostrophic outflow from the eddies off Somalia accentuates the Ekman drift. It is this core that was considered to be the SMC in earlier work. We do not distinguish between the core and the rest of the flow because they are forced by the same set of processes. The mature phase of the monsoon currents, as defined in this paper, is summarised in a schematic (Fig. 27).

Numerical simulations with a reduced-gravity model show that the monsoon currents are composed of several parts, each of which is forced by one or more processes. In the Bay of Bengal, the major processes are Ekman pumping and remote forcing from the equatorial Indian Ocean. The continuity of the SMC south of Sri Lanka is primarily the result of remote forcing by the winds along the east coasts of India

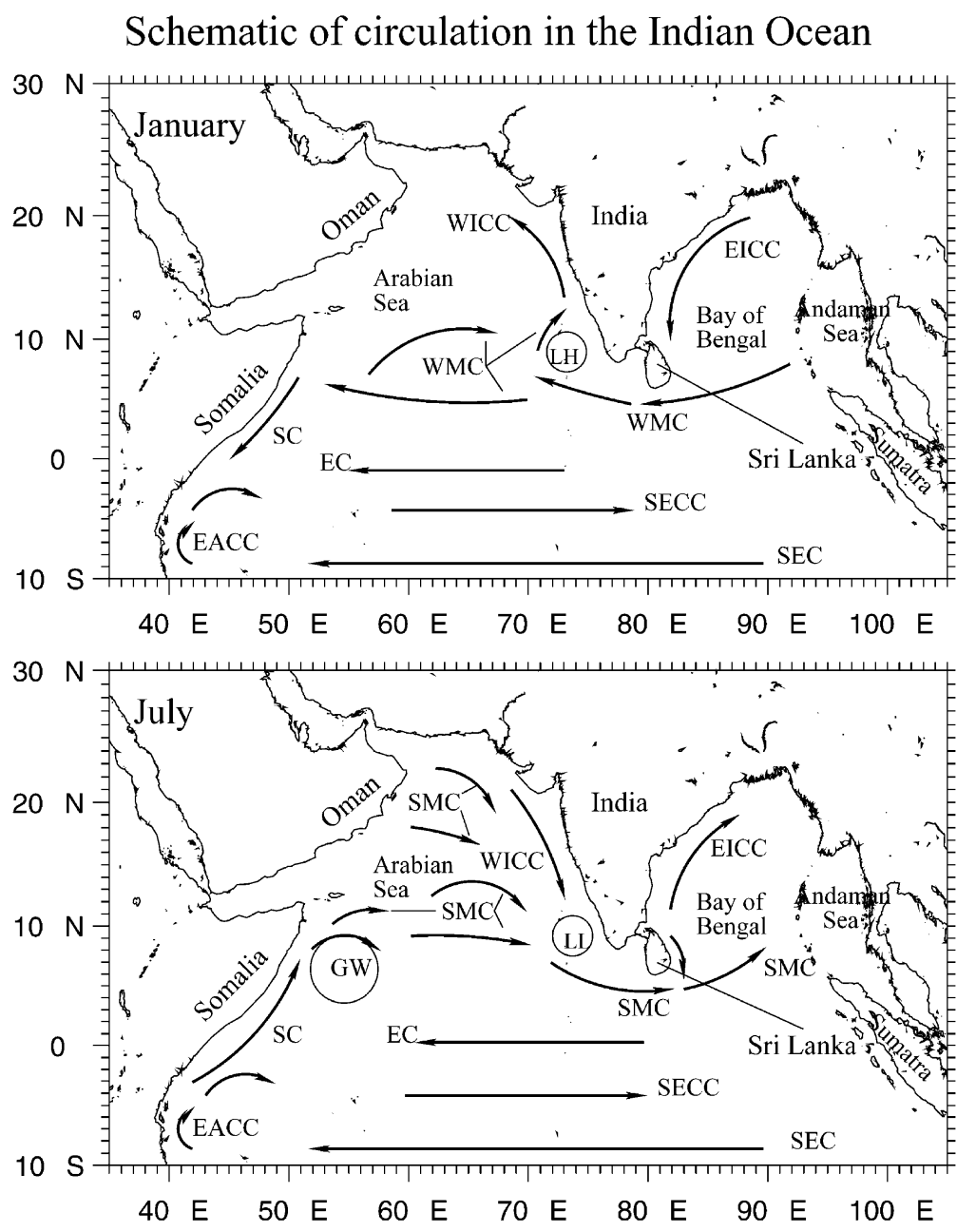

Fig. 27. Schematic representation of the circulation, as described in this paper, in the Indian Ocean during January (winter monsoon) and July (summer monsoon). Comparison with the schematic shown in Fig. 2 illustrates the differences between earlier descriptions of the monsoon currents and that herein. The abbreviations are as follows. SC, Somali Current; EC, Equatorial Current; SMC, Summer Monsoon Current; WMC, Winter Monsoon Current; EICC, East India Coastal Current; WICC, West India Coastal Current; SECC, South Equatorial Counter Current; EACC, East African Coastal Current; SEC, South Equatorial Current; LH, Lakshadweep high; LL, Lakshadweep low; and GW, Great Whirl. 
and Sri Lanka, which force the Lakshadweep high off southwest India and which contribute significantly to forcing the monsoon currents in the eastern Arabian Sea. In the rest of the Arabian Sea, Ekman pumping combines with Rossby waves radiated from the west coast of India to produce the curving flows associated with the geostrophic monsoon currents. Superimposed on these geostrophic flows is the local Ekman drift. Thus, a simple linear framework based on three linear, baroclinic waves, viz. the equatorial Kelvin wave, the equatorial Rossby wave, and the coastal Kelvin wave, together with the Ekman drift is sufficient to explain the seasonal cycle of the monsoon currents.

That the monsoon currents, despite their complexity, are seen in climatology is the result of the regular seasonal cycle associated with the monsoon. This regularity, which borders on predictability, is one facet of the monsoon. Another facet of the monsoon is its fickleness: the monsoon varies considerably from one year to another. This results in considerable interannual variability in the monsoon currents (Fig. 28). There are also variations on the sub-monthly time scale superimposed on the seasonal monsoon, forcing submonthly variability in the monsoon currents (Fig. 29). The sea-level anomalies and geostrophic currents from each TOPEX/Poseidon cycle (Fig. 29) show a much richer structure than do the monthly averages or climatology (Fig. 28). Though still identifiable as continuous trans-basin flows in these 'snapshots', the currents meander much more in flowing past the many eddies that dominate the flow field. The climatological geostrophic monsoon currents are, therefore, the weaker ensembles of these meandering currents.

The multiplicity of eddies in the TOPEX/Poseidon sea-level anomalies is reminiscent of the eddy-dominated flow seen in the hydrographic data of the IIOE (Düing, 1970; Wyrtki, 1971). Those eddies were, however, the result of the sparsity of the data, which prevented the mean currents from standing out. The eddies seen in altimetry are, on the other hand, the result of the better resolution afforded by satellite data in both space and time. The vast amount of such 'near-synoptic' data being made available by satellites is revealing more and more complex structures in the domain of the monsoon currents as the resolution of the data becomes finer in both time and space. That eddies are common in the north Indian Ocean is obvious from these data, which reveal a picture of the surface circulation that is quite different from the smooth currents seen in climatology, the monthly means, or in the simulations described in this paper. It remains to be seen if the linear theoretical framework described herein will hold even for the eddying motion evident at these spatial and temporal scales, or if its applicability is restricted to the ensemble of these eddies that is represented by the seasonal cycle.

\section{Acknowledgements}

We thank Satish Shetye for initiating this work and for sharing his insights into the physical oceanography of the north Indian Ocean. The altimeter products have been produced by the CLS (Collecte Localisation Satellites) Space Oceanography Division as part of the European Union's Environment and Climate projects AGORA (ENV4-CT9560113) and DUACS (ENV4-CT96-0357), with financial support from the CEO (Centre for Earth Observations) programme and Midi-Pyrénés regional council. The ship-drift data are from the Ocean Current Drifter Data CDROMs NODC-53 and NODC-54, which are a product of the National Oceanic Data Center (NODC), US Department of Commerce, National Oceanic and Atmospheric Administration (NOAA), USA. We thank Beena Sarojini for helping with these data. The figures were made using Ferret, GMT, and Xfig. This work was carried out under projects funded by the Department of Ocean Development, New Delhi. The simulations with the OGCM were carried out when P.N. Vinayachandran was at the Institute for Global Change Research, Frontier Research System for Global Change, Tokyo, Japan. The comments of the anonymous reviewers helped to improve the manuscript. This is NIO contribution 3719 . 


\section{Interannual variability in surface geostrophic flow}


$\longrightarrow$ 100. $\mathrm{cm} \mathrm{s}^{-1}$

Fig. 28. Monthly-mean geostrophic current $\left(\mathrm{cm} \mathrm{s}^{-1}\right)$, derived from TOPEX/Poseidon, for January (left panels) and July (right panels). The top panels show the monthly climatology (1993-1997), as in Fig. 5. The middle panels show the monthly-mean geostrophic currents for 1994 (January on left, July on right), and the bottom panels for 1997. The monthly averages for the years 1994 and 1997 differ from climatology, even though the monsoon currents can be traced in both these years.

\section{References}

Bauer, S., Hitchcock, G. L., \& Olson, D. B. (1991). Influence of monsoonally-forced Ekman dynamics upon surface layer depth and plankton biomass distribution in the Arabian Sea. Deep-Sea Research, 38, 531-553.

Böhm, E., Morrison, J. M., Manghnani, V., Kim, H. -S., \& Flagg, C. N. (1999). The Ras al Hadd Jet: remotely sensed and acoustic Doppler current profiler observations in 1994-1995. Deep-Sea Research II, 46, 1531-1549. 


\section{Surface geostrophic flow for 1994}
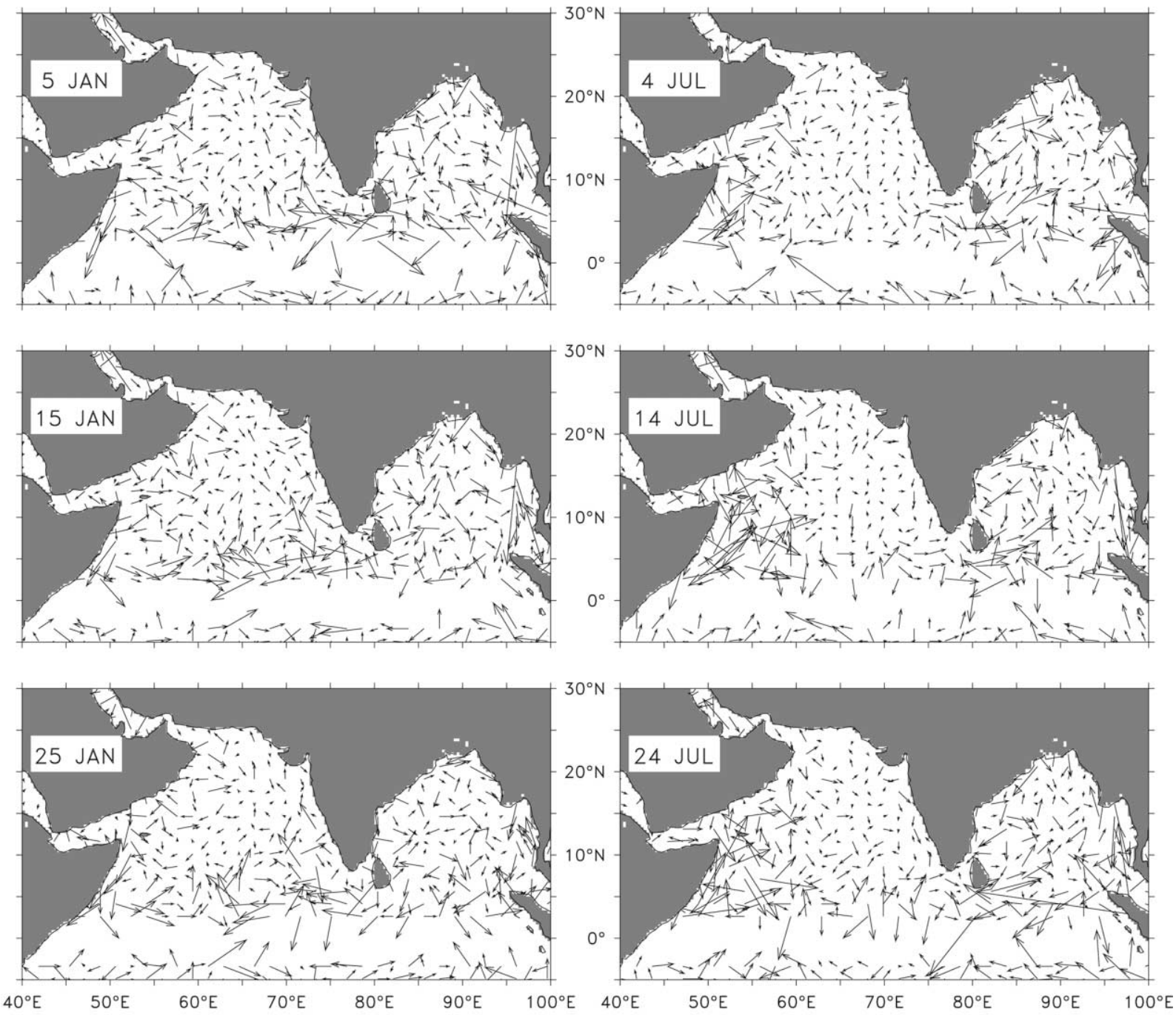

$\longrightarrow$ 100. $\mathrm{cm} \mathrm{s}^{-1}$

Fig. 29. Geostrophic currents $\left(\mathrm{cm} \mathrm{s}^{-1}\right)$ from TOPEX/Poseidon altimetry for three cycles each during January (left panels) and July (right panels) of 1994. The GWMC and GSMC can be traced even in individual TOPEX/Poseidon cycles, even though the currents are more noisy and meander more than in either the climatology or the monthly averages (Fig. 28).

Bruce, J. G. (1968). Comparison of near surface dynamic topography during the two monsoons in the western Indian Ocean. DeepSea Research, 15, 665-667.

Bruce, J. G., Johnson, D. R., \& Kindle, J. C. (1994). Evidence for eddy formation in the eastern Arabian Sea during the northeast monsoon. Journal of Geophysical Research, 99, 7651-7664.

Bruce, J. G., Kindle, J. C., Kantha, L. H., Kerling, J. L., \& Bailey, J. F. (1998). Recent observations and modeling in the Arabian Sea Laccadive high region. Journal of Geophysical Research, 103, 7593-7600.

Cane, M. A. (1980). On the dynamics of equatorial currents, with application to the Indian Ocean. Deep-Sea Research, $27,525-544$. 
Cutler, A. N., \& Swallow, J. C. (1984). Surface currents of the Indian Ocean (to $25^{\circ} \mathrm{S}, 100^{\circ} \mathrm{E}$ ): Compiled from historical data archived by the Meteorological Office, Bracknell, UK. Report 187, Institute of Oceanographic Sciences, Wormley, England, 36 charts, 8pp.

Defant, A. (1961). Physical oceanography, Vol. I. Oxford: Pergamon Press.

Donguy, J. R., \& Meyers, G. (1995). Observations of geostrophic transport variability in the western tropical Indian Ocean. DeepSea Research I, 42, 1007-1028.

Düing, W. (1970). The monsoon regime of the currents in the Indian Ocean. International Indian Ocean Expedition Oceanographic Monographs, Number 1. Honolulu: East-West Center Press.

Eigenheer, A., \& Quadfasel, D. (2000). Seasonal variability of the Bay of Bengal circulation inferred from TOPEX/Poseidon altimetry. Journal of Geophysical Research, 105, 3243-3252.

Gopalakrishna, V. V., Pednekar, S. M., \& Murty, V. S. N. (1996). T-S variability and volume transport in the central Bay of Bengal during southwest monsoon. Indian Journal of Marine Science, 25, 50-55.

Han, W. (1999). Influence of salinity on dynamics, thermodynamics and mixed-layer physics in the Indian Ocean. Ph.D. thesis, Nova Southeastern University, Dania, FL, USA.

Han, W., \& McCreary, J. P. (2001). Modeling salinity distributions in the Indian Ocean. Journal of Geophysical Research, 106, 859-877.

Han, W., McCreary, J. P., Anderson, D. L. T., \& Mariano, A. J. (1999). On the dynamics of the eastward surface jets in the equatorial Indian Ocean. Journal of Physical Oceanography, 29, 2191-2209.

Han, W., McCreary, J. P., \& Kohler, K. (2001). Influence of precipitation minus evaporation and Bay of Bengal rivers on dynamics, thermodynamics, and mixed layer physics in the upper Indian Ocean. Journal of Geophysical Research, 106, 6895-6916.

Hastenrath, S., \& Greischar, L. L. (1991). The monsoonal current regimes of the tropical Indian Ocean. Observed surface flow fields and their geostrophic and wind-driven components. Journal of Geophysical Research, 96, 12619-12633.

Hellerman, S., \& Rosenstein, M. (1983). Normal monthly wind stress over the world ocean with error estimates. Journal of Physical Oceanography, 13, 1093-1104.

Howden, S. D., \& Murtugudde, R. (2001). Effect of river inputs into the Bay of Bengal. Journal of Geophysical Research, 106, 19825-19843.

Jensen, T. G. (1993). Equatorial variability and resonance in a wind-driven Indian Ocean model. Journal of Geophysical Research, 98, 22533-22552.

Kumar, S. P., \& Unnikrishnan, A. S. (1995). The seasonal cycle of temperature and associated wave phenomena in the Bay of Bengal. Journal of Geophysical Research, 100, 13585-13593.

Le Traon, P. Y., Gaspar, P., Bouyssel, F., \& Makhmara, H. (1995). Using TOPEX/Poseidon data to enhance ERS-1 data. Journal of Atmospheric and Oceanic Technology, 12, 161-170.

Le Traon, P. Y., Nadal, F., \& Ducet, N. (1998). An improved mapping method of multi-satellite altimeter data. Journal of Atmospheric and Oceanic Technology, 25, 522-534.

Le Traon, P. Y., \& Ogor, F. (1998). ERS-1/2 orbit improvement using TOPEX/Poseidon: the 2 cm challenge. Journal of Geophysical Research, 103, 8045-8057.

Levitus, S. (1982). Climatological atlas of the world ocean. NOAA Professional Paper 13. Washington, DC: US Government Printing Office, $173 \mathrm{pp}$.

Levitus, S., \& Boyer, T.P. (1994). World Ocean Atlas 1994, Volume 4: Temperature. NOAA Atlas NESDIS 4, 117 pp.

Levitus, S., Burgett, R., \& Boyer, T.P., 1994. World Ocean Atlas 1994, Volume 3: Salinity. NOAA Atlas NESDIS 3,99 pp.

Lighthill, M. J. (1969). Dynamic response of the Indian Ocean to the onset of the southwest monsoon. Philosophical Transactions of the Royal Society of London, Series A, 265, 45-92.

Luis, A. J., \& Kawamura, H. (2000). Wintertime wind forcing and sea surface cooling near the south India tip observed using NSCAT and AVHRR. Remote Sensing of the Environment, 73, 55-64.

Matsuno, T. (1966). Quasi-geostrophic motions in the equatorial area. Journal of the Meteorological Society of Japan, 44, $25-43$.

McCreary, J. P., Han, W., Shankar, D., \& Shetye, S. R. (1996). Dynamics of the East India Coastal Current: 2. Numerical solutions. Journal of Geophysical Research, 101, 13993-14010.

McCreary, J. P., Kundu, P. K., \& Molinari, R. L. (1993). A numerical investigation of the dynamics, thermodynamics and mixedlayer processes in the Indian Ocean. Progress in Oceanography, 31, 181-244.

Molinari, R. L., Olson, D., \& Reverdin, G. (1990). Surface current distributions in the tropical Indian Ocean derived from compilations of surface buoy trajectories. Journal of Physical Oceanography, 95, 7217-7238.

Moore, D. W. (1968). Planetary-gravity waves in an equatorial ocean. Ph.D. thesis, Harvard University, Cambridge, MA.

Murty, V. S. N., Sarma, M. S. S., Lambata, B. P., Gopalakrishna, V. V., Pednekar, S. M., Rao, A. S., Luis, A. J., Kaka, A. R., \& Rao, L. V. G. (2000). Seasonal variability of upper-layer geostrophic transport in the tropical Indian Ocean during $1992-1996$ along TOGA-I XBT tracklines. Deep-Sea Research I, 47, 1569-1582.

Murty, V. S. N., Sarma, Y. V. B., Rao, D. P., \& Murty, C. S. (1992). Water characteristics, mixing and circulation in the Bay of Bengal during southwest monsoon. Journal of Marine Research, 50, 207-228.

O'Brien, J. J., \& Hurlburt, H. E. (1974). Equatorial jet in the Indian Ocean: theory. Science, 184, 1075-1077. 
Pacanowski, R. C. (1996). MOM2 Version 2.0 (Beta): documentation, user's guide, and reference manual. GFDL Technical Report 3.2. Princeton, NJ: GFDL.

Pacanowski, R. C., \& Philander, S. G. H. (1981). Parameterization of vertical mixing in numerical models of the tropical ocean. Journal of Physical Oceanography, 11, 1442-1451.

Perigaud, C., \& Delecluse, P. (1992). Annual sea level variations in the southern tropical Indian Ocean from Geosat and shallowwater simulations. Journal of Geophysical Research, 97, 20169-20178.

Pond, S., \& Pickard, G. L. (1983). Introductory dynamical oceanography (2nd ed.). Oxford: Pergamon Press.

Potemra, J. T., Luther, M. E., \& O’Brien, J. J. (1991). The seasonal circulation of the upper ocean in the Bay of Bengal. Journal of Geophysical Research, 96, 12667-12683.

Rao, A.S. (1998). Rossby waves in the Bay of Bengal: observations and simulations. Ph.D. thesis, Andhra University, Vishakhapatnam, India.

Rao, R. R., Molinari, R. L., \& Festa, J. F. (1989). Evolution of the climatological near-surface thermal structure of the tropical Indian Ocean: 1. Description of mean monthly mixed-layer depth and sea-surface temperature, surface-current and surface meteorological fields. Journal of Geophysical Research, 94, 10801-10815.

Reppin, J., Schott, F. A., Fischer, J., \& Quadfasel, D. (1999). Equatorial currents and transports in the upper central Indian Ocean: annual cycle and interannual variability. Journal of Geophysical Research, 104, 15495-15514.

Reverdin, G. (1987). The upper equatorial Indian Ocean: the climatological seasonal cycle. Journal of Physical Oceanography, 17, 903-927.

Schott, F. (1983). Monsoon response of the Somali current and associated upwelling. Progress in Oceanography, 12, 357-381.

Schott, F., \& McCreary, J. P. (2001). The monsoon circulation of the Indian Ocean. Progress in Oceanography, 51, 1-123.

Schott, F., Reppin, J., Fischer, J., \& Quadfasel, D. (1994). Currents and transports of the Monsoon Current south of Sri Lanka. Journal of Geophysical Research, 99, 25127-25141.

Shankar, D. (1998). Low-frequency variability of sea level along the coast of India. Ph.D. thesis, Goa University, Goa, India.

Shankar, D. (2000). Seasonal cycle of sea level and currents along the coast of India. Current Science, 78, $279-288$.

Shankar, D., McCreary, J. P., Han, W., \& Shetye, S. R. (1996). Dynamics of the East India Coastal Current: 1. Analytic solutions forced by interior Ekman pumping and local alongshore winds. Journal of Geophysical Research, 101, 13975-13991.

Shankar, D., \& Shetye, S. R. (1997). On the dynamics of the Lakshadweep high and low in the southeastern Arabian Sea. Journal of Geophysical Research, 102, 12551-12562.

Shankar, D., \& Shetye, S. R. (1999). Are interdecadal sea level changes along the Indian coast influenced by variability of monsoon rainfall? Journal of Geophysical Research, 104, 26031-26042.

Shankar, D., \& Shetye, S. R. (2001). Why is mean sea level along the Indian coast higher in the Bay of Bengal than in the Arabian Sea? Geophysical Research Letters, 28, 563-565.

Shenoi, S., Saji, P., \& Almeida, A. (1999). Near-surface circulation and kinetic energy in the tropical Indian Ocean derived from Lagrangian drifters. Journal of Marine Research, 57, 885-907.

Shenoi, S. S. C., Shankar, D., \& Shetye, S. R. (1999). On the sea surface temperature high in the Lakshadweep Sea before the onset of the southwest monsoon. Journal of Geophysical Research, 104, 15703-15712.

Shetye, S. R. (1998). West India Coastal Current and Lakshadweep high/low. Sadhana, 23, 637-651.

Shetye, S. R., \& Gouveia, A. D. (1998). Coastal circulation in the north Indian Ocean. Coastal segment (14,S-W). In The Sea, Vol. 11 (pp. 523-556). John Wiley and Sons, Inc.

Shetye, S. R., Gouveia, A. D., Shankar, D., Shenoi, S. S. C., Vinayachandran, P. N., Sundar, D., Michael, G. S., \& Nampoothiri, G. (1996). Hydrography and circulation in the western Bay of Bengal during the northeast monsoon. Journal of Geophysical Research, 101, 14011-14025.

Shetye, S. R., Gouveia, A. D., Shenoi, S. S. C., Michael, G. S., Sundar, D., Almeida, A. M., \& Santanam, K. (1991). The coastal current off western India during the northeast monsoon. Deep-Sea Research, 38, 1517-1529.

Shetye, S. R., Gouveia, A. D., Shenoi, S. S. C., Sundar, D., Michael, G. S., Almeida, A. M., \& Santanam, K. (1990). Hydrography and circulation off the west coast of India during the southwest monsoon 1987. Journal of Marine Research, 48, 359-378.

Shetye, S. R., Gouveia, A. D., Shenoi, S. S. C., Sundar, D., Michael, G. S., \& Nampoothiri, G. (1993). The western boundary current of the seasonal subtropical gyre in the Bay of Bengal. Journal of Geophysical Research, 98, 945-954.

Shetye, S. R., Shenoi, S. S. C., Gouveia, A. D., Michael, G. S., Sundar, D., \& Nampoothiri, G. (1991). Wind-driven coastal upwelling along the western boundary of the Bay of Bengal during the southwest monsoon. Continental Shelf Research, 11, $1397-1408$.

Shi, W., Morrison, J. M., Böhm, E., \& Manghnani, V. (2000). The Oman upwelling zone during 1993, 1994, and 1995. Deep-Sea Research II, 47, 1227-1247.

Stramma, L., Fischer, J., \& Schott, F. (1996). The flow field off southwest India at $8^{\circ} \mathrm{N}$ during the southwest monsoon of August 1993. Journal of Marine Research, 54, 55-72.

Unnikrishnan, A. S., Kumar, S. P., \& Navelkar, G. S. (1997). Large-scale processes in the upper layers of the Indian Ocean inferred from temperature climatology. Journal of Marine Research, 55, 93-115. 
Unnikrishnan, A. S., Murty, V. S. N., Babu, M. T., Gopinathan, C. K., \& Charyulu, R. J. K. (2001). On the anomalous current structure in the eastern equatorial Indian Ocean during southwest monsoon of 1994. Marine and Freshwater Research, 52, 727-734.

Vinayachandran, P. N., Masumoto, Y., Mikawa, T., \& Yamagata, T. (1999). Intrusion of the Southwest Monsoon Current into the Bay of Bengal. Journal of Geophysical Research, 104, 11077-11085.

Vinayachandran, P. N., Saji, N. H., \& Yamagata, T. (1999). Response of the equatorial Indian Ocean to an unusual wind event during 1994. Geophysical Research Letters, 26, 1613-1616.

Vinayachandran, P. N., Shetye, S. R., Sengupta, D., \& Gadgil, S. (1996). Forcing mechanisms of the Bay of Bengal circulation. Current Science, 71, 753-763.

Vinayachandran, P. N., \& Yamagata, T. (1998). Monsoon response of the sea around Sri Lanka: generation of thermal domes and anticyclonic vortices. Journal of Physical Oceanography, 28, 1946-1960.

Warren, B. A. (1966). Medieval Arab references to the seasonally reversing currents of the north Indian Ocean. Deep-Sea Research, 13, 167-171.

Wyrtki, K. (1971). Oceanographic atlas of the International Indian Ocean Expedition. 531 pp. Washington, DC: National Science Foundation.

Wyrtki, K. (1973a). An equatorial jet in the Indian Ocean. Science, 181, 262-264.

Wyrtki, K. (1973b). Physical oceanography of the Indian Ocean. Vol. 3 of Ecological studies: analysis and synthesis. In B. Zeitschel, \& S. A. Gerlach (Eds.), Biology of the Indian Ocean (pp. 18-36). London: Chapman and Hall Ltd.

Yu, L., O’Brien, J. J., \& Yang, J. (1991). On the remote forcing of the circulation in the Bay of Bengal. Journal of Geophysical Research, 96, 20449-20454. 